University of Wollongong

Research Online

Australian Institute for Innovative Materials -

Papers

Australian Institute for Innovative Materials

$1-1-2018$

Progress and future prospects of high-voltage and high-safety electrolytes in advanced lithium batteries: From liquid to solid electrolytes

Shimou Chen

Chinese Academy Of Sciences

Kaihua Wen

Chinese Academy Of Sciences

Juntian Fan

Chinese Academy Of Sciences

Yoshio Bando

University of Wollongong, National Institute for Materials Science, yoshio@uow.edu.au

Dmitri Golberg

National Institute For Materials Science, Queensland University of Technology

Follow this and additional works at: https://ro.uow.edu.au/aiimpapers

Part of the Engineering Commons, and the Physical Sciences and Mathematics Commons

Research Online is the open access institutional repository for the University of Wollongong. For further information contact the UOW Library: research-pubs@uow.edu.au 


\title{
Progress and future prospects of high-voltage and high-safety electrolytes in advanced lithium batteries: From liquid to solid electrolytes
}

\author{
Abstract \\ Developing the next-generation high-energy density and safe batteries is of prime importance to meet the \\ emerging demands in electronics, automobile industries and various energy storage systems. High- \\ voltage lithium-ion batteries (LIBs) and solid-state batteries (SSBs) are two main directions attracting \\ increasing interest in recent years, due to their potential applications in the near future. In both kinds of \\ batteries, the electrolytes play a pivotal role but also create several bottleneck problems. In this review, \\ recent progress in designing electrolytes for high-voltage LIBs and SSBs is summarized. First, the \\ solvents, additives, ionic liquids and superconcentrated salts strategies for constructing high-voltage \\ liquid electrolytes are reviewed, and then the applications of inorganic solids, solid polymers, gels and \\ ionic liquids in solid-state electrolytes are presented. Finally, the general design rules of the electrolytes \\ and their current limitations and future prospects are briefly discussed.

\section{Disciplines} \\ Engineering | Physical Sciences and Mathematics

\section{Publication Details} \\ Chen, S., Wen, K., Fan, J., Bando, Y. \& Golberg, D. (2018). Progress and future prospects of high-voltage \\ and high-safety electrolytes in advanced lithium batteries: From liquid to solid electrolytes. Journal of \\ Materials Chemistry A, 6 (25), 11631-11663.
}




\section{Progress and prospective on designing electrolytes for high voltage lithium ion batteries and solid-state lithium batteries}

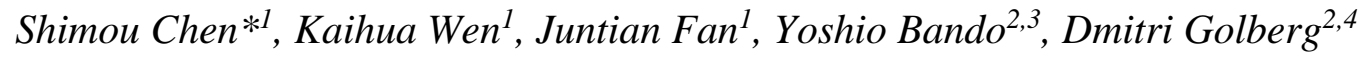

(Dedication to Prof. Yoshio Bando on the occasion of his $70^{\text {th }}$ birthday)

1. Beijing Key Laboratory of Ionic Liquids Clean Process, Key Laboratory of Green Process and Engineering, Institute of Process Engineering, Chinese Academy of Sciences, Beijing 100190, P. R. China

E-mail: chenshimou@ipe.ac.cn

2. International Center for Materials Nanoarchitectonics (MANA), National Institute for Materials Science (NIMS), Namiki 1-1, Tsukuba, Ibaraki 305-0044, Japan

3.Australian Institute for Innovative Materials (AIIM), University of Wollongong (UOW), Squires Way, North Wollongong, NSW 2500, Australia

4. School of Physics, Chemistry and Mechanical Engineering, Science and Engineering Faculty, Queensland University of Technology (QUT), $2^{\text {nd }}$ George st., Brisbane, QLD 4070, Australia

Keywords: lithium ion battery, high voltage electrolyte, solid-state electrolyte, additive, ionic liquid

Abstract: Developing next generation high energy density and safe batteries is of prime importance to meet the emerging challenges in electronics, automobile industries and various energy storage systems. High voltage lithium ion batteries (LIBs) and solid state batteries (SSBs) are two main directions gaining increasing interests in recent years due to their visible applications in the near future. In both of these battery types, the electrolytes play a pivotal role but also create several bottle-neck problems. In this review, recent progress in designing electrolytes for high voltage LIBs lithium ion batteries and SSBs is summarized. First, the solvents, additives, ionic liquids and super-concentrated salts strategy for constructing the high voltage liquid electrolytes are reviewed, and then the applications of inorganic solids, solid polymers, gel and ionic liquids in solid state electrolytes are presented. Finally, the general design rules of the electrolytes and their current limitations and future prospects are discussed.

\section{Introduction}


Recently, growing demands for electronic devices, electric vehicles and mass energy storage systems have spurred the research on lithium ion batteries (LIBs) with high power/energy density and safety. Developing new materials and systems for the LIBs play a key role along with this challenge, because the present LIBs cannot satisfy the increasing requirements for their reliable applications, especially with respect to the rapid developments of electric vehicles. It is widely recognized that the advanced LIBs should bring a combination of high-voltage cathodes, high capacity anodes and high-voltage electrolytes. ${ }^{[1-5]}$ However, conventional carbonate solvent-based electrolytes exhibit inferior anodic stability of lower than $4.3 \mathrm{~V}$ vs. $\mathrm{Li} / \mathrm{Li}^{+}$, which makes them highly unstable against high-voltage cathodes. With the development and commercialization of high-voltage cathode materials, designing electrolytes at voltages greater than $4.3 \mathrm{~V}$ vs. $\mathrm{Li} / \mathrm{Li}^{+}$and mitigating the undesirable oxidative decomposition of electrolytes have become the decisive factors to boost electrode capacity of high-voltage LIBs. These issues have gained much attentions from both the academia and industry. ${ }^{[6]}$

On the other hand, as a key component in LIBs, the commonly used electrolytes are organic liquids, which are volatile and flammable. When the liquid electrolytes are replaced by an inorganic solid, gel polymer or solid polymer electrolytes, the safety risks can be significantly lowered. Thus, developing solid-state lithium batteries (SSBs) is considered as the ultimate solution for the safety of LIBs. Furthermore, because the solid electrolytes can suppress the lithium dendrite growth, lithium metal anodes can be adopted for remarkable increasing the energy density of a battery. However, there are still many challenges in a design of the solid state electrolytes, such as their low ion conductivity, poor electrolyte/electrode interface, high cost, sensitivity, etc. ${ }^{[7-12]}$ Therefore, how to design a suitable solid electrolyte is the key issue in developing practical solid-state LIBs. 


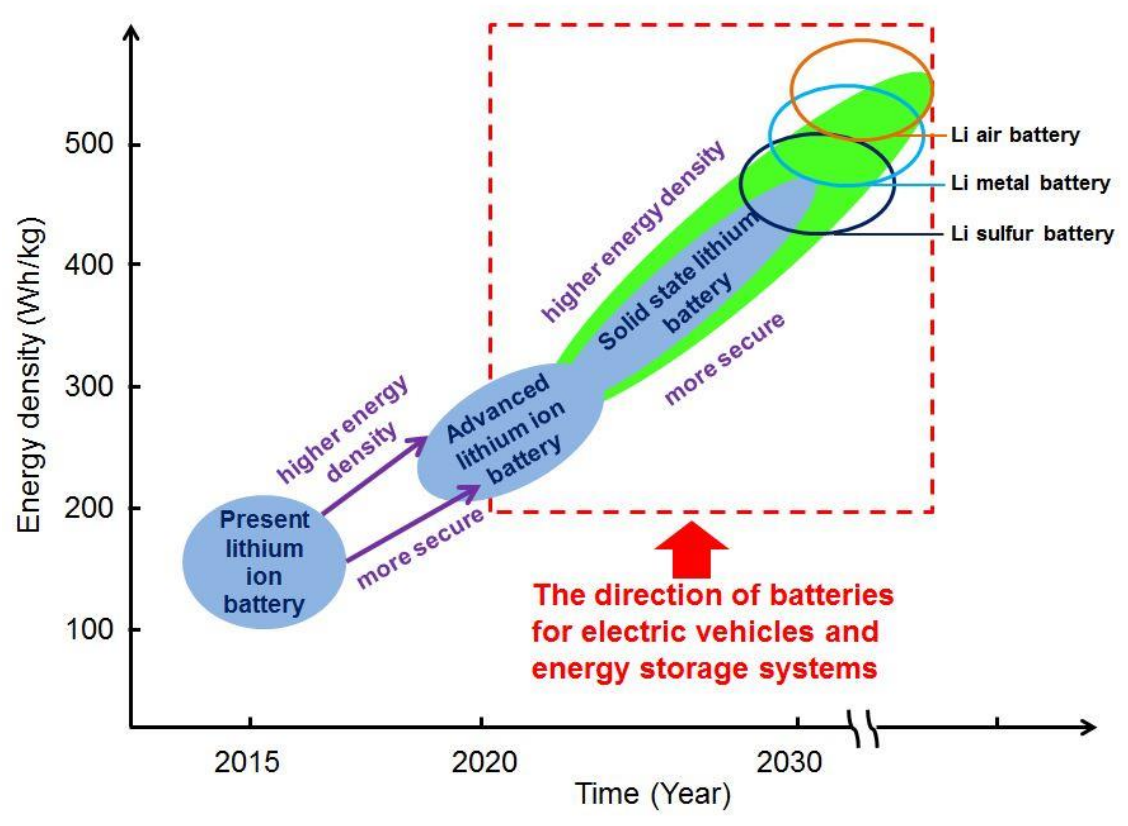

Figure 1. The roadmap for the LIB development.

Considering that advanced LIBs and SSBs are the two kinds of batteries widely studied and used in the following years, they show the main-stream research direction for the near-future electric vehicles and energy storage systems (Figure 1). The suitable electrolytes for the two systems create the bottle-neck problems for real applications. In this review, we mainly focus on how to design the high voltage electrolytes and solid electrolytes for the advanced LIBs and solid-state LIBs, respectively. We summarize the recent progress on how to find a functional solvent, additives, ionic liquids and lithium salts for the high-voltage electrolytes. For the solid state electrolytes, we consider three main categories: solid inorganic electrolytes, solid polymer electrolytes and gel polymer electrolytes. Then we discuss the state-of-the-art progress in ionic liquid-based electrolytes, exemplifying how ionic liquids can contribute to high voltage LIBs and solid state LIBs systems. Finally, this review ends up with the author personal outlook and proposed directions toward future safe and high performance electrolytes..

\section{High voltage electrolytes}


LIBs have already been successfully commercialized in various flexible electronic devices due to many outstanding properties, including no memory effect, long cycle life, high capacity and energy density. ${ }^{[13-15]}$ To satisfy the increasing demands for the next generation electronic devices, like electronic vehicles, LIBs with better safety, longer cycle life and higher energy densities are urgently required, and as a result they have witnessed the intensive development progresses. ${ }^{[16-23]}$ It is well known that the general method to improve the energy densities of a battery is exploring the cathode materials having high working voltages or high specific capacities. ${ }^{[24]}$ For example, novel high capacity cathode materials, such as $\mathrm{Li}_{2} \mathrm{FeSiO}_{4}$, and high voltage cathode materials, such as $\mathrm{LiNi}_{0.5} \mathrm{Mn}_{1.5} \mathrm{O}_{4}$ have been successfully tried. ${ }^{[25]}$ However, the oxidative decomposition of a traditional electrolyte has restricted their practical applications. In this review, recent progresses in LIBs are summarized in conformity with the electrolyte evolutions, including finding diversified high voltage solvents and additives, superconcentrated salt strategy etc. Although these ways towards real industries still have many problems to overcome, recent progresses in electrolyte technology create a promising picture of the on-going LIBs revolution.

\subsection{High voltage solvents}

Electrolyte is indispensable in all LIBs and its basic function is serving as a medium to transport $\mathrm{Li}^{+}$ions between the cathode and anode, thus ensuring the effectiveness of the inner circuit. ${ }^{[6,26]}$ Because the electrolyte is sandwiched between cathode and anode electrodes, it can directly interact with both of them. So, the interfaces between the electrolyte and the two electrodes become crucial for the cycling performance of an electrochemical device. ${ }^{[4,27]}$ To transport $\mathrm{Li}^{+}$between cathode and anode (and being compatible with the electrodes), the electrolytes used nowadays are mainly composed of carbonate solvents, lithium salts and diversified additives. They should fulfill the following requirements: (1) They should have a high solubility and ionizability of lithium salts; (2) They should exhibit high chemical and physical stability, namely, they should have high flash point and low electrode reaction 
activity; (3) They should possess a wide electrochemical window; (4) They should reveal stable interfacial chemistry, i.e., they should be able to form protective SEI layers on the electrode surfaces; and finally (5) They should be environment friendly.

\subsubsection{Traditional solvents}

In the first generation of commercial LIBs, the superb physical properties of propylene carbonate (PC), such as low melting point $\left(-49.2{ }^{\circ} \mathrm{C}\right)$, high boiling point $\left(241.7^{\circ} \mathrm{C}\right)$ and high flash point $\left(132{ }^{\circ} \mathrm{C}\right)$, made it excellent low-temperature and safe solvent compatible with petroleum coke by "Sony Corporation". Following the energy revolution, the graphite anodes have achieved enormous success owing to their ability to intercalate/de-intercalate $\mathrm{Li}^{+}$ reversibly. Further investigations have indicated that ethylene carbonate (EC) is more compatible with graphite anodes because of a peculiar protective SEI layer formed under its sacrificial reduction decomposition. ${ }^{[28-32]}$ However, EC has some undesirable features, such as high melting point $\left(36{ }^{\circ} \mathrm{C}\right.$ ) and high viscosity (about $1.9 \mathrm{mPa}$ s at $25^{\circ} \mathrm{C}$ ), so the electrolyte should usually contain EC and other carbonate solvents to satisfy the diverse requirements which can hardly be met by any individual compound. ${ }^{[26]}$ Lithium salt, another essential component in the electrolyte, is the source of lithium ions. Its anions can directly influence the structure and stability of an electrolyte. ${ }^{[33-35]}$ There are various Li salts used in the battery applications, such as lithium perchlorate $\left.\left(\mathrm{LiClO}_{4}\right),{ }^{[35,} \quad 36\right]$ lithium hexafluoroarsenate $\left(\mathrm{LiAsF}_{6}\right),{ }^{[37]}$ lithium hexafluorophosphate $\left(\mathrm{LiPF}_{6}\right),{ }^{[38]}$ lithium tetrafluoroborate $\left(\mathrm{LiBF}_{4}\right)^{[39-41]}$ and lithium bis(trifluoromethanesulfonyl)imide(LiTFSI). ${ }^{[42-45]}$ Each lithium salt mentioned has its advantages and disadvantages. For instance, $\mathrm{LiAsF}_{6}$ is deemed to be better than $\mathrm{LiClO}_{4}$ as an electrolyte for lithium metal batteries. However, the application of $\mathrm{LiAsF}_{6}$ is fairly limited because of its toxicity and high price. As for $\mathrm{LiBF}_{4}$, the low ionic conductivity limits its practical application. $\mathrm{LiPF}_{6}$, without any single outstanding property, is eventually commercialized because of its combination of many well-balanced features, such as good ionic conductivity and electrochemical stability. ${ }^{[26]}$ Most of the 
electrolytes used in lithium-based batteries are made of $1 \mathrm{M}$ lithium hexafluorophosphate $\left(\mathrm{LiPF}_{6}\right)$ dissolved in organic carbonate solvents, especially as the mixture of ethylene carbonate (EC), diethyl carbonate (DEC), dimethyl carbonate (DMC), propylene carbonate (PC) or ethyl methyl carbonate (EMC). ${ }^{[10]}$ However, the high flammability of these solvents can cause a major safety issue. In addition, their high reactivity towards the electrodes above $50{ }^{\circ} \mathrm{C}$ is an issue that further retards the application of Li-based batteries in the vehicle industry.

\subsubsection{Sulfone-based solvents}

As we mentioned above, even though being widely adopted, the use of $\mathrm{LiPF}_{6}$, together with carbonate molecular solvents, is also restricted in some aspects, e.g. the safety issue and the oxidation decomposition at a high voltage $\left(>4.5 \mathrm{~V}\right.$ vs. $\left.\mathrm{Li} / \mathrm{Li}^{+}\right) \cdot{ }^{[46]}$ Thus it is fairly urgent to explore new solvents with high voltage stability to address these problems. ${ }^{[47,48]}$ Among various high voltage solvents, sulfone-based electrolytes have frequently been investigated for LIBs owing to their strong resistance to burning and exceptional electrochemical stability. ${ }^{[49-54]}$ Obviously, the stronger electron-withdrawing sulfonyl group compared to carbonyl in carbonate molecules can lower the energy level of the highest occupied molecular orbital (HOMO), leading to higher stability of an electrolyte/cathode interface. To demonstrate the possibility of the sulfone-based solvents in the Li-based batteries, Abouimrane et al. evaluated $\mathrm{Li}_{4} \mathrm{Ti}_{5} \mathrm{O}_{12} / \mathrm{LiMn}_{2} \mathrm{O}_{4}$ and $\mathrm{Li}_{4} \mathrm{Ti}_{5} \mathrm{O}_{12} / \mathrm{LiNi}_{0.5} \mathrm{Mn}_{1.5} \mathrm{O}_{4}$ mixtures in several sulfone-based electrolytes. The results of cyclic voltammetry indicate that tetramethyl sulfone (TMS) and ethyl methyl sulfone (EMS) show the highest anodic potentials, above 5.0 V vs. $\mathrm{Li} / \mathrm{Li}^{+}$. So TMS- and EMS-based electrolytes can be selected for the $\mathrm{LiNi}_{0.5} \mathrm{Mn}_{1.5} \mathrm{O}_{4}$. Cycling tests also validated the possibility of using these two sulfone-based solvents for the high voltage conditions. ${ }^{[51]}$ However, the solfone-based solvents have problems associated with the complexity of the synthesis, ${ }^{[55]}$ the high melting points (usually higher than room temperature), ${ }^{[52]}$ high viscosity ${ }^{[56]}$ and the inability to form a stable and protective film at the 
graphite-based anodes, ${ }^{[57]}$ these severely restrict their applications. Introducing additives to the electrolytes or mixing the solfone-based solvents with the high fluidity carbonate solvents can be the most efficient methods to solve these problems. Wu and co-workers introduced p-Toluenesulfonyl isocyanate (PTSI) as a film-forming additive into the electrolyte based on tetramethylene sulfone (TMS). ${ }^{[58]}$ The composite electrolyte shows lower melting points, better wettability and superior anodic stability up to $5.0 \mathrm{~V}$ vs. $\mathrm{Li}^{2} / \mathrm{Li}^{+}$, meanwhile, this electrolyte can improve the cycling stability of Li/MCMB owing to the SEI layer formed by PTSI. From another point of view, Xue and co-workers tested a series of sulfone or sulfone-carbonate binary electrolytes with a variety of cathodes and anodes. They found that sulfone-carbonate mixed electrolytes can improve the Coulombic efficiency, capacity retention and safety of the batteries under high voltage operations owing to the synergic effect of the sulfone and carbonate. ${ }^{[56,59]}$

\subsubsection{Fluorinated solvents}

The HOMO and LUMO energies of the fluorinated molecules are lower than their nonfluorinated counterparts due to the strong electro-withdrawing ability of the fluorine which has strong electronegativity. ${ }^{[60,61]}$ Thus the fluorinated molecules have higher oxidation potentials, while higher reduction potentials. Based on the significant oxidation-tolerant stability and low reduction-tolerant stability, the fluorinated molecules can be applied in the high voltage battery applications and may be used as SEI film-forming additives for the anodes. Zhang et al. validated the superior oxidation stability of fluorinated solvents by using $\mathrm{LiNi}_{0.5} \mathrm{Mn}_{1.5} \mathrm{O}_{4} / \mathrm{Li}$ and $\mathrm{LiNi}_{0.5} \mathrm{Mn}_{1.5} \mathrm{O}_{4} / \mathrm{Li}_{4} \mathrm{Ti}_{5} \mathrm{O}_{12}$ electrochemical couples. ${ }^{[62]}$ Wang and $\begin{array}{llll}\text { co-workers } & \text { utilized } & \text { a } & \text { new }\end{array}$ 3-(1,1,2,2-tetrafluoroethoxy)-1,1,2,2-tetrafluoropropane(F-EPE) as a solvent to improve the cycling stability of a full cell based on $\mathrm{LiNi}_{1 / 3} \mathrm{Co}_{1 / 3} \mathrm{Mn}_{1 / 3} \mathrm{O}_{2} /$ graphite cycled in a voltage range of 3.0-4.5 V (vs. $\left.\mathrm{Li} / \mathrm{Li}^{+}\right) .{ }^{[63]}$ The improved performance can be ascribed to a fact that F-EPE 
can not only greatly improve the oxidation-tolerant ability of electrolyte, but also takes part in the formation of SEI film on the graphite anode, indicating the positive effect of F-EPE on the performances of the full cells. As shown in Figure 2a, there is no obvious distinction in the reduction peaks between the electrolyte with and without F-EPE. This implies that the electrolyte with F-EPE can also be compatible with the anode of LIBs. Meanwhile, the electrolyte without F-EPE is decomposed at about $4.7 \mathrm{~V}$, while the electrolyte with 20 wt \% F-EPE is stable even over 5.4 V. Moreover, the floating test shows that the addition of F-EPE can significantly improve the stability of the electrolyte (Figure 2e). The discharge capacity retention of the full cells with 20 wt \% F-EPE is obviously increased from $12.3 \%$ to $85.0 \%$ after 100 cycles compared with the counterpart without F-EPE in the electrolyte (Figure $2 \mathbf{b}$ ). As shown in Figure 2c, depicting TEM images of $\mathrm{LiNi}_{1 / 3} \mathrm{Co}_{1 / 3} \mathrm{Mn}_{1 / 3} \mathrm{O}_{2}$ electrodes at different stages: (a) fresh, (b-d) with $0 \%, 10 \%$ and $20 \%$ F-EPE after 100 cycles, the addition of $20 \%$ F-EPE makes the SEI layer thinner, which is beneficial for the $\mathrm{Li}^{+}$intercalation into the cathode materials. Luo and co-workers applied F-EPE in a high voltage cathode $\mathrm{LiNi}_{0.5} \mathrm{Mn}_{1.5} \mathrm{O}_{4}$. The physical characterization results showed that there had been a thin and uniform layer on the cathode surface after the addition of F-EPE (Figure 2d). ${ }^{[24]}$ 

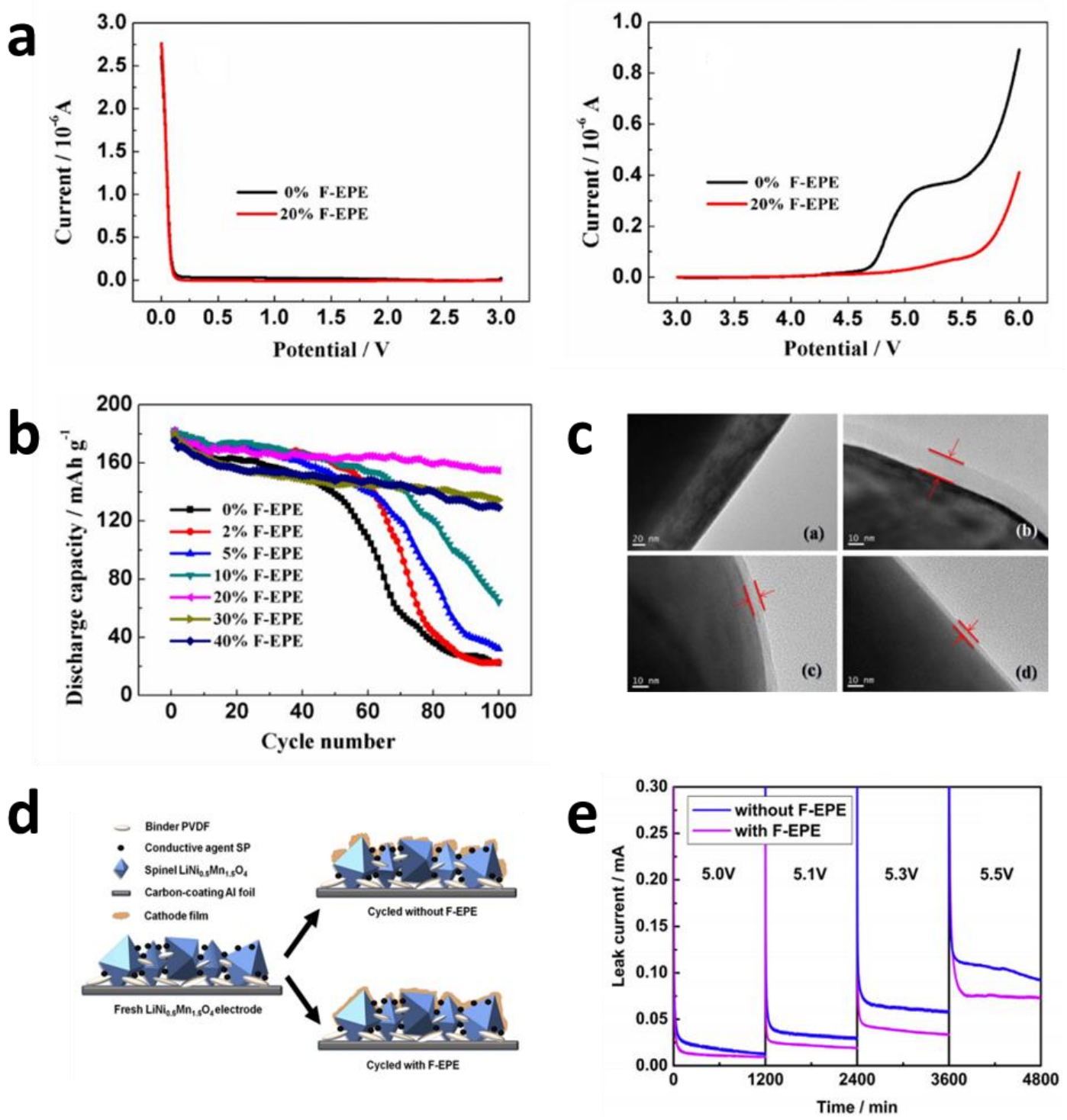

Figure 2. a) The profiles of linear sweep voltammetry at a Pt electrode in traditional electrolyte with and without 20\% F-EPE. b) Discharge capacity of the cells based on a $\mathrm{LiNi}_{1 / 3} \mathrm{Co}_{1 / 3} \mathrm{Mn}_{1 / 3} \mathrm{O}_{2} /$ graphite charged to $4.5 \mathrm{~V}$. c) TEM images of $\mathrm{LiNi}_{1 / 3} \mathrm{Co}_{1 / 3} \mathrm{Mn}_{1 / 3} \mathrm{O}_{2}$ electrodes after 100 cycles. Reproduced with permission. ${ }^{[63]}$ Copyright 2015 , the Electrochemical Society. d) Schematic illustrations of $\mathrm{LiNi}_{0.5} \mathrm{Mn}_{1.5} \mathrm{O}_{4}$ electrodes cycling with and without F-EPE. e) The floating test of the electrolytes with and without F-EPE. Reproduced with permission. ${ }^{[24]}$ Copyright 2016, Elsevier B.V.

\subsubsection{Nitriles}


In recent years nitrile-based compounds have increasingly gained attention in the battery application because of their excellent physiochemical and thermodynamic stability. ${ }^{[64-66]}$ Particularly, nitrile-based electrolytes have better thermal stability and high oxidative-tolerant ability. For example, many dinitriles have been reported as additives or cosolvents for high energy LIBs and the results demonstrate that they can improve the stability of the cathode/electrolyte surface. Nagahama et al. indicated that a sebaconitrile-containing electrolyte (carbonate solvents: sebaconitrile 50:50 vol \%) possessed a good electrochemical stability above $6 \mathrm{~V}$ vs. $\mathrm{Li}^{+} / \mathrm{Li}$ at a glassy carbon electrode. ${ }^{[66]}$ Additionally, Elise et al. analyzed the influence of sebaconitrile at a lower volume ratio (0-50 vol \%) and also found that adding sebaconitrile allowed for reaching a higher oxidation potential limit at the inert electrode glassy carbon. ${ }^{[67]}$ However, dinitriles cannot form an efficient SEI on the graphite or lithium metal-based anode surfaces. For example, $\mathrm{Xu}$ et al. demonstrated that for $\mathrm{LiNi}_{0.5} \mathrm{Mn}_{1.5} \mathrm{O}_{4} / \mathrm{Li}$ cells with $10 \mathrm{wt} \%$ glutaronitrile (GLN), in the traditional carbonate-based electrolyte, the discharge capacity retention of the cell after 50 cycles rapidly decreased, reaching $29.09 \%$ after 150 cycles at $1 \mathrm{C}$ rate, owing to incompatibility of GLN with Li anode, especially at a high current density. ${ }^{[68]}$ Fortunately, this incompatibility can be circumvented by adding SEI-forming compounds, such as ethylene carbonate (EC) and other functional additives, to protect the interface between the anode and the electrolyte.

\subsubsection{Others}

Apart from the high voltage solvents mentioned above, there are also many other kinds of solvents which combine various functional groups developed in recent years. For example, $\mathrm{Su}$ et al. synthesized new fluorinated sulfones (Figure 3a) and tested the electrochemical performances in full cells based on $\mathrm{LiNi}_{0.5} \mathrm{Mn}_{0.3} \mathrm{Co}_{0.2} \mathrm{O}_{2} /$ graphite chemistry. ${ }^{[6]}$ The fluorination can lower the HOMO and LUMO energy levels and thus improve the oxidation-tolerant ability of the sulfone compounds (Figure 3b). Additionally, the results suggest that fluorinated sulfones are characterized by low viscosity, great separator wetting 
and improved safety characteristics (Figure 3c). The cell based on trifluoromethyl ethyl sulfone (FMES)/difluoroethylene carbonate (DFEC) was reported to deliver $>80 \%$ capacity retention after 500 cycles owing to the excellent oxidative stability of FMES on the charged cathode, whereas the traditional electrolyte-based cell suffers from intensive capacity decay with cycling (Figure 3d).

a

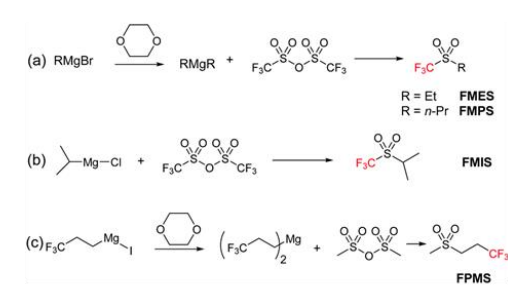

b

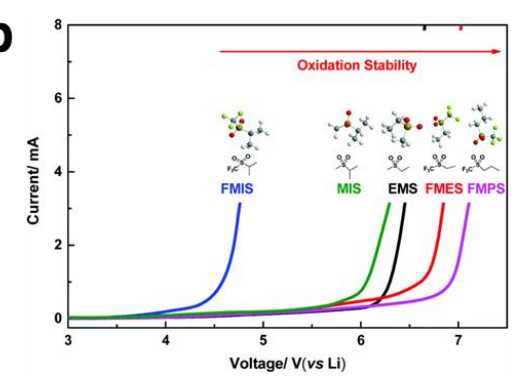

C

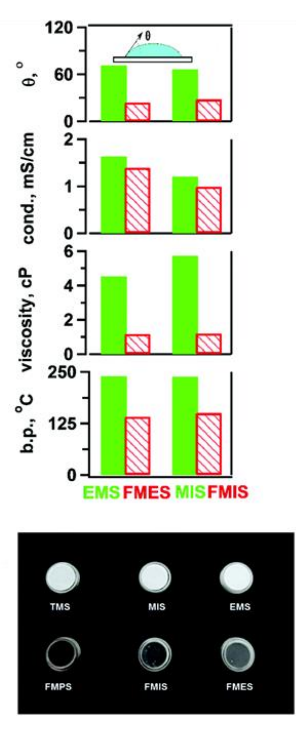

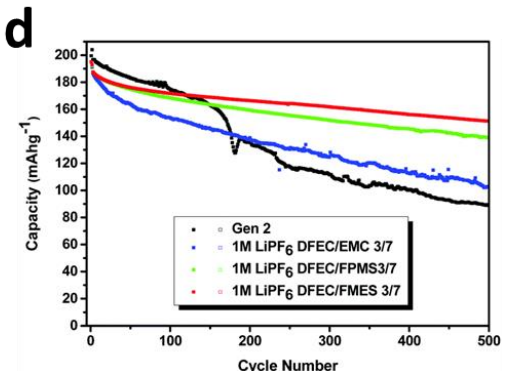

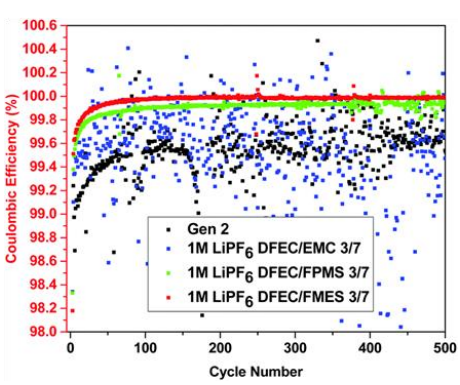

Figure 3. a) Synthetic routes for FMES, FMPS, FMIS and FPMS; b) Profiles of linear sweep voltammograms of the various sulfones; c) Comparison of physical properties for EMS and FMES; d) Electrochemical performance of $\mathrm{LiNi}_{0.5} \mathrm{Mn}_{0.3} \mathrm{Co}_{0.2} \mathrm{O}_{2} /$ graphite full cells. Reproduced with permission. ${ }^{[69]}$ Copyright 2017, the Royal Society of Chemistry.

\subsection{Additives}

Since the commercialization of LIBs, one of the main issues is the intercalation and de-intercalation of the $\mathrm{Li}^{+}$was the graphite anode. The potential of intercalation and de-intercalation of $\mathrm{Li}^{+}$is far below the stability limits of the most available organic solvents. And, therefore, the interface between the electrolyte and graphite anode is thermodynamically unstable. ${ }^{[6]}$ Thus suppressing the interfacial reaction dynamically by forming an effective solid electrolyte interface layer (SEI layer) can solve this problem. ${ }^{[70]}$ SEI layer is formed by 
the reductive decomposition of the electrolyte and it is nonconductive to the electrons, but conductive to Li ions. ${ }^{[26]}$ SEI layer is essential to protect the interfacial stability. Without any changes of the main components in electrolytes, putting additives can improve the battery performance; this way is economical and convenient. Thus intensive efforts have been put to develop the electrolyte additives for better interfacial protection. The energy levels of HOMO and LUMO can be calculated in theory to smartly select additives. Additives used for anode are expected to have the lower unoccupied LUMO than traditional organic solvents to initiate the reduction at a higher potential and the products of the reductive decomposition should be stable enough to prevent the continuous decomposition of the electrolytes. For example, Zheng et al. introduced a new solid electrolyte interphase (SEI) forming additive, di(2,2,2-trifluoroethyl) sulfite (DTFES), which can dramatically enhance the performance of LIBs based on the MCMB anode. ${ }^{[71]}$ Despite the organic additives, there are also inorganic additives developed for improving the cycling performance of the batteries. For example, in 1994, Aurbach at al. firstly proposed to use $\mathrm{CO}_{2}$ as an additive for graphite anodes. ${ }^{[72]}$ The reason behind is that $\mathrm{CO}_{2}$ can improve the performance of graphite electrodes while reacting at a low potential and forming $\mathrm{Li}_{2} \mathrm{CO}_{3}$ on the carbon surface.

Apart from the progresses made for the anode additives, there have also been many developments for the high voltage cathode additives. ${ }^{[73-75]}$ In order to apply LIBs to the transportation field, researchers have made intensive efforts to design 5 V-class cathode materials, such as $\mathrm{LiNi}_{0.5} \mathrm{Mn}_{1.5} \mathrm{O}_{4}(4.6 \mathrm{~V}),{ }^{[76-79]} \mathrm{LiNiPO}_{4}{ }^{[80,81]}$ and $\mathrm{LiCoPO}_{4}(4.8 \mathrm{~V}) .{ }^{[82-84]}$ Among these promising high voltage cathodes, $\mathrm{LiNi}_{0.5} \mathrm{Mn}_{1.5} \mathrm{O}_{4}$ has recently attracted prime attention owing to its high working potential of $4.8 \mathrm{~V}\left(\mathrm{vs} . \mathrm{Li} / \mathrm{Li}^{+}\right)$, excellent structural stability and low price. However, the continuous decomposition of $\mathrm{LiPF}_{6}$ and conventional organic molecular carbonate-based electrolytes above $4.5 \mathrm{~V}$ vs. $\mathrm{Li}^{+} / \mathrm{Li}$ severely hampers the application of these materials. In addition to the aforementioned development of new high-voltage solvents, the evolution of the high-voltage additives is also a booming subject in 
recent years. ${ }^{[85-88]}$ Many attempts to select additives have been performed via computational approaches on the basis of the HOMO and LUMO energies. ${ }^{[89-92]}$ Higher HOMO energy level means lower oxidation potentials, while lower LUMO energy level means higher reductive potential. Herein we will choose several kinds of additives which will decompose at a lower potential than the oxidation potential of the electrolyte to form a protective layer on the cathode surface.

\subsubsection{Boron-containing additives}

Besides the successful application on the graphite anode, boron-containing additives have also been investigated as cathode additives. ${ }^{\left[{ }^{[9-95]}\right.}$ Lithium bis(oxalate)borate (LiBOB) is one of the most investigated B-containing additives. ${ }^{[96,97]}$ Nayak et al. applied LiBOB as an additive to the high-voltage cathode material $\mathrm{Li}_{1.2} \mathrm{Ni}_{0.16} \mathrm{Mn}_{0.56} \mathrm{Co}_{0.08} \mathrm{O}_{2}$ and observed clear enhancement in both capacity retention and lowering impedance. ${ }^{[98]}$ Ex situ analysis, such as Raman and transmission electron microsocpy (TEM) showed that the cathode surface chemistry had been changed and passivated by $\mathrm{BOB}^{-}$. More recently, $\mathrm{Xu}$ et al. synthesized and reported the behaviors of $\mathrm{Li}$ organoborate additives in the traditional electrolytes. ${ }^{[99]}$ The additives were synthesized via the procedure illustrated in Figure 4a. These $\mathrm{Li}$ aryl trimethyl borates and $\mathrm{Li}$ alkyl trimethyl borates were designed to decompose and then form a borate-rich surface with designed function on the $\mathrm{LiNi}_{0.5} \mathrm{Mn}_{1.5} \mathrm{O}_{4}$ surface at high voltage and elevated temperature to protect the cathode materials and the electrolytes. The electrochemical results showed that the addition of these borate-based compounds, especially lithium 4-pyridyl trimethyl borate(LPTB) in the traditional electrolytes, could enhance the cycling performance of graphite/ $\mathrm{LiNi}_{0.5} \mathrm{Mn}_{1.5} \mathrm{O}_{4}$ (Figure 4b). Meanwhile, Li et al. used triethyl borate (TEB) as a

high voltage additive to the Li-rich layered oxide, $\mathrm{Li}\left[\mathrm{Li}{ }_{0.2} \mathrm{Mn}_{0.54} \mathrm{Ni}_{0.13} \mathrm{Co}_{0.13}\right] \mathrm{O}_{2}{ }^{[100]}$ Electrochemical performance tests showed that when 3\% TEB was introduced, the capacity retention had been increased from $30 \%$ in the traditional carbonate electrolyte to $79 \%$ in the TEB-containing electrolyte owing to the protective SEI layer formed by the preferential 
oxidation of TEB (Figure 4c). And the rate capability tests indicated that the addition of TEB significantly had improved the rate property of $\mathrm{Li}\left[\mathrm{Li}_{0.2} \mathrm{Mn}_{0.54} \mathrm{Ni}_{0.13} \mathrm{Co}_{0.13}\right] \mathrm{O}_{2} / \mathrm{Li}$ (Figure $4 \mathbf{d}$ ). From the electrochemical impedance spectroscopy, one can see that the SEI layer formed in the TEB-containing electrolyte can prevent the electrolyte from continuous oxidative decomposition and reduce the interfacial impedance, whereas the film formed in the standard electrolyte cannot do so (Figure 4e). These breathtaking findings show that B-based additives are promising for the application in high voltage electrolytes.

a
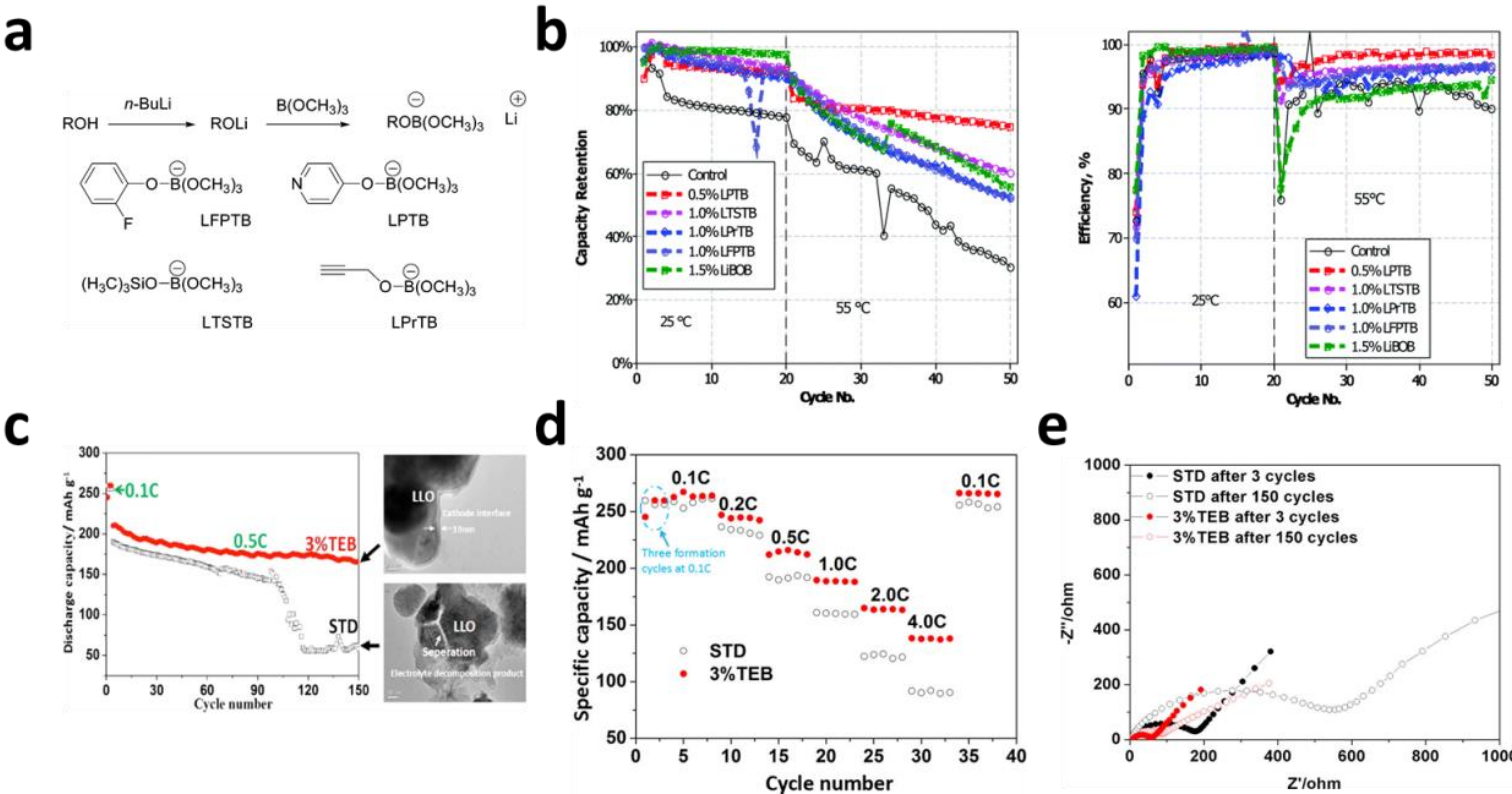

e

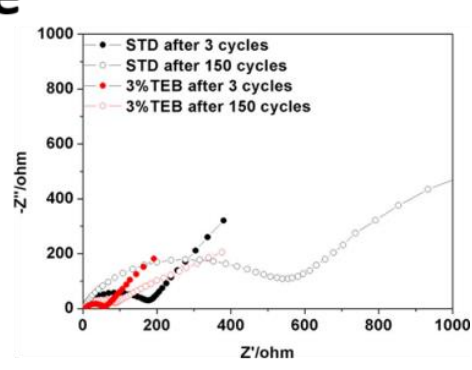

Figure 4. a) The procedure and structure of the boron-based additives; b) Cycling performance of graphite/ $\mathrm{LiNi}_{0.5} \mathrm{Mn}_{1.5} \mathrm{O}_{4}$ cells at 25 and $55^{\circ} \mathrm{C}$. Reproduced with permission. ${ }^{[99]}$ Copyright 2016, the Royal Society of Chemistry. c) Cycling performance of $\mathrm{Li}\left[\mathrm{Li}_{0.2} \mathrm{Mn}_{0.54} \mathrm{Ni}_{0.13} \mathrm{Co}_{0.13}\right] \mathrm{O}_{2} / \mathrm{Li} ; \quad$ d) Rate capability of $\mathrm{Li}\left[\mathrm{Li}_{0.2} \mathrm{Mn}_{0.54} \mathrm{Ni}_{0.13} \mathrm{Co}_{0.13}\right] \mathrm{O}_{2} / \mathrm{Li}$; e)Electrochemical impedance spectra of the $\mathrm{Li}\left[\mathrm{Li}_{0.2} \mathrm{Mn}_{0.54} \mathrm{Ni}_{0.13} \mathrm{Co}_{0.13}\right] \mathrm{O}_{2}$. Reproduced with permission. ${ }^{[100]}$ Copyright 2016, American Chemical Society.

\subsubsection{Benzene derivatives and heterocyclic compounds}

Abe et al. found that benzene derivatives and heterocyclic aromatics can serve as electrolyte additives in $\mathrm{LiCoO}_{2}$ /graphite batteries through improving the cathode cycling stability 
performance. ${ }^{[101]}$ The monomers usually oxidize at a potential above the $4 \mathrm{~V} \mathrm{vs} . \mathrm{Li} / \mathrm{Li}^{+}$. Except for $\mathrm{LiCoO}_{2}$, the other cathodes usually require charging to $4.0 \mathrm{~V}$ or higher, which is ideal for the polymerization of heterocyclic aromatic monomers. So, polymer film formation is always proceeded successfully. For example, Lee and co-workers introduced a new benzene-based additive, dopamine, into the high voltage LIBs. Dopamine can be electrochemically oxidized to polydopamine on cathode surface to protect both the electrode and electrolyte from destruction (Figure 5a). ${ }^{[102]}$ The results from XPS evidenced that a new peak of $\mathrm{N}$ 1s implied that dopamine had already been decomposed after pre-cycling (Figure 5b). And the results from SEM showed that the cathode material cycled in the blank electrolyte was no longer porous. In addition, the counterpart cycled in the dopamine-containing electrolyte was similar to its original morphology (Figure 5d). All these findings implied that the SEI layer formed by dopamine could protect the cathode surface. Therefore, the cycling and rate performances were significantly improved by addition of dopamine (Figure 5c). Abouimrane et al. applied 3-hexylthiophene (3HT) as an additive to high capacity $\mathrm{Li}_{1.2} \mathrm{Ni}_{0.15} \mathrm{Co}_{0.1} \mathrm{Mn}_{0.55} \mathrm{O}_{2}$ and high voltage $\mathrm{LiNi}_{0.5} \mathrm{Mn}_{1.5} \mathrm{O}_{4}$ cathodes and observed significant enhancement in the discharge capacity retention owing to the ability of $3 \mathrm{HT}$ to form a conductive, conjugated polymer film on the cathode surface. ${ }^{[103]}$ And Chen et al. used $\mathrm{N}$-methylpyrrole (MPL) as an additive to high voltage cathode. ${ }^{[104]}$ By adding $0.3 \mathrm{wt} \% \mathrm{MPL}$ into electrolyte, the discharge capacity retention of $\mathrm{Li} / \mathrm{LiNi}_{0.5} \mathrm{Mn}_{1.5} \mathrm{O}_{4}$ cell after 200 cycles was increased from $83.2 \%$ to $89.5 \%$ at room temperature and from $59.1 \%$ to $87.4 \%$ at elevated temperature $\left(55^{\circ} \mathrm{C}\right)$. The reason why the cycling performance had been enhanced is electrochemical polymerization of MPL during the initial charge process and a consequent formation of a thin and protective film on the $\mathrm{LiNi}_{0.5} \mathrm{Mn}_{1.5} \mathrm{O}_{4}$ surface. 
a

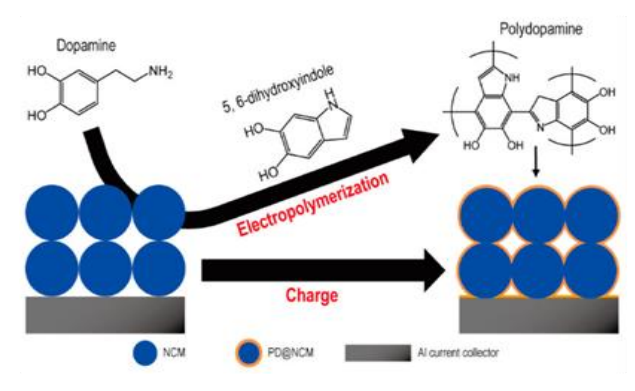

b

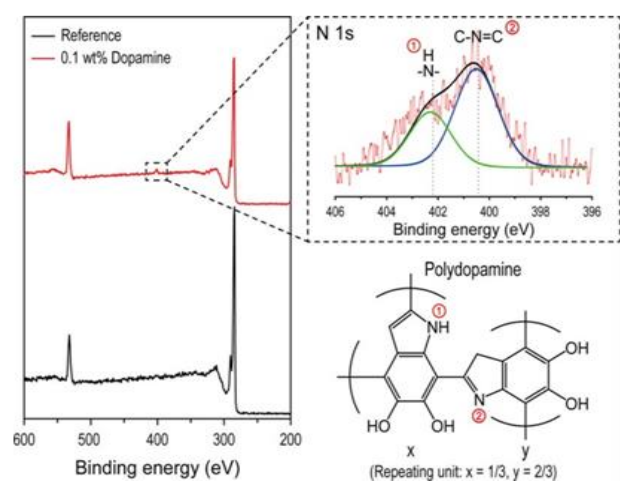

C

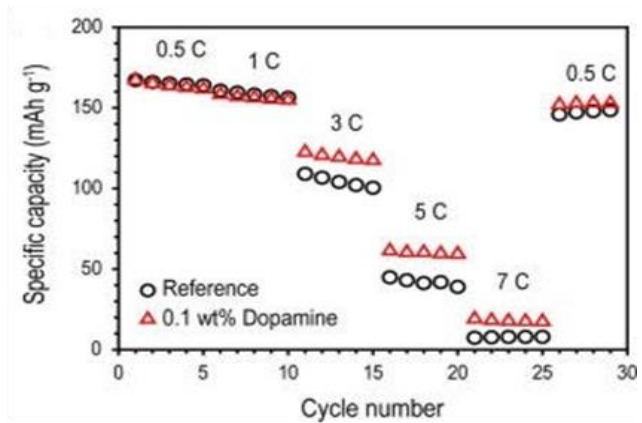

d

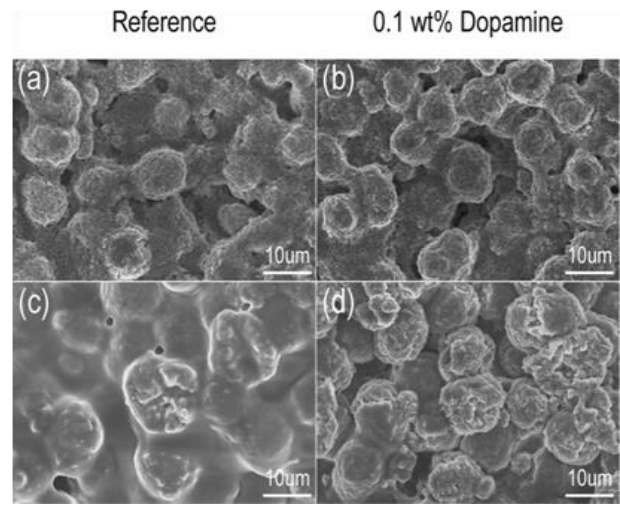

Figure 5. a) Mechanism of the electrochemical polymerization of dompine. b) XPS of the cathodes with and without dopamine after precycling, and expected polydopamine chemical structure. c) The rate performance of the $\mathrm{LiNi}_{1 / 3} \mathrm{Co}_{1 / 3} \mathrm{Mn}_{1 / 3} \mathrm{O}_{2} /$ graphite cells charged to $4.5 \mathrm{~V}$. d) SEM images of the cathodes with and without dopamine. Reproduced with permission. ${ }^{[102]}$ Copyright 2016, American Chemical Society.

\subsubsection{Ethers}

According to the molecular orbital energy calculations, the HOMO level of ethers is relatively high among a variety of aprotic solvents. As a result, they are usually susceptible to oxidation decomposition and have been considered as high voltage additives. ${ }^{[15]}$ Extensive efforts have been dedicated to confirm this point. For example, the HOMO energy of $\mathrm{N}$-(triphenylphosphoranylidene) aniline (TPPA) is higher than those of conventional electrolyte solvents. And TPPA contains the electron-donating benzene and aniline derivatives, thus TPPA is speculated to be a proper candidate as a high voltage additive in the electrolyte. To conform this, Lee et al. applied TPPA to the flagship cathode lithium cobalt 
oxide $\left(\mathrm{LiCoO}_{2}\right)$ and reported that capacity retention after 200 cycles increased by $10 \%$, benefiting from the surface films that TPPA formed on the cathode surface. ${ }^{[105]}$ XPS data validated that a modified film was formed at the cathode surface and prevented the solvent from decomposition under high voltage.

\subsubsection{Others}

Apart from the additives aforementioned, there have been many other additives for high voltage electrolytes, such as phosphorus-based additives, some special functional carbonate additives and so on. For example, Wang and co-workers demonstrated that for $\mathrm{LiNi}_{1 / 3} \mathrm{Co}_{1 / 3} \mathrm{Mn}_{1 / 3} \mathrm{O}_{2} / \mathrm{Graphite}$ pouch cells with $0.5 \mathrm{wt} \%$ 3,3'-(Ethylenedioxy)dipropiononitrile (EDPN) in the traditional carbonate-based electrolyte, the discharge capacity retention of the cell was improved from $32.5 \%$ to $83.9 \%$ after 100 cycles at $1 \mathrm{C}$ rate in the range of $3.0-4.5$ $\mathrm{V}{ }^{[65]}$ The reason for the improved electrochemical performance is the stable protective interphase film formed on the $\mathrm{LiNi}_{1 / 3} \mathrm{Co}_{1 / 3} \mathrm{Mn}_{1 / 3} \mathrm{O}_{2}$ electrode surface due to the sacrificial oxidative decomposition of EDPN in the electrolyte. Wang et al. demonstrated that the addition of $0.5 \%$ fumaronitrile (FN) into the blank electrolyte $\left(1.0 \mathrm{~mol} \mathrm{~L}^{-1} \mathrm{LiPF}_{6}\right.$ in EC/EMC/DEC (3:5:2 by weight) can maintain the structural integrity of lithium cobalt oxide $\left(\mathrm{LiCoO}_{2}\right)$ through a protective cathode interphase film formed by the sacrificial oxidative decomposition when it was charged to $4.5 \mathrm{~V}$ (vs. $\left.\mathrm{Li} / \mathrm{Li}^{+}\right){ }^{[64]}$ Zhang et al. used tris(trimethylsilyl)phosphate (TMSP) as an additive to form a solid electrolyte interface on lithium-rich cathode material $\mathrm{Li}\left[\mathrm{Li}_{0.2} \mathrm{Ni}_{0.13} \mathrm{Mn}_{0.54} \mathrm{Co}_{0.13}\right] \mathrm{O}_{2}$ to improve the electrochemical performances. ${ }^{[106]}$ Furthermore, Zheng et al. demonstrated that adding 0.1 wt $\%$ di(methylsulfonyl) methane(DMSM) into the blank electrolyte can significantly improve the discharge capacity retention of the $\mathrm{LiNi}_{1 / 3} \mathrm{Co}_{1 / 3} \mathrm{Mn}_{1 / 3} \mathrm{O}_{2} /$ graphite full cell cycled in a voltage range of $3.0-4.6 \mathrm{~V}$ from $61.0 \%$ to $80.1 \%$ after 100 cycles owing to the protective film formed by the sacrificial oxidation of the DMSM. ${ }^{[107]}$

\subsection{Ionic liquids}


Ionic liquids, namely room temperature molten salts, are characterized by a wide electrochemical window, low volatility and non-flammability, which make them attractive alternatives of traditional carbonate solvents. ${ }^{[50,108]}$ Recently the scientific community has been driven to apply LIBs in electric and hybrid vehicle industry, so the concern on battery safety has particularly been raised. ${ }^{[109,110]}$ From this perspective, as the conventional carbonate electrolyte is flammable, ionic liquids which are non-flammable, have been considered as the safest electrolytes and have been extensively investigated in recent years. ${ }^{[111-113]}$. These ionic liquids are mainly employed with respect to three aspects LIBs: as the solvents or co-solvents in an electrolyte, as additives, and as components for a polymer electrolyte which will be discussed further. Ionic liquids possess great electrochemical anodic stability, usually 5-5.5 V vs. Li/Li ${ }^{+}{ }^{[108]}$ For example, Santosh and co-workers synthesized two novel ionic liquids made of functional imidazolium cations in amalgamation with bis(trifluoromethanesulfonyl)imide (TFSI) anion and studied their physicochemical and electrochemical stability. ${ }^{[114]} 1 \mathrm{~mol} \mathrm{~kg}^{-1}$ LiTFSI in the ether-ether ionic liquid possessed a wide electrochemical window of $5.9 \mathrm{~V}$ and good conductivity of $2.2 \mathrm{mS} \mathrm{cm}^{-1}$. We assume that ILs are suitable for the high voltage conditions, but the main challenge for the application of ionic liquids is the unstable electrolyte/anode interface.. As for usual ionic liquids, for example, ionic liquids based on imidazoliums, cations always intercalate into the graphite layers and decompose before the lithium intercalation, resulting in the irreversible capacity of the batteries. The introduction of new chemical structure, such as pyrrolidinium and piperidinium, has advanced the development of ionic liquids in LIBs because they are stable to lithium. ${ }^{[115]}$ Owing to their wide electrochemical windows, many researchers have performed detailed investigations to verify a possibility of using these in high voltage rechargeable LIBs. However, one of the main drawbacks of pure ILs used as solvents for electrolyte is their high viscosity, which implies a poor electrochemical capability. From this 
perspective, ionic liquids used as electrolyte additives may be the optimal method to enhance the cell performance.

\subsubsection{Imidazoliums}

Among ionic liquids, imidazolium-based ILs are characterized by a relative ease in synthesis, rather cheap price, low viscosity and decent electrical conductivity, thus they have intensively been investigated. ${ }^{[10,} \quad{ }^{116-118]} \quad$ Ethylmethyl imidazolium bis(trifluoromethanesulfonyl-imide)(EMITFSI) is the most popular agent owing to its desirable features, such as low melting point and high thermal stability. However, this class of ionic liquid has its own drawbacks. Because of the three acidic protons of $\mathrm{EMI}^{+}$, especially the protons of $\mathrm{C}(2)$ which has strong reducibility, this kind of system is prone to reduction at about 1.0 vs. $\mathrm{Li} / \mathrm{Li}^{+}$, which is higher than the potential of $\mathrm{Li}$ deposition. ${ }^{[119-121]}$ As a result, this kind of ionic liquid was initially excluded from the applications in LIBs. When this kind of ionic liquid is used with the graphite anode, the reduction products cannot form a stable and protective film on the graphite surface to retard successive reduction decomposition of the electrolyte. Extensive investigations have been conducted to improve the reduction-tolerant ability of imidazolium-based ILs. Searching for new anions and substituent groups, mixing with traditional organic molecular carbonate solvents are the two possible solutions proposed in recent works. Masashi and co-workers firstly used a pure ionic liquid to achieve the reversible lithium intercalation/de-intercalation at the graphitized negative electrode without any additives. ${ }^{[122]}$ An exchange from TFSI to FSI, as a counter anion, co significantly improve the interfacial stability. The reason is that SEI layer (formed in the electrolyte containing $\mathrm{FSI}^{-}$) is stable. The second method is replacing the protons of $\mathrm{C}$ (2) by other groups, like alkyl groups. ${ }^{[110,123]}$ This method can improve the electrochemical stability of imidazolium ring, and thereby they can become possible electrolytes for LIBs. Seki et al. applied a modified imidazolium cation-based ionic liquid as an electrolyte solvent for half cells based on $\mathrm{LiCoO}_{2} / \mathrm{Li}^{[124]}$ The cells achieved a stable charge-discharge running over more than 100 
cycles at a current density of 1/8 C. Another method to apply this kind of ionic liquid into the practical batteries is the usage of co-solvents, such as VC.

\subsubsection{Pyrrolidiniums}

In addition to imidazolium-based ionic liquids, pyrrolidiniums-based and piperidinium-based ionic liquids have also been reported. ${ }^{[125-127]}$ According to extensive investigations on the properties of pyrrolidiniums-based ionic liquids, it can be concluded that a wide electrochemical window, rather high conductivity $\left(>1 \mathrm{mS} \mathrm{cm}{ }^{-1}\right)$, high $\mathrm{Li}^{+}$-transference number, safety, and low viscosity are available from this kind of ionic liquid. ${ }^{[128]}$ To demonstrate its high voltage and high temperature-tolerant ability, Cao and co-workers conducted a contrastive analysis between traditional electrolyte and two pyrrolidiniums-based ILs (Figure 6). ${ }^{[109]}$ The results from linear sweep voltammetry at different temperatures indicated that the electrochemical window had been dependent on the temperature and when the temperature was increased, the electrochemical window became narrow. Fortunately, the ILs-based electrolytes have a wider electrochemical window than the traditional electrolyte at elevated temperatures (Figure 6a). SEM images showed a clean cathode surface in the ILs-based electrolytes, whereas rough cathode surface in the traditional electrolyte (Figure 6b). This implies less decomposition in the ILs-based electrolytes. And the constant current charge/discharge cycling at elevated temperature demonstrated the superior cycling properties of ILs-based electrolytes (Figure 6c). Agostini et al. used $\mathrm{LiPF}_{6}$ dissolved in a mixture of carbonate solvents and $\mathrm{N}-n$-butyl-N-methylpyrrolidinium hexafluorophosphate $\left(\mathrm{PYR}_{14} \mathrm{PF}_{6}\right)$ ionic liquid as an electrolyte in the full cells based on $\mathrm{LiNi}_{0.5} \mathrm{Mn}_{1.5} \mathrm{O}_{4} / \mathrm{TiO}_{2}{ }^{[129]}$ Compared to commercial electrolytes, this new configuration for high voltage electrolyte was able to provide an intrinsically higher safety and prolonged cycling life. It was then generally recognized that pyrrolidinum-based ionic liquids can provide superior cathodic-tolerant ability than imidazolium-based ionic liquids. Thus pyrrolidinum-based ionic liquids can serve as electrolytes with a Li anode, whereas imidazolium-based ionic liquids cannot. Anand and 
co-workers applied 1-propyl-1-methyl-pyrrolidinium bis(fluorosulfonyl)imide (C3mpyrFSI) as an electrolyte solvent to investigate the morphological changes of Li surfaces. ${ }^{[130,131]}$ The results indicate that electrolyte based on the C3mpyrFSI (containing either LiFSI or LiTFSI) is compatible with $\mathrm{Li}$ metal electrodes, as was evident by the reversible deposition and stripping of lithium. Yang et al. reported a mixture electrolyte based on N-propyl-N-methylpyrrolidiniumbis (trifluoromethanesulfonyl) imide (PYR 13 TFSI), EC/DMC-5\% VC, and lithium bis (trifluoromethanesulfonyl) imide (LiTFSI). The results indicated that the addition of $65 \% \mathrm{PYR}_{13}$ TFSI by volume led to be the best overall properties, such as high safety, low viscosities of about $30 \mathrm{mPa} s$ at room temperature, a wide electrochemical window of $4.8 \mathrm{~V}$, and thus high reversible discharge capacities of $\mathrm{LiFePO}_{4} / \mathrm{Li}$ cells. ${ }^{[132]}$
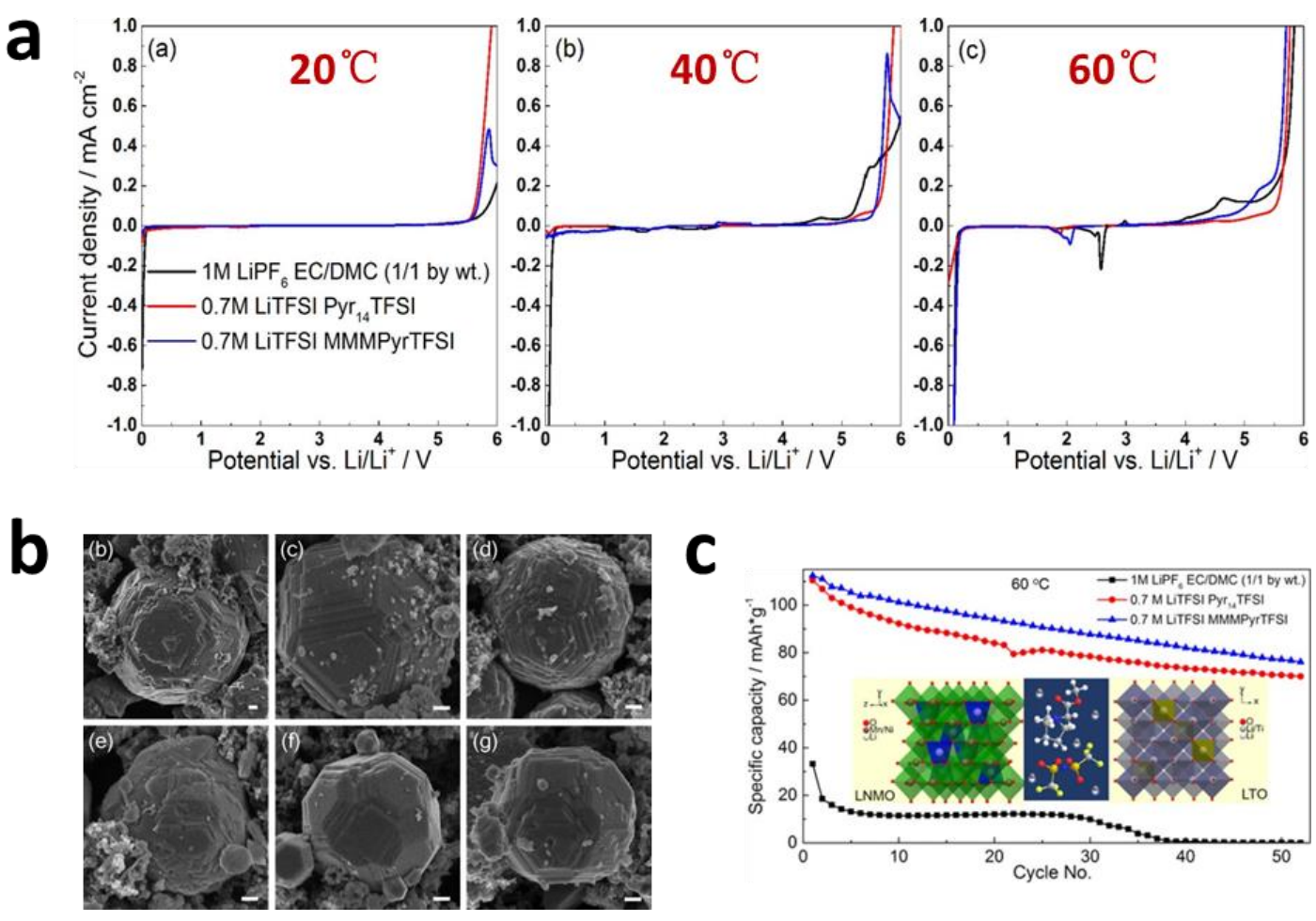

Figure 6. a) Linear sweep voltammetry profiles of the investigated electrolytes at different temperatures. b) SEM images of an LNMO electrode after cycling in different electrolyte and at different temperatures: b-d is at $40{ }^{\circ} \mathrm{C}$ and e-g is at $60{ }^{\circ} \mathrm{C}$; b,e are in traditional electrolyte; $\mathrm{c}, \mathrm{f}$ are in PYR ${ }_{14}$ TFSI-based electrolyte; $\mathrm{d}, \mathrm{g}$ are in MMMPyrTFSI-based electrolyte. c) 
Discharge capacity of LNMO/LTO full cells. Reproduced with permission. ${ }^{[109]}$ Copyright 2016, American Chemical Society.

\subsubsection{Piperidiniums}

Like pyrrolidinium-based ionic liquids, piperidinium-based ionic liquids are also promising candidates for the electrolyte application owing to their excellent physicochemical properties, such as high voltage stability (up to $5.0 \mathrm{~V}$ ), high thermal-tolerant stability (up to $385^{\circ} \mathrm{C}$ ), and commercially acceptable $\mathrm{Li}^{+}$conductivity at room temperature $\left(1.4 \mathrm{mS} \mathrm{cm}{ }^{-1}\right)^{[133-139]}$ Madhulata et al. studied the molecular structure in details by infrared (IR), Raman spectroscopies and density functional theory (DFT). They concluded that the H-bonding interaction along with constituents largely controlled the physical state of the salt. ${ }^{[140]}$ Dong and co-workers synthesized N-methylpiperidinium-N-acetate bis(trifluoromethyl-sulfonyl)imide ([MMEPip][TFSI]), a piperidinium-based ionic liquid and applied it as an additive to the blank electrolyte(LiTFSI $\left(0.6 \mathrm{~mol} \mathrm{~kg}^{-1}\right)$ into the mixture of ethylene carbonate and diethyl carbonate) in the $\mathrm{LiFePO}_{4}$ half cells to improve the cycling stability. ${ }^{[141]}$ Andrzej and co-workers demonstrated that with $10 \%$ VC the cells based on $\mathrm{LiMn}_{2} \mathrm{O}_{4}$ in the piperidinium-based electrolyte may be cycled with small capacity decay and high Coulombic efficiency. ${ }^{[142]}$

\subsubsection{Others}

Apart from three main kinds of ionic liquids, other ionic liquids can also be applied for LIBs. For example, Bucher et al. synthesized and characterized the properties of $\mathrm{N}, \mathrm{N}, \mathrm{N}$ ',N'-tetramethyl-N",N"-pentamethyleneguanidinium bis(trifluoromethyl-sulfonyl)imide (PipGuan-TFSI) which combined the advantages of guanidinium and piperidinium structural elements. ${ }^{[143]}$ Navarra et al. prepared and characterized two different ionic liquids based on morpholinium and piperidinium cations and TFSI anions. ${ }^{[144]}$ Substitution of a $\mathrm{CH}_{2}$ group in the cation ring with an ether bond in the side chain could restrain the crystallization of the ILs and consequently enhanced ion transport properties. ${ }^{[145,146]}$ 
Although ionic liquids possess intensive desirable properties mentioned above, they have not yet been commercialized owing to their high viscosities, poor wettability with separator and electrodes, and co-intercalation into graphitized carbon-based anode. Recent literatures have proposed some possible methods to solve these problems. However, challenges still remain, such as exploring new kinds of separators which can be well wetted by the ionic liquids.

\subsection{Superconcentrated electrolytes}

The traditional electrolyte in LIBs may have infinite variations of aprotic solvents, lithium salts and their concentrations. ${ }^{[15]}$ In fact, restrictions remain when choosing the solvents, lithium salts and their concentration. For example, to match with the commercial graphite-based anode, ethylene carbonate (EC) based solution is the only option because of the SEI layer formation ability of EC. Because other lithium salts, such as LiTFSI, LiFSI, LiBOB, and LiDFOB, have their own limitations, $\mathrm{LiPF}_{6}$ has dominated the market owing to its superb and comprehensive properties. The concentration of the electrolyte is optimized at around $1 \mathrm{~mol} \mathrm{~L}^{-1}$ to obtain the maximum ionic conductivity. However, the traditional electrolytes suffer from severe oxidation decomposition under high voltage. This leads to the eventual failure of a battery. Thus, designing a superior electrolyte is imperative to meet the requirements of high voltage and high energy density batteries. Considerable efforts have been dedicated to invent and develop new classes of solvents, additives, and solid state electrolytes. ${ }^{[6]}$ However, intrinsic disadvantages remain in these new electrolytes. For example, solid state electrolytes are always characterized by low conductivities. New high voltage solvents always demonstrate high viscosities and incompatibility with the graphite anode. Thus, optimizing physical and chemical properties of traditional electrolytes is necessary. Herein, we intend to popularize a new strategy named superconcentrated salt strategy. This strategy has recently been developed by the University of Tokyo. ${ }^{[15,147-151]}$ 
Superconcentrated salt strategy is to use more than $1 \mathrm{~mol} \mathrm{~L}^{-1}$ lithium salt to obtain unusual properties of the electrolytes, such as high reductive and oxidative stability, $\mathrm{Al}$ anti-corrosion, high thermal stability, fast electrode reactions and low volatility with some compromise in ionic conductivity and viscosity.

\subsubsection{High oxidative stability}

As we mentioned above, the ethers are susceptible to oxidation decomposition and are considered to be used as high voltage additives owing to their high HOMO levels. Despite their inferior oxidative-tolerant ability at $>4.0 \mathrm{~V} \mathrm{vs}$. $\mathrm{Li} / \mathrm{Li}^{+}$, a pronounced advantage of ethers is their significant solvation ability for salt dissociation. To take full advantage of their solvation ability, Kazuki et al. used the superconcentrated salt strategy in order to improve the oxidative stability as solvents in LIBs. ${ }^{[152]}$ The results of linear sweep voltammograms showed that oxidative stability of Li salt-glyme equimolar solutions [Li(G3 or G4)1][TFSA] ([Li(glyme) $\left.)_{\mathrm{x}}\right][$ TFSA $]$, where the molar ratio of glyme:Li[TFSA $\left.]=x: 1\right)$, was enhanced to $4.5 \mathrm{~V}$ vs. $\left.\mathrm{Li}^{+} / \mathrm{Li}\right)$. Current constant charge/discharge curves revealed that the cells based on $[\mathrm{Li}(\mathrm{G} 3$ or G4) $\left.{ }_{4}\right][$ TFSA] failed rapidly (Figure $7 \mathbf{b}$ ). As a comparison, the cells based on [Li(G3 or G4)1][TFSA] both had reversible charge and discharge behaviors cycled from 3.0 to $4.2 \mathrm{~V}$. The initial discharge capacity of the $\mathrm{LiCoO}_{2}$ cathode was $130 \mathrm{~mA} \mathrm{~h} \mathrm{~g}^{-1}$ in both electrolytes and the Coulombic efficiencies were higher than $95 \%$ at the first cycle. The discharge capacity after 200 cycles was 100 and $85 \mathrm{~mA} \mathrm{~h} \mathrm{~g}^{-1}$, respectively, for [Li(G3) $\left.)_{1}\right]$ TFSA] and $\left[\mathrm{Li}(\mathrm{G} 4)_{1}\right][$ TFSA] (Figure 7c). Through the superconcentrated salt strategy, ether was the first used as a solvent for the LIBs thanks to the improved oxidative stability. Form this viewpoint, superconcentrated salt strategy proposes a feasible method to improve the oxidative-tolerant ability of solvents. 
a

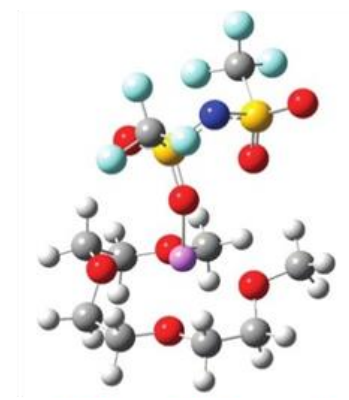

[Li(G3) $\left.)_{1}\right]$ TFSA]

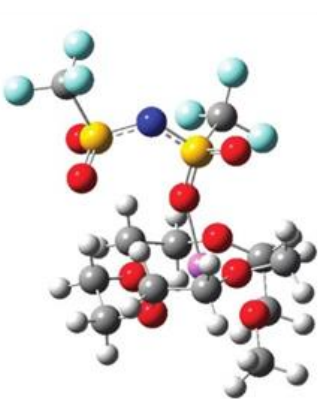

[Li(G4) $\left.)_{1}\right][$ TFSA]

\section{G3 = triglyme HOMO Level \\ G3 \\ $-11.45 \mathrm{eV}$ \\ [Li(G3) 1 [TFSA] $-12.10 \mathrm{eV}$}

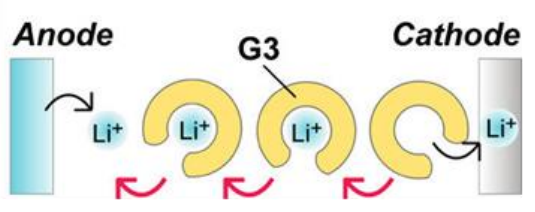

b
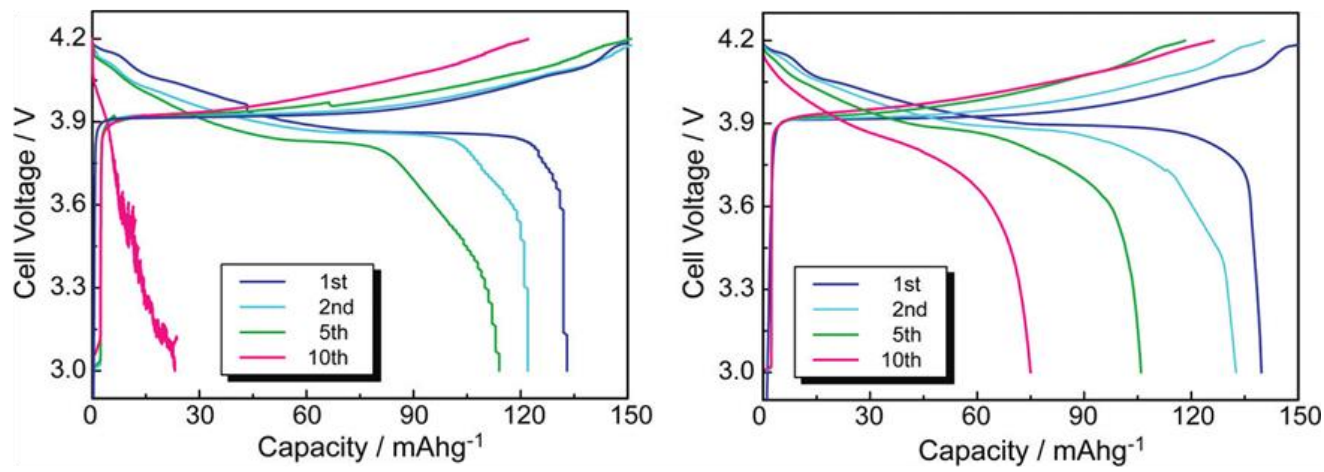

C
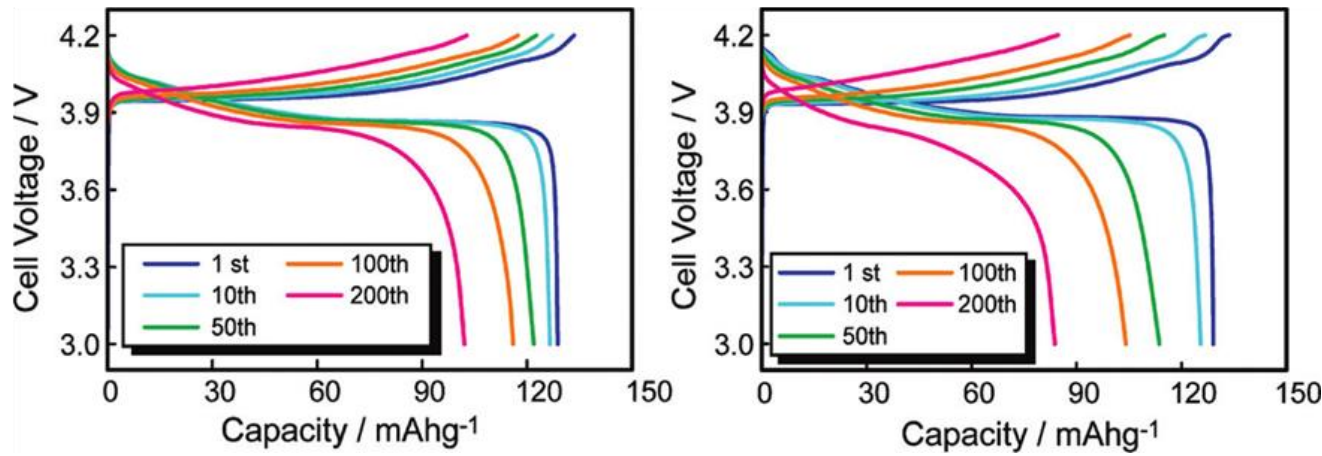

Figure 7. a) Optimized structures of [Li (G3 or G4) $]$ [TFSA]; b) Charge and discharge profiles of $\mathrm{LiCoO}_{2} / \mathrm{Li}$ based on $\left[\mathrm{Li}(\mathrm{G} 3)_{4}\right][\mathrm{TFSA}]$ (left) and [Li(G4)4][TFSA] (right); c) Charge and discharge profiles of $\mathrm{LiCoO}_{2} / \mathrm{Li}$ based on $\left[\mathrm{Li}(\mathrm{G} 3)_{1}\right][\mathrm{TFSA}]$ (left) and $\left[\mathrm{Li}(\mathrm{G} 4)_{1}\right]\left[\right.$ TFSA] (right). Reproduced with permission. ${ }^{[152]}$ Copyright 2011, American Chemical Society.

\subsubsection{High reductive stability}

Recently, aprotic solvents have been successfully used to achieve the reversible intercalation/de-intercalation on the graphite-based anodes without EC at a high concentration. ${ }^{[15,149-151,153]}$ For example, Yamada et al. found that acetonitrile (AN), one of 
the most oxidation-tolerant organic molecular solvents with high dielectric constant (to easily dissolve lithium salts) but poor reductive stability (ease in reaction with metal lithium), can serve as electrolyte when the concentration of lithium salt LiTFSI is above $4.2 \mathrm{~mol} \mathrm{~L}^{-1}$ because of the improved reductive stability. ${ }^{[150]}$ As shown in Figure 8a, 1 mol L ${ }^{-1}$ LiTFSI in AN easily dissolve the metal lithium, whereas the $4.2 \mathrm{~mol} \mathrm{~L}^{-1}$ counterpart does not. This result indicates that the superconcentrated electrolyte can overcome the inherent poor stability towards reduction of AN solvent. To confirm the practical validity of this superconcentrated electrolyte, the electrochemical tests of half cells, with the natural graphite and metal lithium as electrodes, have been conducted and the results are shown in Figures $\mathbf{8 b}$ and $\mathbf{8 c}$. One can clearly observe the reversible lithium intercalation/de-intercalation reaction at the natural graphite electrode. Moreover, the half cell in the superconcentrated electrolyte displays a superior rate capacity than that in the traditional electrolyte. The successful application of superconcentrated AN electrolyte validates that superconcentrated salt strategy is a powerful and feasible method to expand the variety of electrolyte other than EC. To explore the mechanism of enhanced reductive stability in a superconcentrated solution, the solution structure was investigated by Raman tests. And the results showed that there is no free solvent in the superconcentrated electrolyte. Thus the reductive stability was significantly improved. To further confirm this consideration, quantum mechanical DFT-MD simulations were conducted and the results are shown in Figure 8d. It can be seen that the energy levels at the lowest energy-level edge of the conduction band of the AN molecular in the dilute electrolyte are lower than those of the TFSI anion. This result is consistent with the experiments confirming that AN is easily reduced. And in the superconcentrated electrolyte, new energy levels of TFSA anion appear and become lower than those of AN molecules. Thus the reductive-tolerant ability of AN in superconcentrated condition has been improved. 

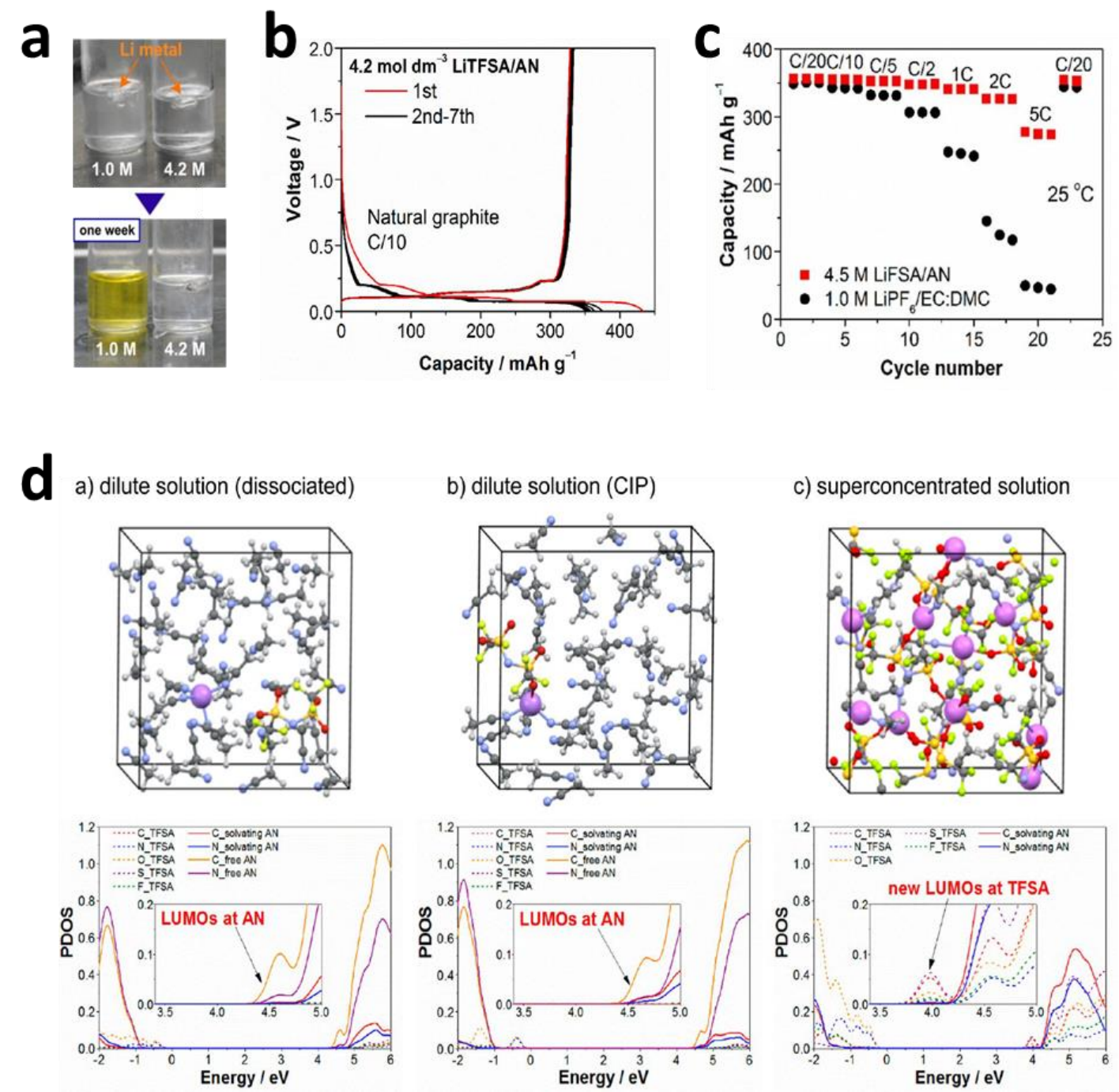

c) superconcentrated solution


Figure 8. a) Reactivity of lithium metal and LiTFSA/AN solutions; b) Charge-discharge profiles of natural graphite/lithium metal cell based on $4.2 \mathrm{~mol} \mathrm{dm}^{-3}$ LiTFSA/AN electrolyte; c) Rate capacity test of natural graphite/lithium metal cell based on traditional electrolyte and superconcentrated electrolyte; d) Supercells used and projected density of states (PDOS) obtained with quantum mechanical DFT-MD simulations. Reproduced with permission. ${ }^{[150]}$ Copyright 2014, American Chemical Society.

Qian et.al applied the superconcentrated electrolyte into the anode-free rechargeable LIBs and found that the superconcentrated electrolyte can improve the reversibility of the Li plating/stripping process. Thus the Coulombic efficiency and cycling life of the battery were improved. ${ }^{[154]}$ 


\subsubsection{Al-anti corrosion}

A $\mathrm{LiPF}_{6}$ salt is chemically unstable and will form hydrofluoric acid (HF) which accelerates transition metal dissolution of the electrode materials, but, fortunately, HF can react with the $\mathrm{Al}$ current collector to form an insoluble layer, $\mathrm{AlF}_{3}$, that can beneficially protect collector from oxidative dissolution. Replacing $\mathrm{LiPF}_{6}$ with more stable lithium salts may diminish transition metal dissolution, but, unfortunately, encounters severe oxidation of a collector. In order to replace the $\mathrm{LiPF}_{6}$ by more stable lithium salts, the corrosion of $\mathrm{Al}$ current collector must be mitigated. The superconcentrated salt strategy can perfectly resolve these problems. Wang and co-workers found that a superconcentrated 1:1.1 LiFSA/DMC electrolytes can suppress the dissolution of metal ions from cathode materials and protect the $\mathrm{Al}$ current collector. ${ }^{[147]}$ The linear sweep voltammetry (LSV) of an Al electrode, as indicated in Figure 9d, shows that with the concentration of lithium salts increasing, the potential of anodic dissolution of the aluminium current collector is also increased and when the concentration is 1:1.1 LiFSA/DMC, the oxidation potential becomes up to $6 \mathrm{~V}$ vs. $\mathrm{Li} / \mathrm{Li}^{+}$. The performance tests show that the discharge capacity retention of the cells after 100 cycles with the commercial electrolyte and superconcentrated electrolyte is $18 \%$ and $90 \%$, respectively (Figure 9b). From these results, we can conclude that superconcentrated salt strategy may be a key to circumvent the $\mathrm{Al}$ corrosion problem without $\mathrm{LiPF}_{6}$. 

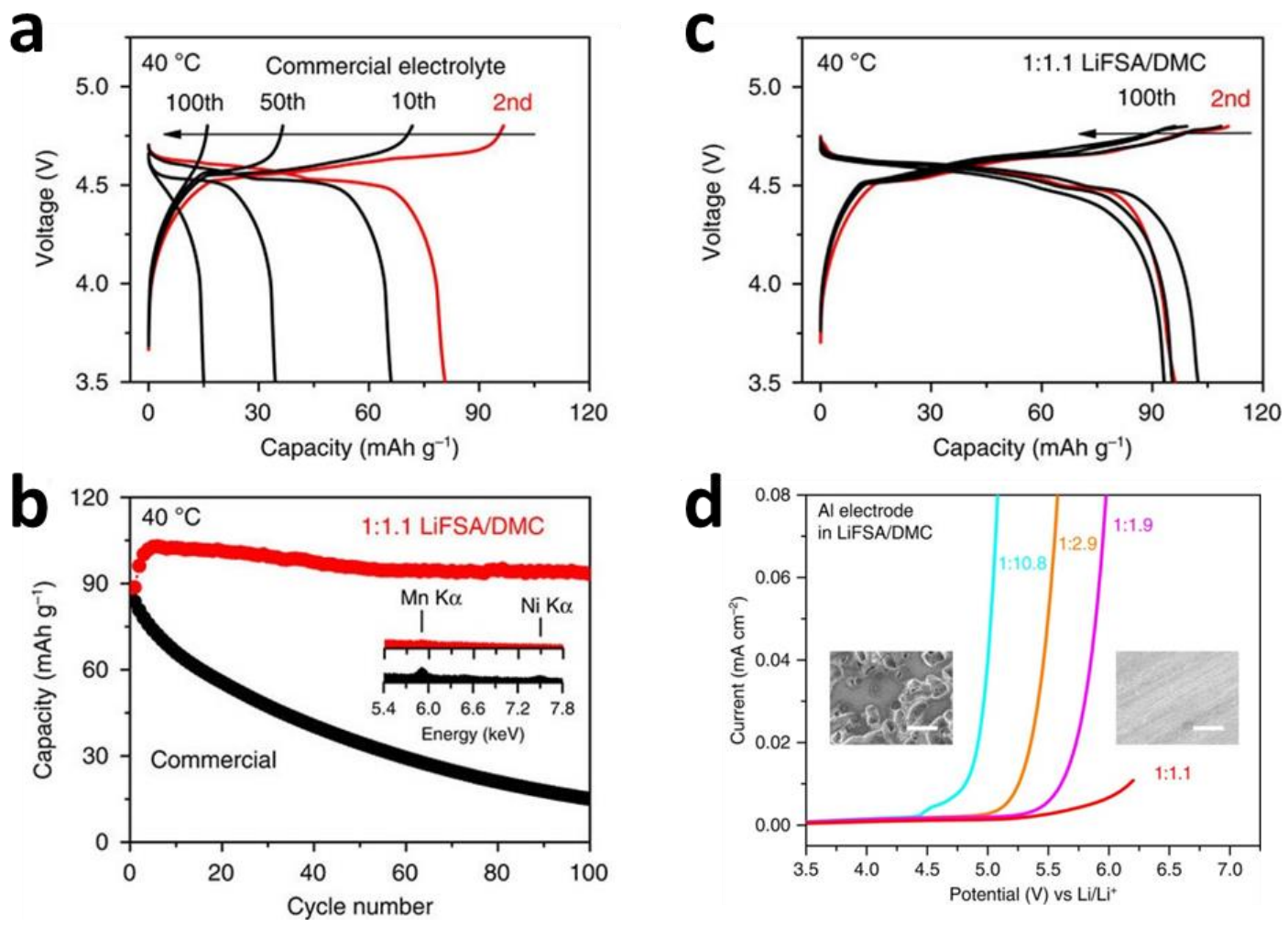

Figure 9. a,b,c) Performance of a high-voltage $\mathrm{LiNi}_{0.5} \mathrm{Mn}_{1.5} \mathrm{O}_{4} /$ natural graphite battery; d) The profiles of LSV of an aluminium electrode in various concentrations of LiFSA/DMC electrolytes. Reproduced with permission. ${ }^{[147]}$ Copyright 2016, Nature Publishing Group.

\subsubsection{Fast electrode reactions}

As ethers can easily dissolve lithium salts through strong coordination to $\mathrm{Li}^{+}$by the lone pair of oxygen atoms. Because of their high chemical stability, they are deemed as attractive electrolyte solvents. Yamada and co-workers used 3.6 M LiFSI in 1,2-dimethoxyethane (DME) (which has low viscosity as electrolyte) in natural graphite/Li half cells and found that this superconcentrated ether electrolyte not only can achieve reversible $\mathrm{Li}$ intercalation/de-intercalation in graphite-based anode, but also can realize a faster $\mathrm{Li}^{+}$ intercalation into graphite compared with traditional electrolyte (Figures 10a and 10c). ${ }^{[151]}$ This successful application on the anode has shown that the superconcentrated electrolyte is compatible with the anode side. The reason of this phenomenon is explained by the Raman 
spectra, i.e. all FSA anions and DME solvents interact with $\mathrm{Li}^{+}$to develop a polymeric fluid network of $\mathrm{Li}^{+}$and FSA (Figure 10b). This unique structure amplifies the $\mathrm{Li}^{+}$ intercalation/de-intercalation in graphite anode for a large variety of organic solvents other than EC. The ultrafast $\mathrm{Li}^{+}$intercalation reaction, namely, small polarization, is contributed by $\mathrm{Li}^{+}$de-solvation kinetics, a remarkable surface film and a high $\mathrm{Li}^{+}$transference number. ${ }^{[151]}$
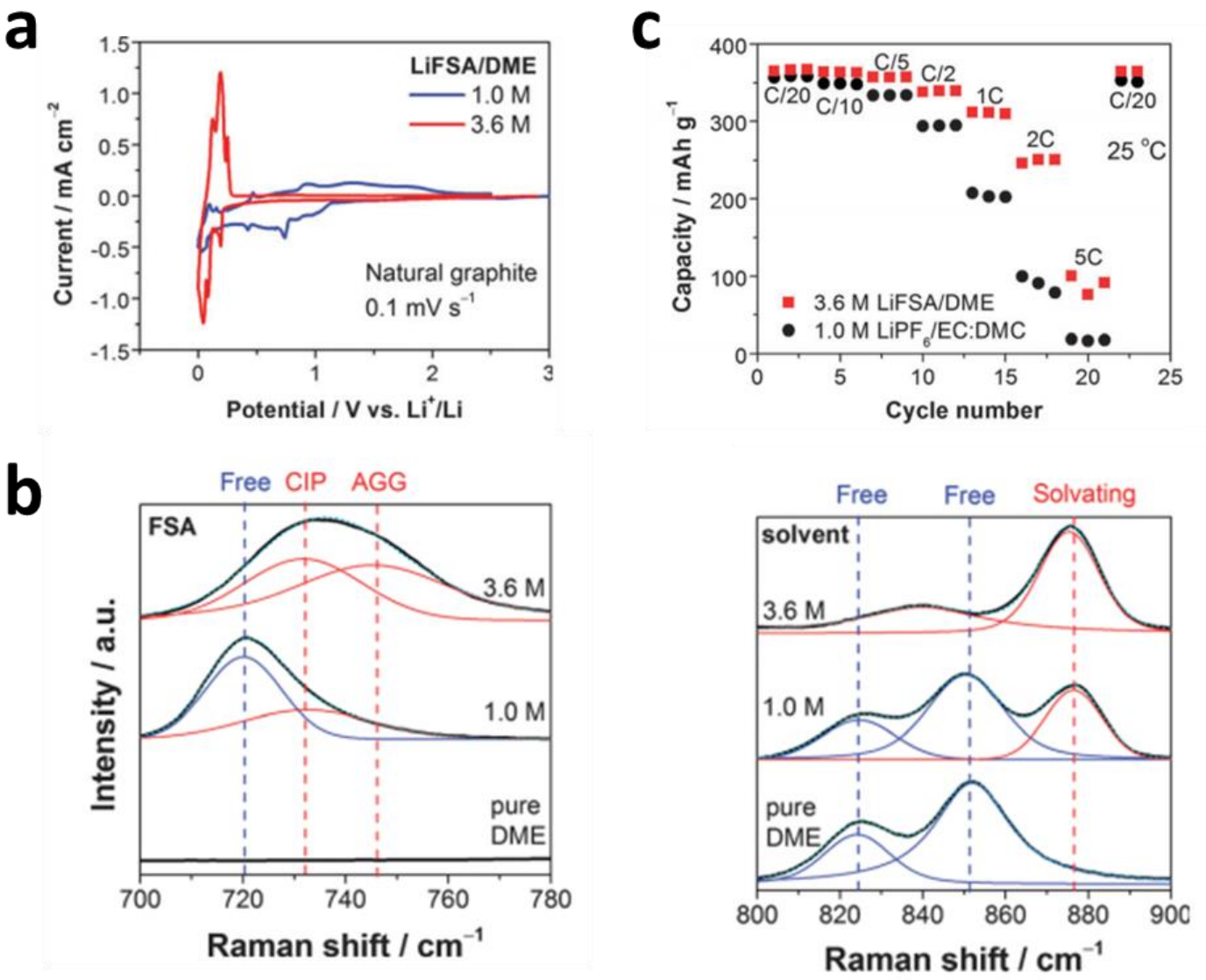

Figure 10. a) Cyclic voltammograms of a natural graphite electrode in LiFSA-DME electrolytes; b) Raman spectra of LiFSA-DME solutions at various concentrations; c) Reversible capacity of a natural graphite/Li based on the two electrolytes at different C-rates. Reproduced with permission. ${ }^{[151]}$ Copyright 2013, the Royal Society of Chemistry.

\section{Solid-state electrolytes for lithium battery}

The most widely used organic liquid electrolytes are low cost and easy to prepare but volatile and flammable. The leakage of the liquid electrolytes, as well as the internal short circuit 
caused by dendrites on lithium anode, increase the safety risks of a Li battery, which are the main concerns in regard of applications.

Solid-state electrolytes are solid materials transforming currents by ions, which are different from metals, graphite and conducting polymers which use electrons. The technology of solid-state electrolytes is currently one of the foremost methods to prevent the growth of $\mathrm{Li}$ dendrites. Solid-state electrolytes can be divided into two main groups: solid inorganic electrolytes and solid polymer electrolytes.

To develop a useful solid electrolyte, several requirements should be fulfilled: (1) high mechanical strength to prevent the dendrite deposition on Li metal; (2) considerable Li ionic conductivity; (3) a wide electrochemical window to match more types of cathodes, especially high voltage cathodes $\left(\mathrm{LiNi}_{0.5} \mathrm{Mn}_{1.5} \mathrm{O}_{4}, \mathrm{LiNi}_{x} \mathrm{Mn}_{y} \mathrm{Co}_{z} \mathrm{O}_{2}\right)$; (4) low interfacial resistance and good stickiness between two electrodes and electrolyte, etc.

In this review section, we focus on the functions of solid-state electrolytes to construct safe and high performance batteries.

\subsection{Solid inorganic electrolytes}

Lithium solid inorganic electrolytes, also called lithium fast ion conductors, can be divided into two streams, i.e. crystalline electrolytes (or ceramic electrolytes) and amorphous electrolytes (or glassy electrolytes). They show extremely high ionic conductivities $\left(>10^{-3} \mathrm{~S}\right.$ $\mathrm{cm}^{-1}$ at room temperature), high lithium ion transference number $(\approx 1)$, and low conductive activation energy $\left(E_{a}<0.5 \mathrm{eV}\right)$. Though somewhat poor mechanical properties, big interfacial resistance when contact with electrodes and narrow electrochemical windows, suppress their wide use.

\subsubsection{Crystalline electrolytes}

Crystalline electrolytes with the structures of perovskite-type, NASICON-type, garnet-type and LISICON-type have mainly been explored. 
Preparation methods for these ceramic electrolyte include high temperature solid-state synthesis process, sol-gel method, sol precipitation method, spray drying method, pulsed laser deposition, microwave induction method, hydro-thermal synthesis, etc.

Sodium super-ionic conductors (NASICON) exhibit good structural stability and fast ionic conductivity. They have a general formula, $\mathrm{MA}_{2}\left(\mathrm{BO}_{4}\right)_{3}$, where $\mathrm{M}, \mathrm{A}, \mathrm{B}$ stand for metal cations with different valence states. The $\mathrm{M}$ position is occupied by $\mathrm{Li}, \mathrm{Na}, \mathrm{K}$ or Ag. Atoms on the position of A are usually occupied by $\mathrm{Ti}, \mathrm{Zr}, \mathrm{Ge}$ or $\mathrm{V}$. The $\mathrm{B}$ site is usually taken by $\mathrm{P}$, $\mathrm{Si}$ or Mo. Elements on $\mathrm{A}$ and $\mathrm{B}$ sites can be replaced by other metal cations to form multitudinous NASICONs. In the structure of NASICON, $\mathrm{AO}_{6}$ octahedra and $\mathrm{BO}_{4}$ tetrahedra use the same corner angles to form a 3D interconnected structure and two kinds of clearance positions (M I and M II ). NASICONs with Ti, $\mathrm{LiTi}_{2}\left(\mathrm{PO}_{4}\right)_{3}$, exhibit high ionic conductivity, compared with other tetravalent metal ions. To further increase the ionic conductivity of $\mathrm{LiTi}_{2}\left(\mathrm{PO}_{4}\right)_{3}$, Ti is partly replaced by cations with a larger ionic radius to form $\mathrm{Li}_{1+x} \mathrm{Ti}_{2-x} \mathrm{M}_{x}\left(\mathrm{PO}_{4}\right)_{3}(\mathrm{M}=\mathrm{Al}, \mathrm{Sc}, \mathrm{La}, \mathrm{Cr}, \mathrm{In}, \mathrm{Ga}$, etc. $)$ and $\mathrm{Li}_{1.3} \mathrm{Ti}_{1.7} \mathrm{Al}_{0.3}\left(\mathrm{PO}_{4}\right)_{3}$. These demonstrated the highest ionic conductivity of $7 \times 10^{-4} \mathrm{~S} \mathrm{~cm}^{-1}$ at room temperature. ${ }^{[155]}$ Besides, NASICON-type electrolytes have a relatively wide electrochemical stability window. The $\mathrm{LiGe}_{2}\left(\mathrm{PO}_{4}\right)_{3}$-based electrolytes can reach nearly $6 \mathrm{~V}$ (vs. $\left.\mathrm{Li} / \mathrm{Li}^{+}\right){ }^{[156]} \mathrm{Li}_{1+x} \mathrm{Al}_{x} \mathrm{Ti}_{2-x}\left(\mathrm{PO}_{4}\right)_{3}$ dispalys a higher ionic conductivity than $\mathrm{Li}_{1+x} \mathrm{Al}_{x} \mathrm{Ge}_{2-x}\left(\mathrm{PO}_{4}\right)_{3}$, when $\mathrm{x}=0.2$ or 0.4 at room temperature. ${ }^{[157]}$ However, $\mathrm{Ti}^{4+}$ is not stable enough against $\mathrm{Li}$ metal. Zhou et al. ${ }^{[158]}$ developed a polymer/ceramic membrane/polymer sandwich electrolyte. In their structure, a polymer layer (PCPSE) wets the Li metal surface and makes the $\mathrm{Li}^{+}$flux more homogeneous. Li/LiFePO4 cells showed a high Coulombic efficiency of $99.8-100 \%$ over 640 cycles (Figure 11). Similarly, Chinnam et al. ${ }^{[159]}$ prepared a hybrid ceramic-polymer electrolyte via interface engineering to get an enhanced performance. 

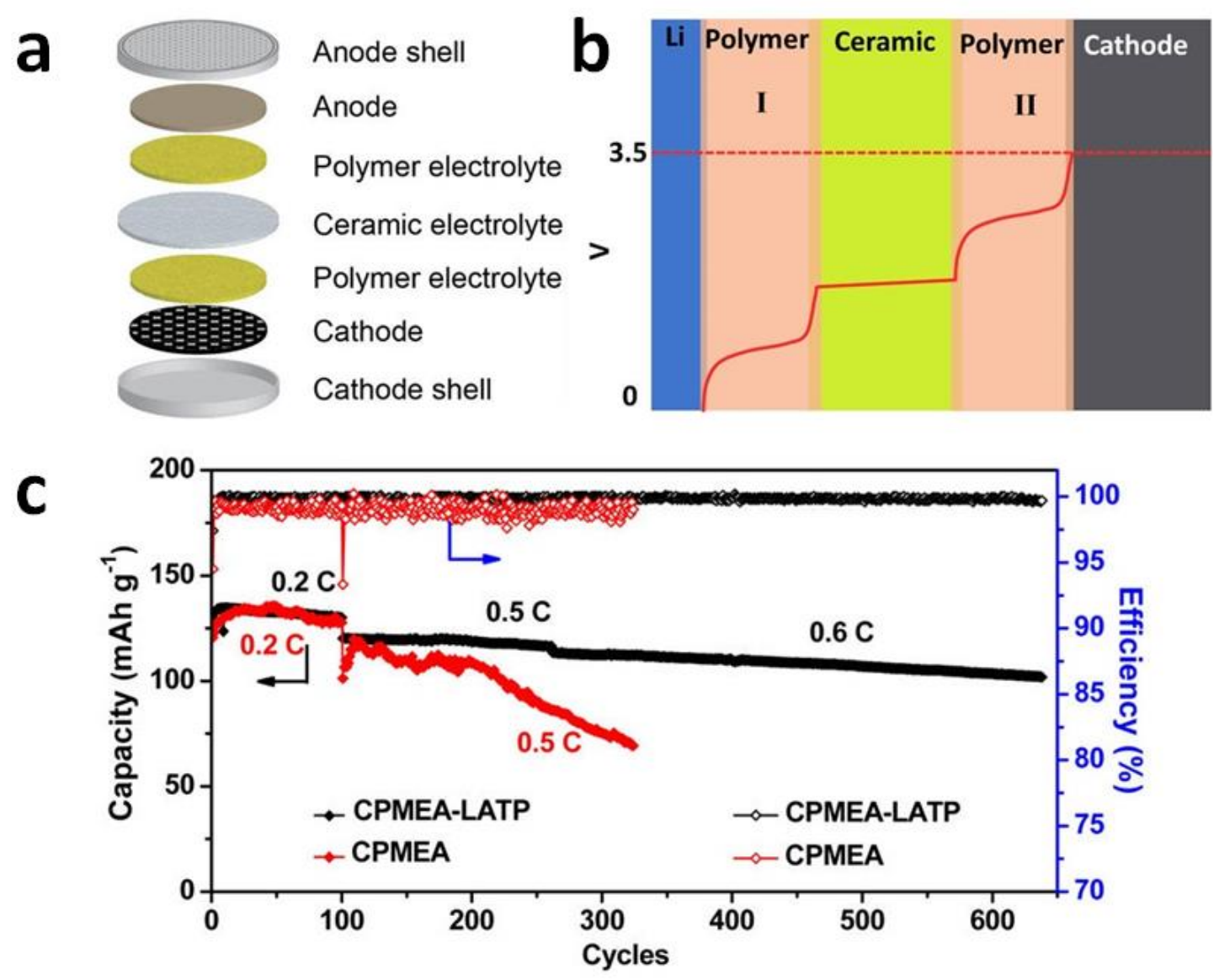

Figure 11. a) Sketch map of an all-solid-state battery design with the PCPSE/LATP/PCPSE sandwich electrolyte. b) Illustration of the potential profile across the sandwich electrolyte in a $\mathrm{Li} / \mathrm{LiFePO}_{4}$ battery during the charge process. c) Cycling and $\mathrm{C}$ rate performance of the $\mathrm{Li} / \mathrm{LiFePO}_{4}$ cells with sandwich electrolyte. Reproduced with permission. ${ }^{[158]}$ Copyright 2016, American Chemical Society.

Perovskite-type electrolytes with a structure $\mathrm{ABO}_{3}$ show high bulk conductivity, about $10^{-3} \mathrm{~S} \mathrm{~cm}^{-1}$ at room temperature. $\mathrm{Li}_{3 x} \mathrm{La}_{2 / 3-x} \mathrm{TiO}_{3}$ (LLTO) $(0.04<x<0.17)$ (LLTO) consists of a mixture of phases, which depends on the product composition and synthesis conditions. $\mathrm{Li}^{+}$ and $\mathrm{La}^{3+}$ on A site were randomly distributed in the cubic phase and orderly arranged in a doubled perovskite structure. LLTO exhibits many advantages, such as high electrochemical stability up to $8 \mathrm{~V}$, lithium single ion conduction, and stability in atmosphere. ${ }^{[160]}$ Low grain-boundary conductivity and instability against Li metal anode are the two disadvantages 
of LLTO electrolytes. Kwon et al. ${ }^{[161]}$ synthesized LLTOs with reduced boundary resistance via microstructure engineering. A total ionic conductivity as high as $4.8 \times 10^{-4} \mathrm{~S} \mathrm{~cm}^{-1}$ was achieved at room temperature by controlling the sintering temperature and Li content (Figure 12). Recently, anti-perovskite electrolytes have been explored for their increased Li ion conductivity and high decomposition voltages. Hood et al. ${ }^{[162]}$ found that a cold-pressed $\mathrm{Li}_{2} \mathrm{OHCl}$ after fast cooling exhibited the highest ionic conductivity. Li et al. ${ }^{[163]}$ reported that $\mathrm{Li}_{2}(\mathrm{OH})_{0.9} \mathrm{~F}_{0.1} \mathrm{Cl}$ showed high stability on contact with lithium metal anode and had an electrochemical stability window extending to $9 \mathrm{~V} v s$. $\mathrm{Li} / \mathrm{Li}^{+}$.


Figure 12. a) Crystal structures of LLTOs; a tetragonal structure (left) and an orthorhombic structure (right). FESEM micrographs of LLTOs sintered at b) $1200{ }^{\circ} \mathrm{C}$ and c) $1400{ }^{\circ} \mathrm{C}$, respectively. d) Arrhenius plots of the boundary conductivities for low-T LLTO, high-T LLTO and Li-excess LLTO measured between 20 and $70{ }^{\circ} \mathrm{C}$. Reproduced with permission. ${ }^{[161]}$ Copyright 2017, The Royal Society of Chemistry.

The typical representative of LISICON-type electrolytes, $\mathrm{Li}_{14} \mathrm{ZnGe}_{4} \mathrm{O}_{16}$, possesses the highest ionic conductivity, $1.25 \times 10^{-1} \mathrm{~S} \mathrm{~cm}^{-1}$ at $300{ }^{\circ} \mathrm{C}$, but only $10^{-7} \mathrm{~S} \mathrm{~cm}^{-1}$ at room temperature. $\left[\mathrm{Li}_{11} \mathrm{ZnGe}_{4} \mathrm{O}_{16}\right]^{3-}$ is a strong $3 \mathrm{D}$ anionic framework and the three remaining $\mathrm{Li}$ ions are located in clearance positions for conduction. Liquid sublattice model can be used to clarify the mechanism of $\mathrm{Li}^{+}$movement through the frameworks. The average size of 
channels in $\mathrm{Li}_{14} \mathrm{ZnGe}_{4} \mathrm{O}_{16}(4.38 \AA)$ is big enough for $\mathrm{Li}^{+}$transport. The minimum size of 4.0 $\AA$ is required. $\mathrm{Li}_{14} \mathrm{ZnGe}_{4} \mathrm{O}_{16}$ is unstable at high temperature and highly reactive to atmospheric $\mathrm{CO}_{2}$ and Li metal. To improve the ionic conductivity of LISICON-type electrolytes, Kanno et al. ${ }^{[164,165]}$ replaced oxide by sulfur within the framework. Sulfur-based inorganic electrolytes show the best conductivity among inorganic electrolytes till now, and we will emphasize this series in section 3.1.3.

Garnet-type lithium solid electrolytes have a general formula $\mathrm{Li}_{5} \mathrm{La}_{3} \mathrm{M}_{2} \mathrm{O}_{12}(\mathrm{M}=\mathrm{Nb}$ or Ta). They have recently been used as electrolytes for all solid state Li batteries. ${ }^{[166]}$ $\mathrm{Li}_{6} \mathrm{BaLa}_{2} \mathrm{Ta}_{2} \mathrm{O}_{12}$ exhibited a high ionic conductivity of $1.69 \times 10^{-5} \mathrm{~S} \mathrm{~cm}^{-1}$ at $25{ }^{\circ} \mathrm{C}$ with an activation energy of $0.40 \mathrm{eV} .{ }^{[167]} \mathrm{Li}_{6.4} \mathrm{La}_{3} \mathrm{Zr}_{1.6} \mathrm{Ta}_{0.6} \mathrm{O}_{12}$ prepared at $1140{ }^{\circ} \mathrm{C}$ revealed the highest bulk conductivity $\left(10^{-3} \mathrm{~S} \mathrm{~cm}^{-1}\right.$ at room temperature $) .{ }^{[168]}$ Garnet-type $\mathrm{Li}_{7} \mathrm{La}_{3} \mathrm{Zr}_{2} \mathrm{O}_{12}$ (LLZO) attracted much attention since it had firstly been reported by Murugan et al. ${ }^{[169]}$ In the phase of LLZO, the change occurs from a tetragonal structure to the cubic structure under increase in sintering temperature, these belong to the space groups Iad and $\mathrm{I} 4{ }_{1} \mathrm{~A} / \mathrm{cd}$, respectively. ${ }^{[170]}$ Cubic phase possesses a higher ionic conductivity, $1 \times 10^{-4} \mathrm{~S} \mathrm{~cm}^{-1}$ at room temperature, which is about two orders of magnitude higher than that of the tetragonal phase. So, garnet electrolytes are attractive for their wide electrochemical windows and the most stable interfaces against $\mathrm{Li}$ metal. However, large interfacial impendence between garnet electrolyte and electrode becomes one of the major problems. Li et al. ${ }^{[171]}$ introduced $2 \mathrm{wt} \%$ $\mathrm{LiF}$ to garnet $\mathrm{Li}_{6.5} \mathrm{La}_{3} \mathrm{Zr}_{1.5} \mathrm{Ta}_{0.5} \mathrm{O}_{12}$ (LLZT) to reduce the interfacial resistance against $\mathrm{Li}$ metal. Han et al. ${ }^{[172]}$ efficiently reduced the interfacial impedance, from $1710 \Omega \mathrm{cm}^{-2}$ to $1 \Omega \mathrm{cm}^{-2}$, between a lithium metal anode and a $\mathrm{Li}_{7} \mathrm{La}_{2.75} \mathrm{Ca}_{0.25} \mathrm{Zr}_{1.75} \mathrm{Nb}_{0.25} \mathrm{O}_{17}$ electrolyte with an ultrathin $\mathrm{Al}_{2} \mathrm{O}_{3}$ film by atomic layer deposition. Li/ALD-garnet $\mathrm{SSE} / \mathrm{Li}_{2} \mathrm{FeMn}_{3} \mathrm{O}_{8}$ full cell showed a stable cycling performance, around $110 \mathrm{mAh} \mathrm{g}^{-1}$ over 50 cycles (Figure 13). 

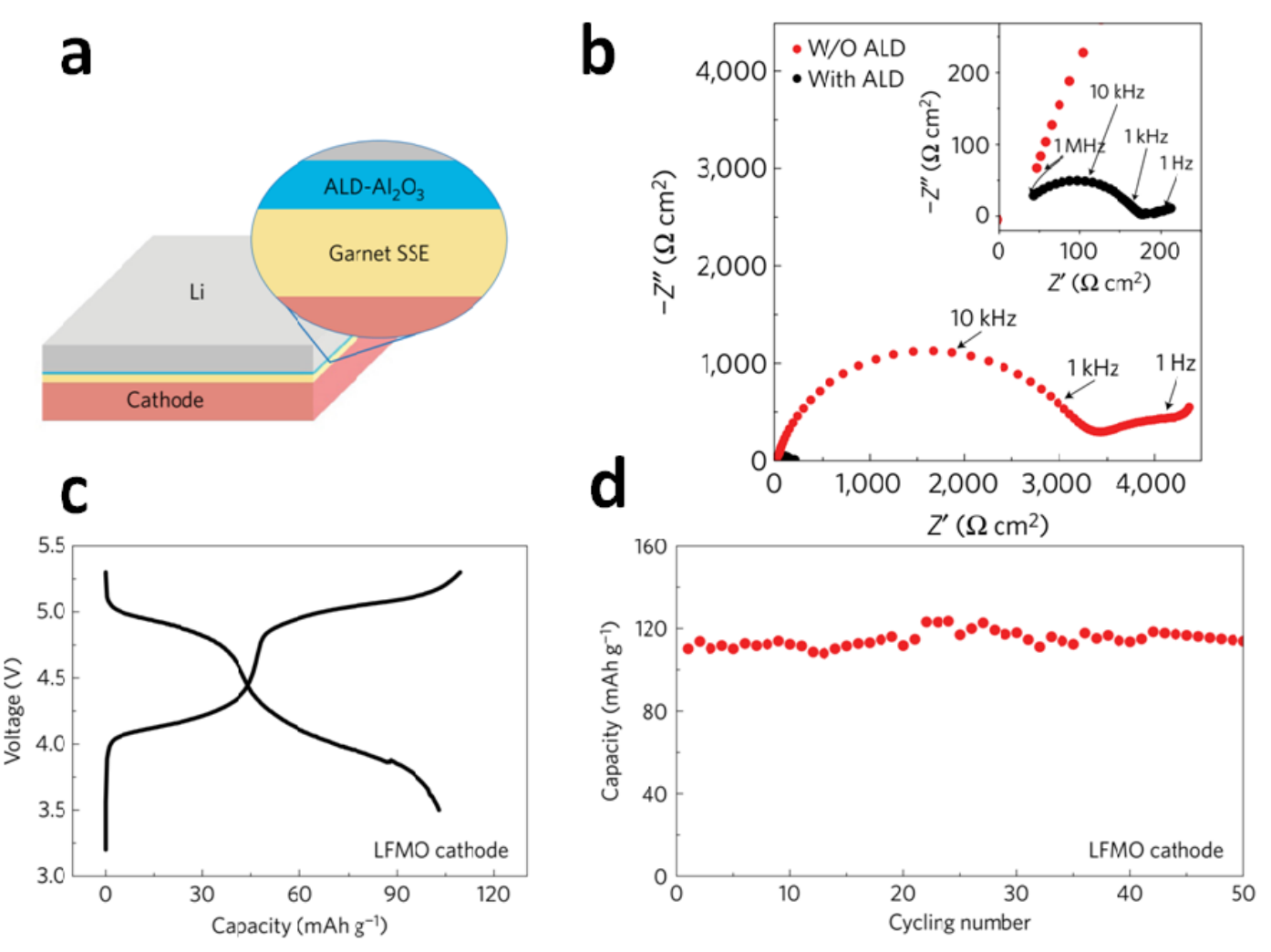

Figure 13. a) Schematic of a full cell using ALD-coated LLCZN as electrolyte, Li metal anode and LFMO cathode. b) Interfacial resistance of the symmetric Li non-blocking cells with/without ALD layer. c) Charge and discharge profile of the LFMO/ALD-garnet SSE/Li full cell. d) Cycling performance of the cell at 0.1 C. Reproduced with permission. ${ }^{[172]}$ Copyright 2017, Macmillan Publishers Limited, part of Springer Nature.

\subsubsection{Amorphous electrolytes}

Amorphous electrolytes have attracted much attention due to the isotropic ionic conduction, zero grain-boundary resistance, easy fabrication into films and low cost. ${ }^{[166]}$ Amorphous electrolytes can be divided into two categories: oxide and sulfide types. The former exhibit electrochemical and thermal stability, but low conductivity $\left(10^{-8} \sim 10^{-6}\right.$ at room temperature), ${ }^{[173]}$ whereas the latter glassy electrolytes show higher conductivity $\left(10^{-4} \sim 10^{-3}\right.$ at room temperature), though they are unstable to moisture and $\mathrm{O}_{2}$, and difficult to prepare. ${ }^{[174]}$ 
The lithium glassy electrolytes can be prepared using a melt quenching technique, ${ }^{[175]}$ high-energy ball-milling, ${ }^{[176,177]}$ and radio frequency magnetron sputtering. ${ }^{[178]}$

Oxide glassy electrolytes consist of network forming oxides $\left(\mathrm{SiO}_{2}, \mathrm{~B}_{2} \mathrm{O}_{3}\right.$ or $\left.\mathrm{P}_{2} \mathrm{O}_{5}\right)$ and network modifying oxides $\left(\mathrm{Li}_{2} \mathrm{O}\right)$. The structure is a stable system at low temperature. The network forming oxides make strongly interconnected giant molecular chains. Chemical reactions between the network modifying and forming oxides can break the oxygen bridge in macro-molecular chains and reduce the average length of the macro-molecular chains. The above process produces an open structure in which only Li ions are allowed to travel within the material. So, the ionic conductivity of amorphous electrolytes is universally higher than crystalline electrolytes made of the same elements.

Binary $\mathrm{Li}_{2} \mathrm{O}-\mathrm{B}_{2} \mathrm{O}_{3}$ glassy electrolyte has a relatively low ionic conductivity, about $1.2 \times 10^{-8} \mathrm{~S} \mathrm{~cm}^{-1}$ at room temperature. Lee et al. ${ }^{[173]}$ increased the ionic conductivity of a $\mathrm{Li}_{2} \mathrm{O}-\mathrm{B}_{2} \mathrm{O}_{3}$ glassy electrolyte by additions of $\mathrm{SeO}_{2}$ with different ratios to form a new electrolyte, $0.5 \mathrm{Li}_{2} \mathrm{O}-0.5\left(y \mathrm{SeO}_{2}-(1-y) \quad \mathrm{B}_{2} \mathrm{O}_{3}\right) \quad(y=0.2 \sim 0.7)$. When $y=0.5$, the ionic conductivity had a maximum, $8 \times 10^{-7} \mathrm{~S} \mathrm{~cm}^{-1}$ at room temperature. In addition, increasing lithium concentration is another approach to enhance the ionic conductivity of glassy electrolytes. Saetova et al. ${ }^{[179]}$ found that the ionic conductivity of the glass, $\mathrm{Li}_{2} \mathrm{O}-\mathrm{B}_{2} \mathrm{O}_{3}-\mathrm{SiO}_{2}$, might sharply be increased above $\mathrm{Li}_{2} \mathrm{O}$ concentration of more than $62.5 \mathrm{~mol} \%$, which was a result of the glass network changes and the formation of boroxol rings and di-borate units. Deshpande et al. ${ }^{[180]}$ doped a series of $\mathrm{LiCl}$ contents into $40 \mathrm{Li}_{2} \mathrm{O}-40 \mathrm{~B}_{2} \mathrm{O}_{3}-20 \mathrm{SiO}_{2}$. The $40 \mathrm{Li}_{2} \mathrm{O}-30 \mathrm{~B}_{2} \mathrm{O}_{3}-15 \mathrm{SiO}_{2}-15 \mathrm{LiCl}$ composition showed the highest ionic conductivity and the lowest activation energy. LiPON is another kind of an oxide amorphous electrolyte fabricated via introducing nitrogen into $\mathrm{Li}_{2} \mathrm{O}-\mathrm{P}_{2} \mathrm{O}_{5}$. We will emphasize this series in section 3.1.4.

The structure of sulfide amorphous electrolytes is the same as that of oxide glass electrolytes, only the replacement of oxygen atoms by sulfur atoms is required. The lower electronegativity of $\mathrm{S}^{2-}$ than $\mathrm{O}^{2-}$ leads to lowering binding ability with $\mathrm{Li}^{+}$, whereas the larger 
radius of $\mathrm{S}^{2-}$ than $\mathrm{O}^{2-}$ can establish the larger $\mathrm{Li}^{+}$transport channels. ${ }^{[181]}$ Compared with oxide glass electrolytes, sulfide glass electrolytes can achieve a relatively higher ionic conductivity $\left(10^{-4} \sim 10^{-3} \mathrm{~S} \mathrm{~cm}^{-1}\right.$ at room temperature). Therefore, $\mathrm{Li}_{2} \mathrm{~S}-\mathrm{P}_{2} \mathrm{~S}_{5}{ }^{[182]} \mathrm{Li}_{2} \mathrm{~S}_{-} \mathrm{SiS}_{2}{ }^{[183]}$ and $\mathrm{Li}_{2} \mathrm{~S}_{-}-\mathrm{B}_{2} \mathrm{~S}_{3}{ }^{[184]}$ are assumed to be excellent electrolytes in all solid state batteries. Ohara et al. ${ }^{[185]}$ found that $\mathrm{P}_{2} \mathrm{~S}_{6}{ }^{4-}$ ions, as well as $\mathrm{PS}_{4}{ }^{3-}$ and $\mathrm{P}_{2} \mathrm{~S}_{7}{ }^{4-}$ ions, are present in $67 \mathrm{Li}_{2} \mathrm{~S}-33 \mathrm{P}_{2} \mathrm{~S}_{5}$, $70 \mathrm{Li}_{2} \mathrm{~S}-30 \mathrm{P}_{2} \mathrm{~S}_{5}$, and $75 \mathrm{Li}_{2} \mathrm{~S}-25 \mathrm{P}_{2} \mathrm{~S}_{5}$ glasses. The structure can be stabilized by P-P correlations in all three glasses. The S-Li-S bond angle distribution at the distinct peak at around $100^{\circ}$ is peculiar to a high $\mathrm{Li}_{2} \mathrm{~S}$ content, which corresponds to the enhancement in the edge sharing polyhedral connection between $\mathrm{PS}_{x}$ and $\mathrm{LiS}_{y}$. The free volume around the PS $x$ polyhedral anion allows for the even distribution of $\mathrm{Li}^{+}$ions. Glassy electrolytes with $\mathrm{P}_{2} \mathrm{~S}_{5}$ show decent electrochemical stability against Li metal anode. Similarly to oxide glassy electrolytes, a mixed network structure can effectively increase the ionic conductivity of sulfide glassy electrolytes. $95 \mathrm{Li}_{3} \mathrm{PS}_{4}-5 \mathrm{Li}_{4} \mathrm{GeS}_{4}$ can reach a high ionic conductivity of $4 \times 10^{-4} \mathrm{~S} \mathrm{~cm}^{-1}$ at room temperature and good $\mathrm{Li}$ ion transference number close to 1 . Takada et al. ${ }^{[186]}$ improved the $\mathrm{Li}$ ionic conductivity of $67 \mathrm{Li}_{2} \mathrm{~S}_{-} 33 \mathrm{P}_{2} \mathrm{~S}_{5}$ from $10^{-4} \mathrm{~S} \mathrm{~cm}^{-1}$ to $10^{-3} \mathrm{~S} \mathrm{~cm}^{-1}$ at room temperature by adding $45 \mathrm{wt} \%$ of LiI. Rangasamy et al. ${ }^{[187]}$ synthesized a fast $\mathrm{Li}$ ion conductor, $\mathrm{Li}_{7} \mathrm{P}_{2} \mathrm{~S}_{8} \mathrm{I}$, which exhibited high ion conductivity and good electrochemical stability $\left(10 \mathrm{~V} v s . \mathrm{Li} / \mathrm{Li}^{+}\right)$, and revealed the characteristics of a solid solution between $\mathrm{LiI}$ and $\mathrm{Li}_{3} \mathrm{PS}_{4}$. Wei et al. ${ }^{[188]}$ investigated the impact of annealing treatment on the ionic transference and storage stability of $70 \mathrm{Li}_{2} \mathrm{~S}-30 \mathrm{P}_{2} \mathrm{~S}_{5}$. The ionic conductivity was enhanced from 1 to $1.5 \times 10^{-3} \mathrm{~cm}^{-1}$, while the interfacial resistance of $\mathrm{Li} / 70 \mathrm{Li} 2 \mathrm{~S}-30 \mathrm{P}_{2} \mathrm{~S}_{5} / \mathrm{Li}$ cell was reduced by an order of magnitude with increasing annealing temperature up to $250{ }^{\circ} \mathrm{C}$. The higher annealing temperature induced formation of a low conductivity $\mathrm{Li}_{4} \mathrm{P}_{2} \mathrm{~S}_{6}$ phase, which increased both the ionic and interfacial resistances. And the storage stability was also improved after annealing treatments. Glassy electrolytes with $\mathrm{SiS}_{2}$ show high ionic conductivity and ease in fabrication under atmospheric pressure. The addition of LiI can enhance ion conductivity to $1.32 \times 10^{-3} \mathrm{~S} \mathrm{~cm}^{-1}$, but reduce its 
decomposition voltage. By contrast, $\mathrm{Li}_{x} \mathrm{MO}_{y}(\mathrm{M}=\mathrm{B}, \mathrm{Al}, \mathrm{Ga}, \mathrm{In})$ in $\mathrm{Li}_{2} \mathrm{~S}-\mathrm{SiS}_{2}$ can increase the conductivity without decreasing the decomposition voltage. ${ }^{[189]} 95\left(0.6 \mathrm{Li}_{2} \mathrm{~S}-0.4 \mathrm{SiS}_{2}\right)-5 \mathrm{Li}_{3} \mathrm{BO}_{3}$ shows high ion conductivity $\left(2.5 \times 10^{-3} \mathrm{~S} \mathrm{~cm}^{-1}\right)$ and particularly high decomposition voltage $(10 \mathrm{~V}) \cdot{ }^{[181]}$

\subsubsection{Thio-LISICON-type electrolytes}

Kanno et al. ${ }^{[165]}$ were first to synthesize a kind of new LISICON, $\mathrm{Li}_{4-x} \mathrm{Ge}_{1-x} \mathrm{P}_{x} \mathrm{~S}_{4}$, when $x=$ 0.75 , the ionic conductivity could reach up to $2.2 \times 10^{-3} \mathrm{~S} \mathrm{~cm}^{-1}$. $\mathrm{Li}_{3.25} \mathrm{Ge}_{0.25} \mathrm{P}_{0.75} \mathrm{~S}_{4}$ showed good electrochemical and thermal stability against lithium metal anode without phase transition even at $500{ }^{\circ} \mathrm{C}$. Recently, Kamaya et al. ${ }^{[190]}$ developed a typical thio-LISICON structure, $\mathrm{Li}_{10} \mathrm{GeP}_{2} \mathrm{~S}_{12}$, with a very high conductivity of $1.2 \times 10^{-2} \mathrm{~S} \mathrm{~cm}^{-1}$ at $27{ }^{\circ} \mathrm{C}$ (Figure 14). $\mathrm{Li}_{10} \mathrm{GeP}_{2} \mathrm{~S}_{12}$ was tested in a practical battery which had exhibited a relatively high discharge specific capacity (over $120 \mathrm{mAh} \mathrm{g}^{-1}$ ) and an excellent discharge efficiency (about 100\% after the 2 nd cycle). $\mathrm{Li}_{10} \mathrm{SnP}_{2} \mathrm{~S}_{12}$ is another kind of thio-LISICON structure where Ge is replaced with $\mathrm{tSn}$; the conductivity reaches $4 \times 10^{-3} \mathrm{~S} \mathrm{~cm}^{-1}$ at room temperature for this case. ${ }^{[191]}$ 

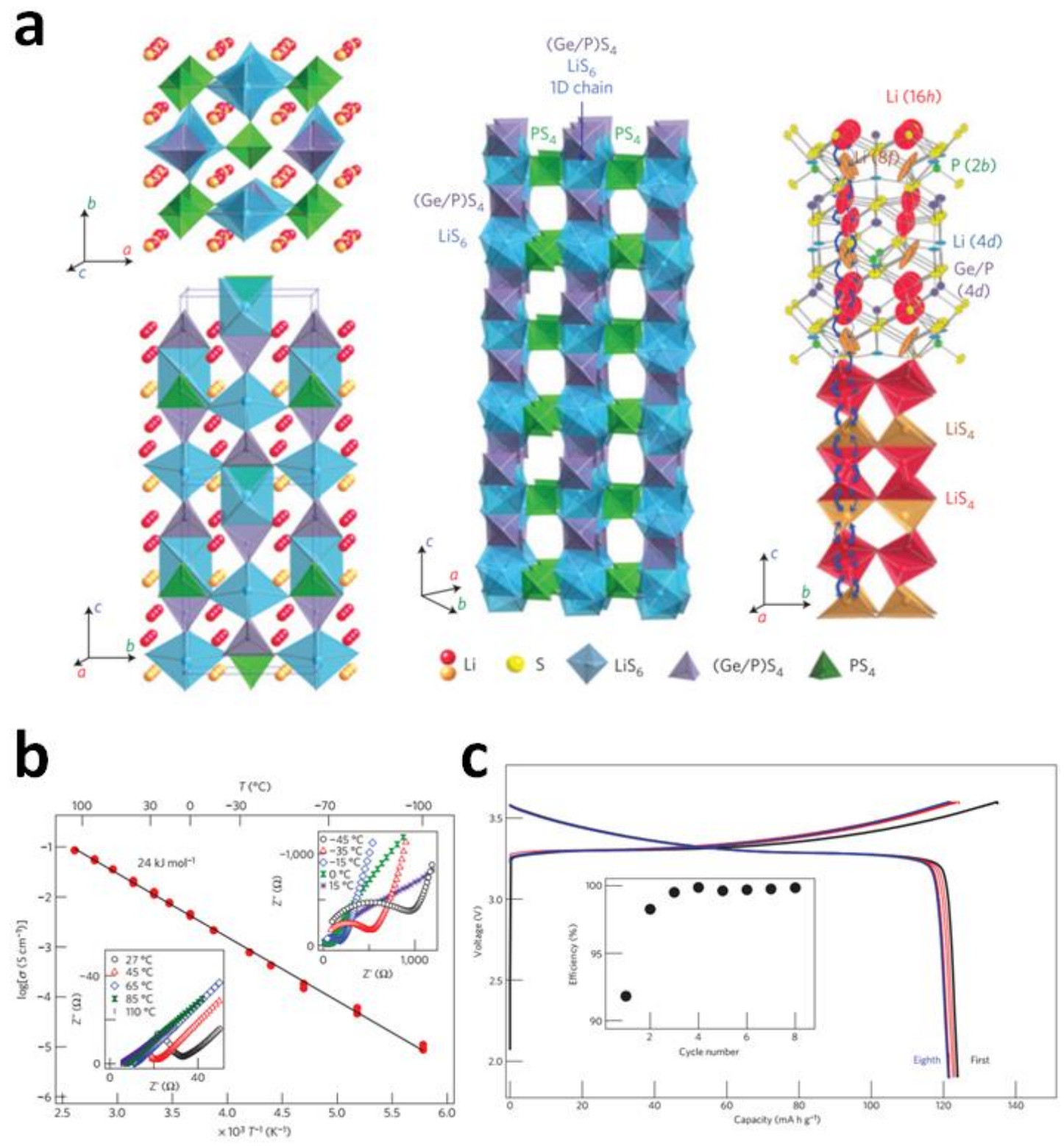

Figure 14. a) Crystal structure of $\mathrm{Li}_{10} \mathrm{GeP}_{2} \mathrm{~S}_{12}$. (Left) The framework structure and Li ions that participate in ionic conduction. (Middle) Framework structure of this electrolyte. (Right) Conduction pathways of $\mathrm{Li}$ ions. b) Li-ion conductivity of $\mathrm{Li}_{10} \mathrm{GeP}_{2} \mathrm{~S}_{12}$. c) Charge-discharge curves of an all-solid-state battery with $\mathrm{Li}_{10} \mathrm{GeP}_{2} \mathrm{~S}_{12}$ electrolyte. Reproduced with permission. ${ }^{[190]}$ Copyright 2011, Nature Publishing Group.

\subsubsection{LiPON-type electrolytes}


Adding $\mathrm{N}$ in an oxide glassy electrolyte, $\mathrm{Li}_{2} \mathrm{O}-\mathrm{P}_{2} \mathrm{O}_{5}$, can form the new glassy electrolyte (LiPON). $\mathrm{Li}_{0.99} \mathrm{PO}_{2.55} \mathrm{~N}_{0.30}$ exhibited the highest ionic conductivity, $3.0 \times 10^{-7} \mathrm{~S} \mathrm{~cm}^{-1}$ at room temperature. LiPONs are stable to lithium metal and cathode materials, but expensive for the large-scale production. LiPONs can be easily fabricated into films using thermal atomic layer deposition (ALD). ${ }^{[192]}$ Flexible thin film batteries can be developed through layer by layer deposition of LiPONs electrolytes and cathodes onto Li metals. ${ }^{[193,194]} \mathrm{Li}$ et al. ${ }^{[195]}$ assembled a high-voltage solid state $\mathrm{Li}$ battery using $\mathrm{LiNi}_{0.5} \mathrm{Mn}_{1.5} \mathrm{O}_{4}$ cathode, $\mathrm{LiPON}$, and $\mathrm{Li}$ metal anode (Figure 15). The batteries showed an outstanding cycling performance with $90 \%$ capacity retention after 10000 cycles. The requirement of electrolyte amount was thousands of times less than that of liquid electrolyte. Such battery demonstrated the lowest electrolyte decomposition, which contributed to high Coulombic efficiency of $99.98+\%$.
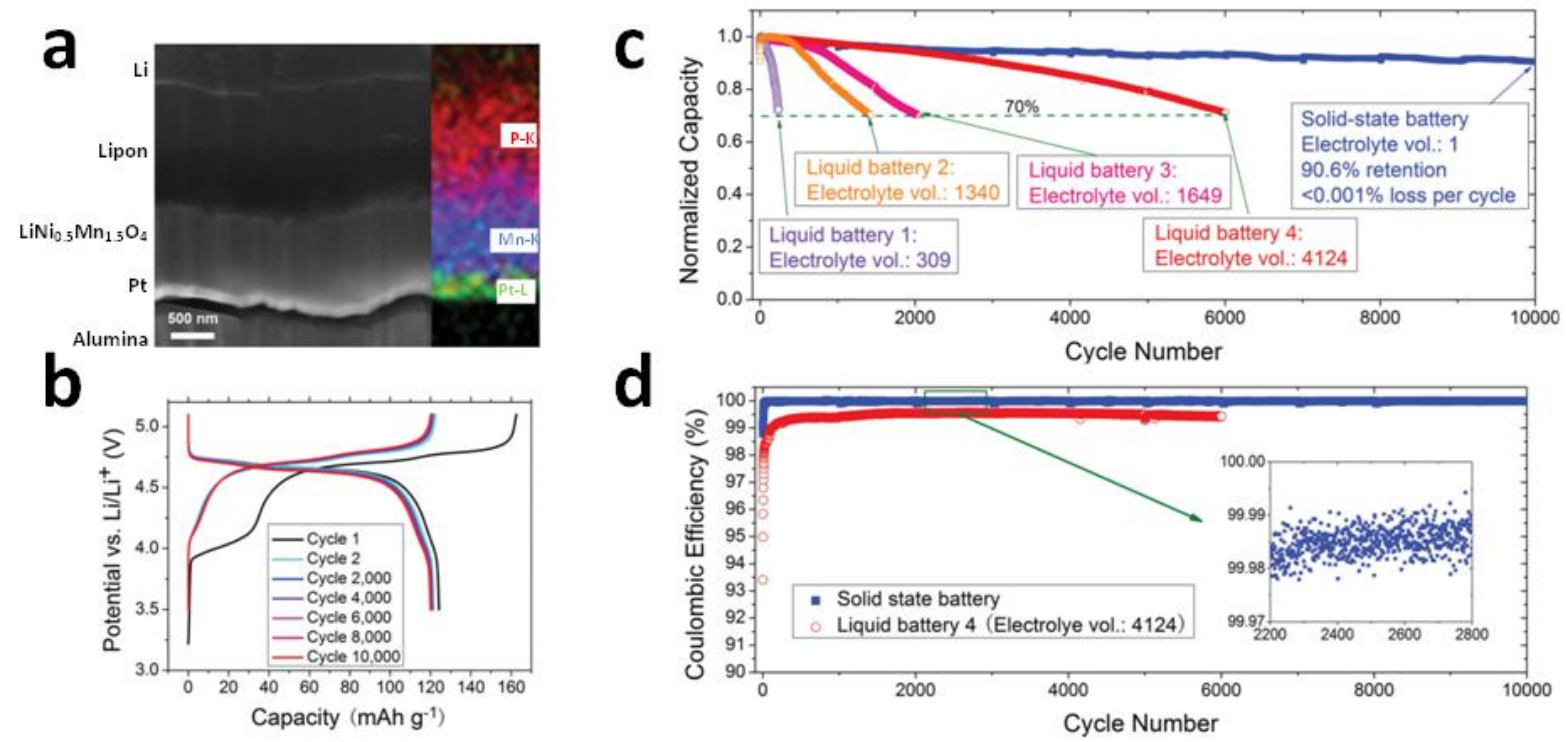

Figure 15. a) SEM image and EDX elemental mapping of the cross-section of a solid-state lithium battery after 1000 cycles. b) Voltage profile of the solid-state battery under $\mathrm{C} / 10$ at different cycles. c) Comparison of capacity retention and d) Coulombic efficiency of high-voltage solid-state and liquid-electrolyte Li batteries. All cells were cycled at a rate of 5 C. Reproduced with permission. ${ }^{[195]}$ Copyright 2014, WILEY-VCH Verlag GmbH \& Co. KGaA, Weinheim. 


\subsubsection{Glass-ceramic electrolytes}

Crystallization is a useful way to enhance the ionic conductivity of glassy electrolytes. Thus produced electrolytes are called glass-ceramic electrolytes. The glass-ceramic electrolytes usually have lower grain-boundary resistance than their crystalline counterparts. ${ }^{[196]}$ Glass-ceramics, like LATP ${ }^{[197,198]}$ and LAGP, ${ }^{[199,200]}$ have been most studied and their ionic conductivities could reach up to $10^{-4} \sim 10^{-3} \mathrm{~S} \mathrm{~cm}^{-1}$ at room temperature. $\mathrm{Xu}$ et al. ${ }^{[201]}$ reported a $\mathrm{MoS}_{2}$-doped $\mathrm{Li}_{2} \mathrm{~S}-\mathrm{P}_{2} \mathrm{~S}_{5}$ glass-ceramic electrolyte $\left(\mathrm{Li}_{7} \mathrm{P}_{2.9} \mathrm{~S}_{10.85} \mathrm{Mo}_{0.01}\right)$ prepared via combining high-energy ball milling and annealing. $\mathrm{Li}_{7} \mathrm{P}_{2.9} \mathrm{~S}_{10.85} \mathrm{Mo}_{0.01}$ exhibited a high ionic conductivity of $4.8 \times 10^{-3} \mathrm{~S} \mathrm{~cm}^{-1}$ at room temperature, and a wide electrochemical window up to $5 \mathrm{~V}$ ( $v s$. $\left.\mathrm{Li} / \mathrm{Li}^{+}\right)$. Eom et al. ${ }^{[202]}$ enhanced the conductivity of the $\mathrm{Li}_{2} \mathrm{~S}-\mathrm{P}_{2} \mathrm{~S}_{5}$ glass-ceramic electrolyte by adding $\mathrm{Li}_{3} \mathrm{BO}_{3}$ in $\mathrm{Li}_{2} \mathrm{~S}-\mathrm{P}_{2} \mathrm{~S}_{5}$.The $97\left(0.78 \mathrm{Li}_{2} \mathrm{~S}-0.22 \mathrm{P}_{2} \mathrm{~S}_{5}\right)-3 \mathrm{Li}_{3} \mathrm{BO}_{3}$ glass-ceramic exhibited the highest conductivity of $1.03 \times 10^{-3} \mathrm{~S} \mathrm{~cm}^{-1}$ at room temperature. In addition, a $\mathrm{Li}_{3} \mathrm{PO}_{4}$-doped $\mathrm{Li}_{7} \mathrm{P}_{3} \mathrm{~S}_{11}$ glass-ceramic, $70 \mathrm{Li} 2 \mathrm{~S}-29 \mathrm{P}_{2} \mathrm{~S}_{5}-1 \mathrm{Li}_{3} \mathrm{PO}_{4}$, possessed the highest total conductivity of $1.87 \times 10^{-3} \mathrm{~S} \mathrm{~cm}^{-1}$ at $25^{\circ} \mathrm{C}$ and the lowest activation energy of $18 \mathrm{~kJ} \mathrm{~mol}^{-1} \cdot{ }^{[203]}$ Nuernberg et al. ${ }^{[204]}$ proposed a series of NASICON based on $\mathrm{Li}_{1+x} \mathrm{Cr}_{x}\left(\mathrm{Ge}_{y} \mathrm{Ti}_{1-y}\right)_{2-x}\left(\mathrm{PO}_{4}\right)_{3}(\mathrm{LCGTP})$ system. The LCGTP glasses show internal nucleation and are relatively stable compared to other self-nucleating glasses. The $\mathrm{LiTi}_{2}\left(\mathrm{PO}_{4}\right)_{3}$-type phase was crystallized and the cell parameters of the structure were in the range of other general systems. This indicated that the composition formed a solid solution and the octahedral sites were shared by $\mathrm{Cr}, \mathrm{Ge}$, Ti. The ionic conductivity of this glass-ceramic is more than 5 orders of magnitude higher than that of the precursor glass. Meanwhile, the highest total ionic conductivity reached $6.6 \times 10^{-5} \mathrm{~S} \mathrm{~cm}^{-1}$, as revealed by the glass-ceramic heat-treated at $900{ }^{\circ} \mathrm{C}$.

\subsection{Solid polymer electrolytes}

The use of polymers in LIBs can enhance mechanical properties and improve safety performance during producing and operating. Polymer electrolytes could be classified into 
three categories: solid polymer electrolytes, gel polymer electrolytes and quasi solid electrolytes.

\subsubsection{PEO-based solid polymer electrolytes}

Researchers have made much effort toward the development of novel polymer electrolytes for LIBs. Among those poly (ethylene oxide) (PEO) is the most commonly used. The mixture of PEO and alkali metal salts displays a conductive behavior. Polymer structures with oligoether $\left(-\mathrm{CH}_{2}-\mathrm{CH}_{2}-\mathrm{O}-\right)_{\mathrm{n}}$ can effectively dissolve $\mathrm{Na}$ and $\mathrm{Li}$ salts. The mechanism of the $\mathrm{Li}^{+}$ movement in polymer chain segments was proposed by Armand decades later (reference? DG). Flexible ethylene oxide segments and ether oxygen atoms were found to be good donors for $\mathrm{Li}^{+}$transport. However, the electrolytes exhibit low ionic conductivities due to their high crystallinity. In 2003, Stoeva et al. ${ }^{[205]}$ reported that the ionic conductivity in a PEO crystalline phase is greater than that in amorphous phase (Figure 16). However, Henderson et al. ${ }^{[206]}$ opposed that an amorphous phase in polymer electrolytes predominates in ionic conductivity.

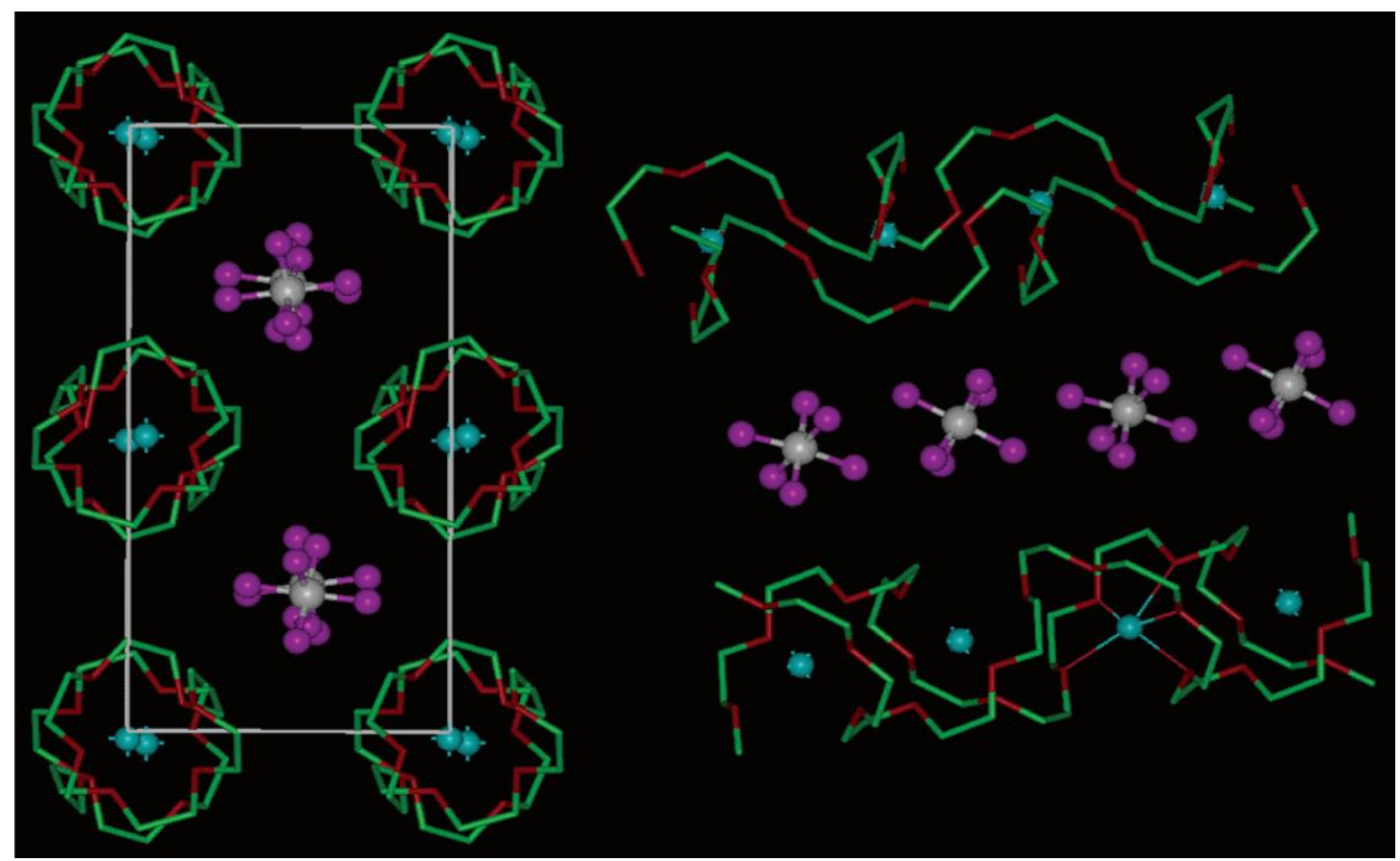

Figure 16. Structures of $\mathrm{PEO}_{6}: \mathrm{LiAsF}_{6}$. (Left) View of the structure along the rows of $\mathrm{Li}^{+}$ions perpendicular to the page. (Right) View of the structure showing the relative position of the 
chains and their conformation (hydrogen atoms are not shown). Thin lines indicate coordination around the $\mathrm{Li}^{+}$cation. Blue spheres - lithium; white spheres -arsenic; magenta fluorine; green -carbon; red -oxygen. Reproduced with permission. ${ }^{[205]}$ Copyright 2003, American Chemical Society.

There are three main ways to improve ionic conductivity. First, adding novel and suitable lithium salts can efficiently improve it. ${ }^{[10]}$ Lithium salts, like $\mathrm{LiClO}_{4}, \mathrm{LiBF}_{4}, \mathrm{LiPF}_{6}, \mathrm{LiAsF}_{6}$, $\mathrm{LiCF}_{3} \mathrm{SO}_{3}$ and $\mathrm{LiN}\left(\mathrm{CF}_{3} \mathrm{SO}_{2}\right)_{2}$ are widely used in polymer electrolytes. While combining the compound action between polymer chains and salt cations, the ability to form polymer electrolytes depends on the solvation energy of polymers on cations and the salt lattice energy. Experiments showed that lithium salts with a smaller lattice energy (usually less than $850 \mathrm{~J}$ mol $^{-1}$ ) merge better with PEO and make a good solid electrolyte. On the other hand, the dissociation constant determines the conductivity by forming ion pairs and ion aggregates in polymers. Lithium salts with higher dissociation constant form less ion pairs and ion aggregates and exhibit better ionic conductivity. Among these lithium salts, lattice energies and dissociation constants are in the following sequence:

Lattice energies $\left(\mathrm{J} \mathrm{mol}^{-1}\right): \mathrm{LiBF}_{4}(699) \sim \mathrm{LiAsF}_{4}<\mathrm{LiClO}_{4}(723) \sim \mathrm{LiCF}_{3} \mathrm{SO}_{3}<\mathrm{LiSCN}$ $(807)<\operatorname{LiI}(757)<\operatorname{LiBr}(807)<\operatorname{LiCl}(853)<\operatorname{LiF}(1036)$

Dissociation constants: $\mathrm{LiN}\left(\mathrm{CF}_{3} \mathrm{SO}_{2}\right)_{2}>\mathrm{LiAsF}_{6}>\mathrm{LiPF}_{6}>\mathrm{LiClO}_{4}>\mathrm{LiBF}_{4}>$ $\mathrm{LiCF}_{3} \mathrm{SO}_{3} \cdot{ }^{[9]}$

Among these salts, $\mathrm{Li}$ trifluoromethanesulfonate (LiFSI), Li bis(trifluoromethanesulfonimidate) (LiTFSI), $\mathrm{Li}$ bis(oxalato)borate (LiBOB) and $\mathrm{Li}$ difluoro(oxalato)borate (LiDFOB) have been used to improve the ionic conductivity. The negative charges have a large degree of delocalization in anionic group, and strong electron withdrawing group, such as $-\mathrm{CF}_{3}$, makes the charge more dispersed. The electrochemical window of $\mathrm{Li}$ salt can reach a value above $3.8 \mathrm{~V}$ vs. $\mathrm{Li} / \mathrm{Li}^{+}$. Recently, Yang et al. ${ }^{[207]}$ reported 
a novel supermolecular $\mathrm{PEO} / \mathrm{Li}^{+}$based solid electrolyte, which contains $\mathrm{PEO}, \mathrm{LiAsF}_{6}$ and $\alpha$-cyclodextrin and exhibits high ionic conductivity.

Secondly, inhibiting the formation of crystalline phase is another useful way to enhance the performance of PEO-based solid polymer electrolytes. In general, researchers achieve it by physical modification (blending) and chemical (copolymerization and cross-linking) modification, respectively. Inspired by the concept of "rigid-flexible" in Chinese Tai-chi, Cui et al. ${ }^{[208]}$ developed a new class of rigid-flexible coupled solid polymer electrolyte (CCPL). They blended PEO, poly (cyano acrylate) (PCA) and LiBOB according to the mass ratio of 10:2:1 and casted the homogeneous solution on a home-made cellulose nonwoven membrane. The electrolyte film possessed high mechanical strength, sufficient ionic conductivity $\left(3.0 \times 10^{-4} \mathrm{~S} \mathrm{~cm}^{-1}\right.$ at $60{ }^{\circ} \mathrm{C}$ ) and improved dimensional thermostability (up to $160{ }^{\circ} \mathrm{C}$ ). Luca et al. ${ }^{[209]}$ added tetraglyme, photoinitiator (MBP) and LiTFSI in PEO to obtain a highly flexible PEO based electrolyte. Under UV irradiation, the in-situ polymerized tetraglyme oligomers can easily crosslink with the PEO backbones to reduce the crystalline phase. The electrolyte demonstrated a high ionic conductivity $\left(10^{-4} \mathrm{~S} \mathrm{~cm}^{-2}\right)$ and good electrochemical stability up to 5 V. Pan et al. ${ }^{[210]}$ synthesized a hybrid electrolyte based on POSS with controlled network structures (Figure 17). The solid polymer electrolytes exhibited high room temperature ionic conductivity $\left(\approx 1 \times 10^{-4} \mathrm{~S} \mathrm{~cm}^{-1}\right)$ and high storage modulus $\left(33.6 \mathrm{MPa}\right.$ at $\left.105^{\circ} \mathrm{C}\right)$, which makes them good electrolyte/separator to block the growth of $\mathrm{Li}$ dendrites. $\mathrm{Li} / \mathrm{LiFePO}_{4}$ batteries using POSS-2PEG6K as electrolytes showed improved cycling stability and rate capability. Zeng et al. ${ }^{[211]}$ developed a bifunctional solid polymer electrolyte with interconnected "cages" formed by branched acrylate to spatially restrain PEO crystallization effectively, and the electrolyte reached relatively high room temperature conductivity $\left(2.2 \times 10^{-4} \mathrm{~S} \mathrm{~cm}^{-1}\right)$. 

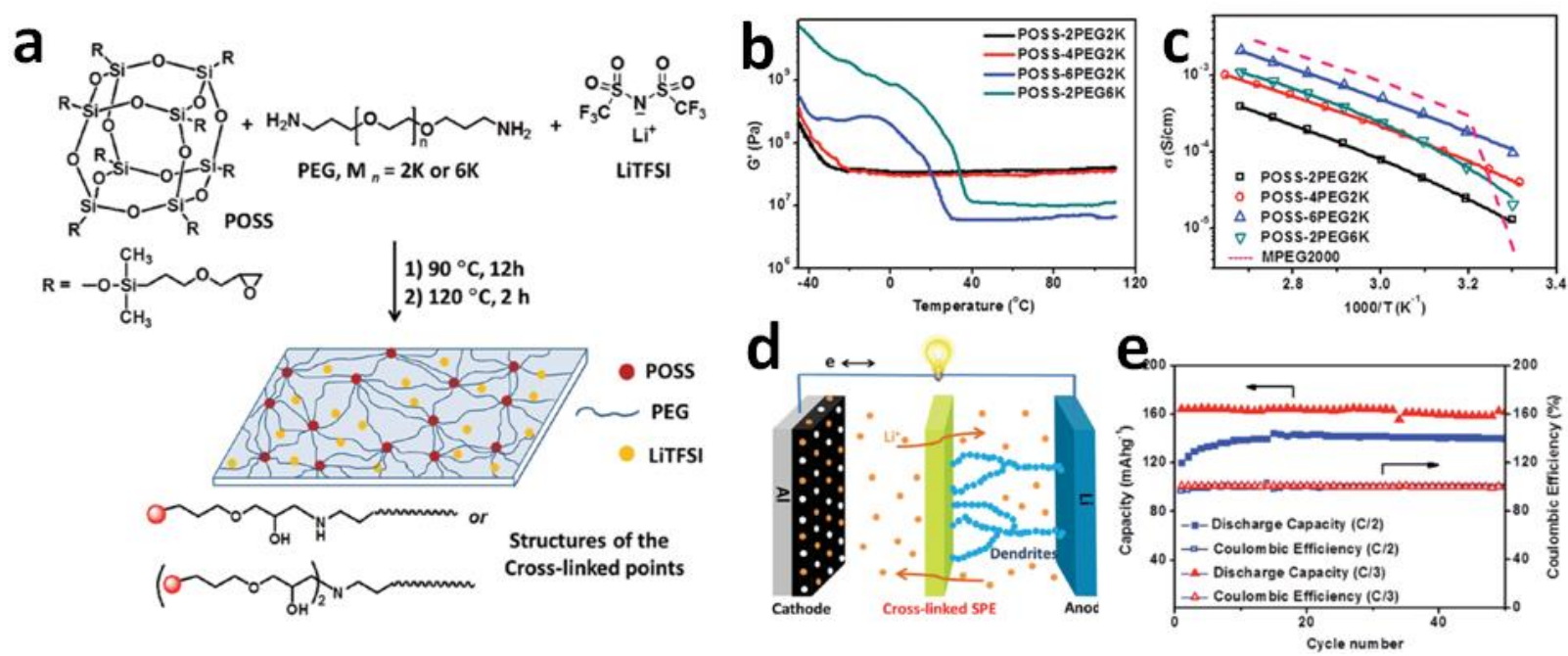

Figure 17. a) Synthetic route of the POSS-PEO cross-linked SPE $\left(E O / \mathrm{Li}^{+}=16\right)$ and its ideal network structure. b) The storage modulus $G^{\prime}$ and c) ionic conductivity of the POSS-PEO solid polymer electrolytes at different temperatures. d) Schematic illustration of a LMB with this SPE as separator/electrolyte to block the growth of Li dendrites. e) Capacity and Columbic efficiency of the LMBs during charge-discharge cycling at $\mathrm{C} / 2$ and $\mathrm{C} / 3$ rates at $90{ }^{\circ} \mathrm{C}$. Reproduced with permission ${ }^{[210]}$. Copyright 2015, WILEY-VCH Verlag GmbH \& Co. KGaA, Weinheim.

Thirdly, the addition of inorganic fillers to form a composite polymer electrolyte (CPE) has been a widely used strategy for decades. Inorganic fillers can be classified into two parts: active fillers and inactive fillers. Active fillers, such as $\mathrm{Li}_{1+x} \mathrm{Al}_{x} \mathrm{Ti}_{2-x}\left(\mathrm{PO}_{4}\right)_{3}, \mathrm{Li}_{7} \mathrm{La}_{3} \mathrm{Zr}_{2} \mathrm{O}_{12}$, $\mathrm{Li}_{0.5} \mathrm{La}_{0.5} \mathrm{TiO}_{3}$ and $\mathrm{Li}_{3} \mathrm{~N}$, are fast $\mathrm{Li}$ ion conductors. They generally exhibit high ionic conductivities and lithium ion transference numbers. Inactive fillers, like $\mathrm{Al}_{2} \mathrm{O}_{3}, \mathrm{TiO}_{2}, \mathrm{ZrO}_{2}$ and $\mathrm{SiO}_{2}$, cannot directly offer a pathway for $\mathrm{Li}^{+}$ions in electrolytes but can facilitate $\mathrm{Li}^{+}$ transport via the amorphorization of PEO and the creation of space-charge regions. An electrolyte with low degree of crystallinity, low glass transition temperature $\left(T_{\mathrm{g}}\right)$, and high melting point $\left(T_{\mathrm{m}}\right)$ is extremely important. Inert ceramic fillers, like Lewis acid or $\mathrm{Al}_{2} \mathrm{O}_{3}$, can improve the ionic conductivity of $\mathrm{PEO} / \mathrm{LiClO}_{4}$ based polymer electrolytes through reducing 
the degree of crystallinity. ${ }^{[212]}$ The charged state on the surface of a nano- $\mathrm{Al}_{2} \mathrm{O}_{3}$ particle can result in different performances of the $\mathrm{PEO}_{20}-\mathrm{LiCF}_{3} \mathrm{SO}_{3}$ system, as studied by Croce et al. ${ }^{[213]}$ Nano- $\mathrm{Al}_{2} \mathrm{O}_{3}$ particles with basic groups cannot improve the ionic conductivity, but with Lewis acid groups or neutral groups the ionic conductivity can rise to $8 \times 10^{-6} \mathrm{~S} \mathrm{~cm}^{-1}$ and $1 \times 10^{-6} \mathrm{~S}$ $\mathrm{cm}^{-1}$ at room temperature, respectively. In addition, the content and particle size of inert ceramic fillers are also important parameters to control the filler functions and corresponding composite polymer electrolytes. It seems that nano- $\mathrm{Al}_{2} \mathrm{O}_{3}$ is much better in increasing ionic conductance than micrometer-sized particles, as was concluded by Dissanayake et al. ${ }^{[214]}$ An appropriate content of $\mathrm{Al}_{2} \mathrm{O}_{3}$ in a composite electrolyte, $\left(\mathrm{Al}_{2} \mathrm{O}_{3}\right)_{x}(\mathrm{PEO})_{12.5-x}\left(\mathrm{LiClO}_{4}\right)$, was researched by Masoud et al. ${ }^{[215]}$ When containing $1.25 \mathrm{~mol}$ of $\mathrm{Al}_{2} \mathrm{O}_{3}$, the electrolyte exhibits the highest value of conductivity $\left(8.3 \times 10^{-5} \mathrm{~S} \mathrm{~cm}^{-1}\right.$ at $\left.20{ }^{\circ} \mathrm{C}\right)$. Other inert ceramic oxides, such as $\mathrm{TiO}_{2}{ }^{[216,217]}, \mathrm{SiO}_{2},{ }^{[218,219]}$ can also enhance conductance of polymer electrolytes. For example, Lin et al. ${ }^{[220]}$ added nanoscale $\mathrm{TiO}_{2}$ with a size of $3.7 \mathrm{~nm}$ into $\mathrm{PEO} / \mathrm{LiClO}_{4}$ and the electrolyte demonstrated a high Li ion transference number (0.51) and high ionic conductivity $\left(1.40 \times 10^{-4} \mathrm{~S} \mathrm{~cm}^{-1}\right.$ at $\left.30{ }^{\circ} \mathrm{C}\right)$. Choudhury et al. ${ }^{[221]}$ developed a solid electrolyte based on crosslinked hairy silica nanoparticles (Figure 18). The strategy of using hairy nanoparticles can go well along with crosslinking of rigid PEO matrixes and the ion-conducting membranes and lead to good mechanical properties $\left(G_{\mathrm{N}}=1 \mathrm{MPa}\right)$ and liquid-like ionic conductivity $(\sigma=$ $5 \times 10^{-3} \mathrm{~S} \mathrm{~cm}^{-1}$ ) at room temperature. The materials can efficiently work in LMBs based on LTO cathodes with high discharge capacity for over 150 cycles at $1 \mathrm{C}$. 

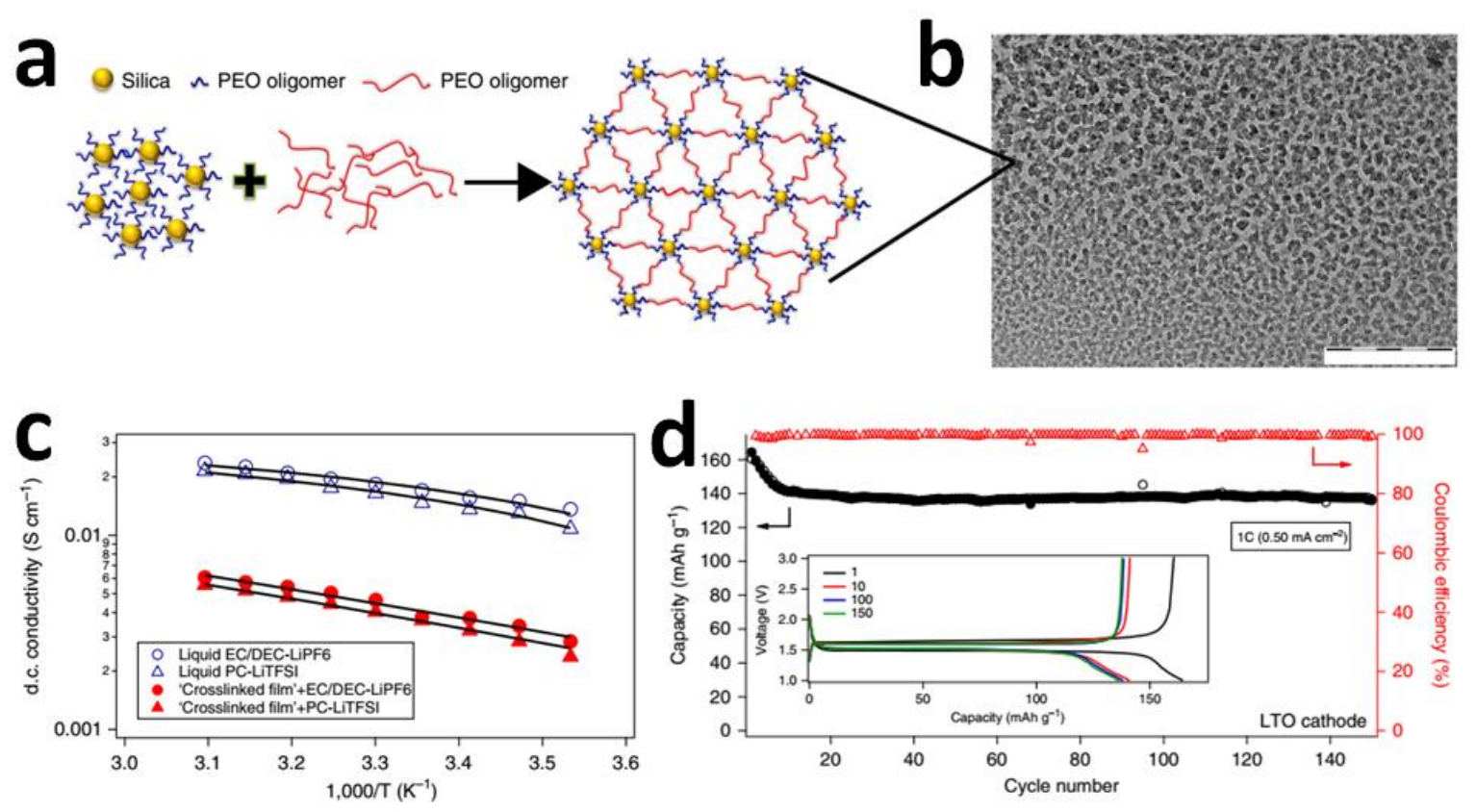

Figure 18. a) Synthetic route of a free-standing crosslinked nanoparticle-polymer composite.

b) TEM image of the crosslinked membrane. Scale bar, $200 \mathrm{~nm}$. c) DC conductivity as a function of inverse absolute temperature. d) Cycling performance for Li/composite electrolyte/LTO at 1C. The inset shows the voltage profiles. Reproduced with permission. ${ }^{[221]}$ Copyright 2015, Nature Publishing Group.

Mostly, polymer matrices possess low dielectric constant, which suppresses the dissociation of Li salts in a polymer. Ferroelectric ceramics are generally polar particles. Doping into the polymer matrixes can efficiently improve the ionic conductivity and Li ion transference number. Itoh et al. ${ }^{[222]}$ prepared a composite polymer electrolyte containing PEO, LiTFSI and $\mathrm{BaTiO}_{3}$. The ionic conductivity of the electrolyte was $2.6 \times 10^{-4} \mathrm{~S} \mathrm{~cm}^{-1}$ at $30{ }^{\circ} \mathrm{C}$ and the electrochemical stability window reached of $4.0 \mathrm{~V}$ at $30{ }^{\circ} \mathrm{C}$. Batteries assembled as $\mathrm{Li} / \mathrm{PEO}-\mathrm{LiTFSI}-\mathrm{BaTiO}_{3} / \mathrm{C}$ exhibited an excellent charging/discharging specific capacity, more than $330 \mathrm{mAh} \mathrm{g}^{-1}$ after 20 cycles. Recently, a novel composite electrolytes composed of $\mathrm{PEO} / \mathrm{PVP} / \mathrm{LiClO}_{4} / \mathrm{PC}$ with different ratios of $\mathrm{BaTiO}_{3}$ has been developed by Kesavan et al. ${ }^{[223]}$ The highest ionic conductivity of $1.2399 \times 10^{-3} \mathrm{~S} \mathrm{~cm}^{-1}$ at $30{ }^{\circ} \mathrm{C}$ was documented after 
addition of $10 \mathrm{wt} \% \mathrm{BaTiO}_{3}$. Other ferroelectric ceramics, such as $\mathrm{PbTiO}_{3}, \mathrm{LiNbO}_{3}$, can also enhance the conductance of polymer electrolytes, reduce the interfacial resistance and enhance mechanical properties of polymer electrolytes. ${ }^{[224,225]}$

Metal-organic frameworks (MOFs) are compounds consisting of metal ions or clusters coordinated to organic ligands to form one-, two-, or three-dimensional structures. They are a subclass of coordination polymers; often they are porous. Due to their high surface areas, regular and porous channels and ease in modifying, MOFs have been used in many fields, including catalysis, gas storage and separation, and sensors. In recent years, they have been applied as fillers in composite polymer electrolytes. ${ }^{[11]}$ Liu et al. ${ }^{[226]}$ prepared an electrolyte containing PEO, LiTFSI and MOF-5 using in situ method. The ionic conductivity and electrode/ electrolyte interface stability of polymer electrolytes were improved by the addition of MOF-5. The highest ionic conductivity was $3.16 \times 10^{-5} \mathrm{~S} \mathrm{~cm}^{-1}$ at $25^{\circ} \mathrm{C}$ for an optimized content of 10 wt $\%$ MOF-5 with EO: Li = 10: 1 . The Lewis sites in MOF-5 can inhibit the crystallization of PEO and build up pathways for conducting $\mathrm{Li}^{+}$on the surface of MOF-5 fillers. Besides, charging/discharging specific capacities of $\mathrm{LiFePO}_{4}$ half cells using the electrolytes at different rates were enhanced by utilizing MOF-5 fillers, 118 to $138 \mathrm{mAh} \mathrm{g}^{-1}$ at $0.5 \mathrm{C}$ and 107 to $132 \mathrm{mAh} \mathrm{g}^{-1}$ at $1 \mathrm{C}$. The electrolyte can be applied in LIBs operated at < $4.57 \mathrm{~V}$ at $60{ }^{\circ} \mathrm{C}$. To further improve the rate performance and ionic conductivity, Liu's group altered MOF-5 by MIL-53(Al) in the above electrolyte system. ${ }^{[227]}$ The electrolytes showed a high oxidation potential of $5.10 \mathrm{~V}$ at $120^{\circ} \mathrm{C}$ and a high ionic conductivity of $3.39 \times 10^{-3} \mathrm{~S} \mathrm{~cm}^{-1}$ at $120^{\circ} \mathrm{C}$. All solid state batteries assembled by Li/CPE/LiFePO4 possessed a high discharge capacity of $136.4 \mathrm{mAh} \mathrm{g}^{-1}$ at $5 \mathrm{C}$ and $120{ }^{\circ} \mathrm{C}$ in the first cycle, $129.2 \mathrm{mAh} \mathrm{g}^{-1}$ in the $300^{\text {th }}$ cycle and remained at $83.5 \mathrm{mAh} \mathrm{g}^{-1}$ after the $1400^{\text {th }}$ cycle. Kumar et al. ${ }^{[228]}$ prepared a CPE composed of PEO/LiTFSI/Cu-BDC (copper benzene dicarboxylate) by using an electrochemical method. Between 0 to $70^{\circ} \mathrm{C}$, the ionic conductivity ranged from $10^{-6}$ to $10^{-3} \mathrm{~S}$ $\mathrm{cm}^{-1}$. The $\mathrm{Li} / \mathrm{CPE} / \mathrm{LiFePO}_{4}$ cells displayed high discharge specific capacity, good rate 
capacity and high Coulombic efficiency. Besides, MOFs can not only provide pathways for $\mathrm{Li}^{+}$, but also work as adsorbents to trap trace amount of impurities, like $\mathrm{O}_{2}$ and $\mathrm{H}_{2} \mathrm{O}$, during cells operation.

In addition to inert ceramics, ferroelectric ceramics and MOFs, application of strong acid oxides (e.g., $\mathrm{Zr}-\mathrm{O}-\mathrm{SO}_{4}{ }^{[229]}$ ) and molecular sieves (e.g., MCM-41 ${ }^{[230]}$, SBA-15 ${ }^{[231-233]}$, ZSM-5 ${ }^{[234,235]}$, etc.) in solid polymer electrolytes was analyzed. In general, the above inactive fillers can more or less improve ionic conductivity, but not significantly.

Inactive fillers, that are not involved in $\mathrm{Li}$ ion conduction process, and active ones can directly participate in Li ion transport. Nanoscale ceramic fillers have large specific surface area and can drastically enhance the ionic conductivity. $\mathrm{Li}_{3} \mathrm{~N}$ exhibits ion conductivity of the order of $10^{-3} \mathrm{~S} \mathrm{~cm}^{-1}$ at ambient temperature ${ }^{[236]}$. Masoud et al. ${ }^{[237]}$ synthesized nano-LiAlO $\mathrm{Al}_{2}$ fillers using a sol-gel method. The addition of nano- $\mathrm{LiAlO}_{2}$ can reduce the crystallization of PEO and promote the growth of a passive layer on the lithium metal anode. Wang et al. ${ }^{[238]}$ prepared a PEO-based solid CPE film with different $\mathrm{Li}_{1.3} \mathrm{Al}_{0.3} \mathrm{Ti}_{1.7}\left(\mathrm{PO}_{4}\right)_{3}$ contents by a solution-cast technique. With LATP acting as both fillers and ion conductors, the PEO/LATP film showed the highest ionic conductivity of $1.185 \times 10^{-4} \mathrm{~S} \mathrm{~cm}^{-1}$ at $100{ }^{\circ} \mathrm{C}$ and $2.631 \times 10^{-6} \mathrm{~S}$ $\mathrm{cm}^{-1}$ at room temperature, at an EO/Li molar ratio of 16 . Meanwhile, the PEO/LiClO $4 / \mathrm{LATP}$ film delivered the highest ionic conductivity of $1.161 \times 10^{-3} \mathrm{~S} \mathrm{~cm}^{-1}$ at $100{ }^{\circ} \mathrm{C}$ and $7.985 \times 10^{-6}$ $\mathrm{S} \mathrm{cm}^{-1}$ at room temperature, at a LATP content of $15 \mathrm{wt} \%$. Recently, Wang et al. ${ }^{[239]}$ have prepared a composite solid electrolyte composed of $\mathrm{Li}_{1.5} \mathrm{Al}_{0.5} \mathrm{Ge}_{1.5}\left(\mathrm{PO}_{4}\right)_{3}$ (LAGP)-PEO-LiTFSI for the suppression of lithium dendrite formation. The ratio of PEO in the composite polymer electrolyte was reduced to become lower, at a level of $1 \mathrm{wt} \%$, and PEO remained stable even at a high potential of $5.12 \mathrm{~V}\left(v s \mathrm{Li} / \mathrm{Li}^{+}\right)$. The molar ratios and integrating modes of polymer and inorganic ceramic particles strongly affect properties and performances of composite electrolytes. Zheng et al. ${ }^{[240]}$ probed the $\mathrm{Li}^{+}$diffusion pathway in a $\mathrm{Li}_{7} \mathrm{La}_{3} \mathrm{Zr}_{2} \mathrm{O}_{12}$-PEO $\left(\mathrm{LiClO}_{4}\right)$ composite electrolyte by $1 \mathrm{D}$ high-resolution ${ }^{6} \mathrm{Li}$ NMR. They 
showed that Li ions mainly pass through LLZO particles, not through the interface or polymer phase. Choi et al. ${ }^{[241]}$ demonstrated that the combination of the organic matrix (PEO) and the inorganic fillers $\left(\mathrm{Li}_{7} \mathrm{La}_{3} \mathrm{Zr}_{2} \mathrm{O}_{12}\right)$ in the solid electrolyte membranes synergistically enhances their ionic conductivities. The composite membrane containing 52.5\% LLZO exhibited the highest ionic conductivity, $4.42 \times 10^{-4} \mathrm{~S} \mathrm{~cm}^{-1}$ at $55{ }^{\circ} \mathrm{C}$. Fu et al. ${ }^{[242]}$ built up a 3D $\mathrm{Li}^{+}$-conducting ceramic network based on garnet-type $\mathrm{Li}_{6.4} \mathrm{La}_{3} \mathrm{Zr}_{2} \mathrm{Al}_{0.2} \mathrm{O}_{12}$ (LLZAO) lithium-ion conductor to provide continuous $\mathrm{Li}^{+}$transfer channels in a PEO-based electrolyte. The flexible electrolyte membrane revealed an ionic conductivity of $2.5 \times 10^{-4} \mathrm{~S} \mathrm{~cm}^{-1}$ at room temperature. It could also effectively suppress lithium dendrite growth in a symmetric $\mathrm{Li} / \mathrm{CPE} / \mathrm{Li}$ cell during multiple lithium stripping/plating measurement at room temperature, at a current density of $0.2 \mathrm{~mA} / \mathrm{cm}^{2}$ for about $500 \mathrm{hrs}$ and a current density of $0.5 \mathrm{~mA} / \mathrm{cm}^{2}$ for more than 300 hrs. Recently, Liu et al. ${ }^{[243]}$ have reported on a composite polymer electrolyte with well-aligned inorganic $\mathrm{Li}^{+}$-conductive nanowires. The latter exhibited an ionic conductivity of $6.05 \times 10^{-5} \mathrm{~S} \mathrm{~cm}^{-1}$ at $30{ }^{\circ} \mathrm{C}$, which is one order of magnitude higher than for previous polymer electrolytes with randomly aligned nanowires. Their further study confirmed that random nanowires could supply a more continuous fast conduction pathway for Li ions than isolated nanoparticles. Also the absence of crossing junctions makes perfect conducting channels for ion diffusion (Figure 19). 

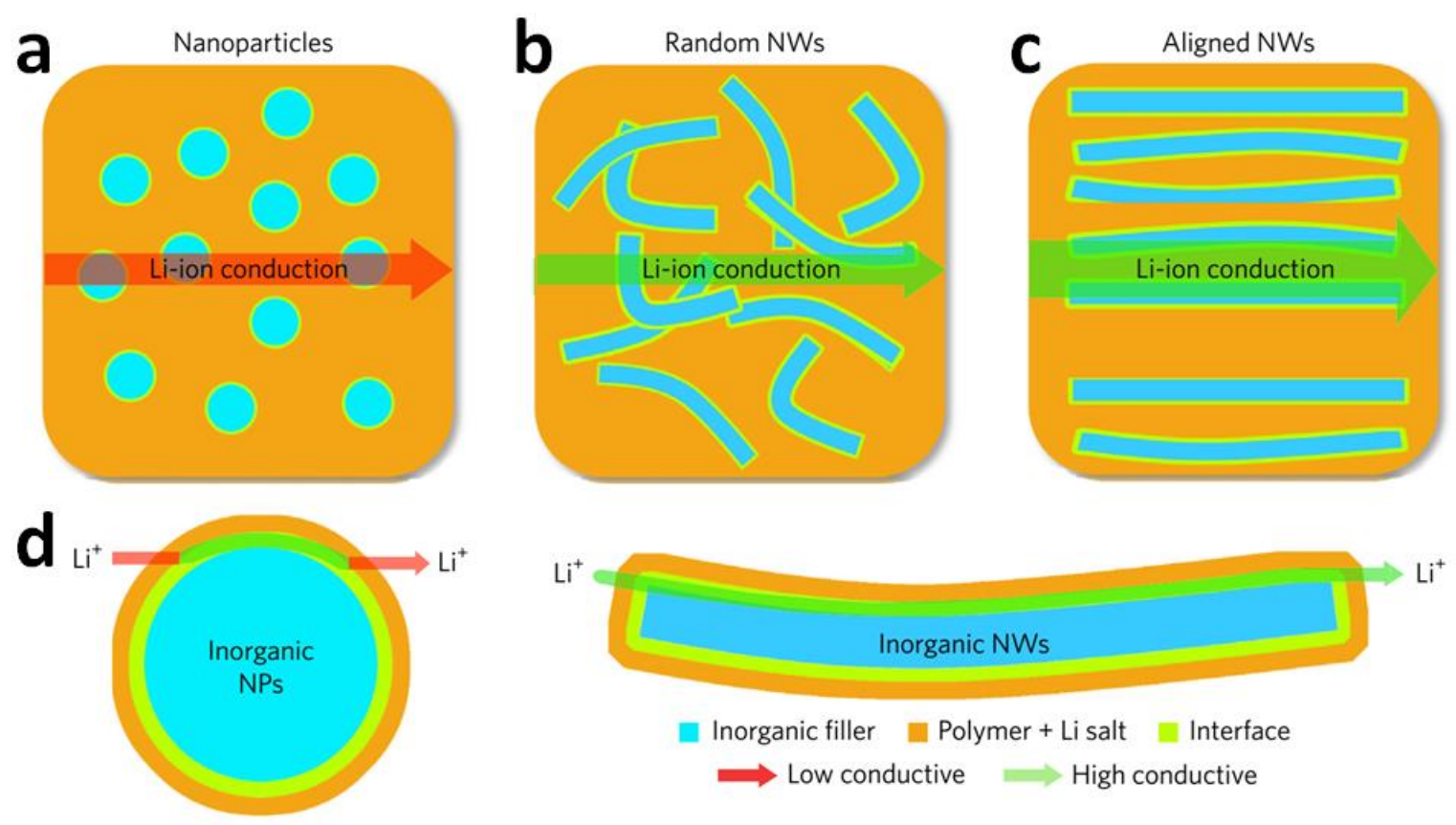

Figure 19. The comparison of possible Li-ion conduction pathways. Li-ion conduction pathways in composite polymer electrolytes with a) Nanoparticles, b) Random nanowires and c) Aligned nanowires. d) The surface region of inorganic nanoparticles and nanowires as an expressway for Li-ion conduction. Reproduced with permission. ${ }^{[243]}$ Copyright 2017, Nature Publishing Group.

\subsubsection{Others}

Though PEO-based electrolytes were researched the most, several drawbacks, like low dielectric constant and ion aggregation phenomenon, are detrimental to the migration of $\mathrm{Li}^{+}$. Different from PEO-based electrolytes, polycarbonate-based electrolytes have strong polar groups, $[-\mathrm{O}-(\mathrm{C}=\mathrm{O})-\mathrm{O}-]$, which can increase dielectric constant and improve ionic conductivity. ${ }^{[244]}$ Cui et al. ${ }^{[245]}$ studied a poly (propylene carbonate)/cellulose nonwoven membrane/LiTFSI based electrolyte. The ionic conductivity of the electrolyte was $3.0 \times 10^{-4} \mathrm{~S}$ $\mathrm{cm}^{-1}$ at $20^{\circ} \mathrm{C}$, which was much higher than for PEO-based electrolyte $\left(2.1 \times 10^{-6} \mathrm{~S} \mathrm{~cm}^{-1}\right)$. The $\mathrm{Li} / \mathrm{LiFe}_{0.2} \mathrm{Mn}_{0.8} \mathrm{PO}_{4}$ cell exhibited superior charge/discharge properties and rate performance at $120{ }^{\circ} \mathrm{C}$. Later on, Cui's group prepared a poly (vinylene carbonate) based solid polymer 
through in situ polymerization. The electrolyte possessed a high ionic conductivity of $9.82 \times 10^{-5} \mathrm{~S} \mathrm{~cm}^{-1}$ at $50{ }^{\circ} \mathrm{C}$ and a considerable electrochemical stability window up to $4.5 \mathrm{~V} v s$. $\mathrm{Li} / \mathrm{Li}^{+}{ }^{[172]}$ Besides, polysiloxane-based electrolytes demonstrated thelow glass transition temperature and high room temperature ionic conductivity. In general, low glass transition temperature results in reduced mechanical properties. Forming a network by blending, grafting and crosslinking can enhance comprehensive performance of these electrolytes. Lim et al. ${ }^{[246]}$ reported a ceramic based composite solid electrolyte composed of $80 \mathrm{wt} \%$ $\mathrm{Li}_{1.3} \mathrm{Ti}_{1.7} \mathrm{Al}_{0.3}\left(\mathrm{PO}_{4}\right)_{3}$, (LTAP) as a lithium ion conducting ceramic, $10 \mathrm{wt} \%$ of poly(vinylidene fluoride) (PVDF) as a binder, and $10 \mathrm{wt} \% 1 \mathrm{M} \mathrm{LiPF} / \mathrm{EC}+\mathrm{DMC}$. The composite electrolyte demonstrated a lithium ionic conductivity of $8.9 \times 10^{-4} \mathrm{~S} \mathrm{~cm}^{-1}$ at room temperature without leakage. Li et al. ${ }^{[247]}$ developed a novel polysiloxane by grafting ethylene oxide oligomer on the side chain of polymethylhydrosiloxane, then the polymer was blended with PVDF and certain amount of LiTFSI. The electrolyte showed the highest ionic conductivity of $7.9 \times 10^{-5} \mathrm{~S} \mathrm{~cm}^{-1}$ at $25^{\circ} \mathrm{C}$ and $8.7 \times 10^{-4} \mathrm{~S} \mathrm{~cm}^{-1}$ at $80{ }^{\circ} \mathrm{C}$ with $30 \mathrm{wt} \%$ LiTFSI. It also exhibited excellent mechanical properties and compatibility with the lithium metal anode with 20 wt $\%$ LiTFSI. The decomposition temperature of the electrolyte was $275^{\circ} \mathrm{C}$, and the electrochemical stability windows at $25{ }^{\circ} \mathrm{C}$ and $60{ }^{\circ} \mathrm{C}$ were up to $5.17 \mathrm{~V}$ and $5.05 \mathrm{~V}$, respectively. Horowitz et al. ${ }^{[248]}$ created a PDMS-supported IL gel electrolyte with $80 \mathrm{wt} \%$ IL loadings via a sol-gel reaction at room temperature. The electrolytes displayed favorable ionic conductivity $\left(\sim 3 \times 10^{-3} \mathrm{~S} \mathrm{~cm}^{-1}\right.$ at room temperature $)$ and excellent mechanical behavior. Zhou et al. ${ }^{[249]}$ prepared a $\mathrm{SiO}_{2}$ hollow nanosphere-based composite solid electrolyte by in situ interpenetrating polymerization of the tripropylene gycol diacrylate (TPGDA) monomers with $\mathrm{SiO}_{2}$ hollow nanospheres. The composite polymer electrolytes had high room temperature ionic conductivity $\left(1.74 \times 10^{-3} \mathrm{~S} \mathrm{~cm}^{-1}\right)$ due to the large liquid electrolyte uptake of $\mathrm{SiO}_{2}$ hollow nanospheres (Figure 20). 


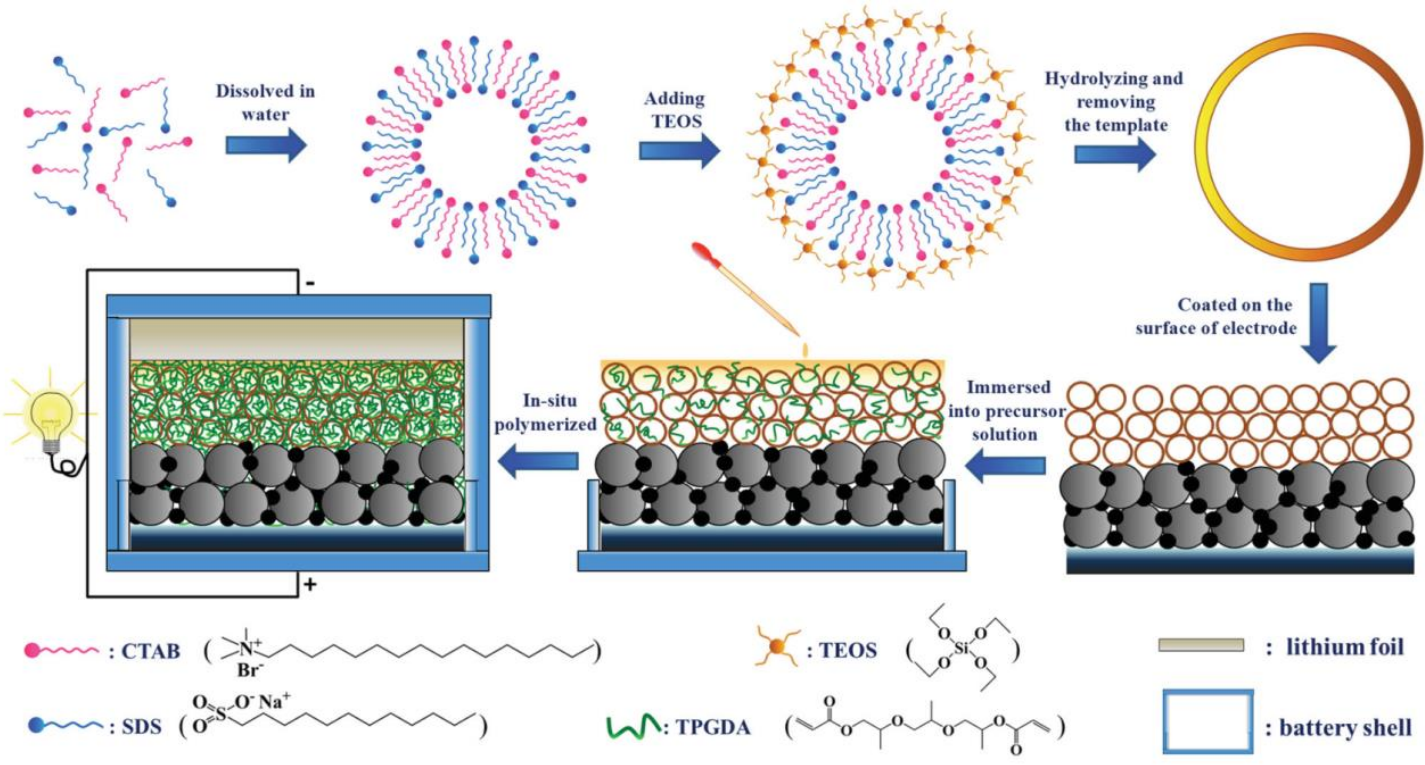

Figure 20. Preparation route of a $\mathrm{SiO}_{2}$ hollow nanosphere-based composite solid electrolyte.

Reproduced with permission. ${ }^{[249]}$ Copyright 2016, WILEY-VCH Verlag GmbH \& Co. KGaA, Weinheim.

a

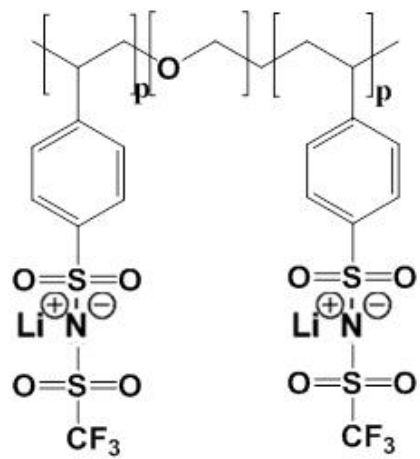

b

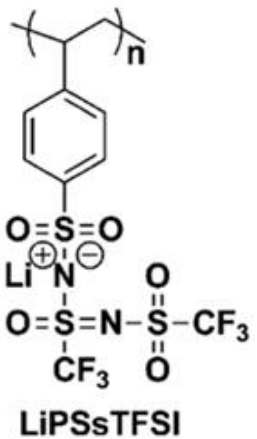
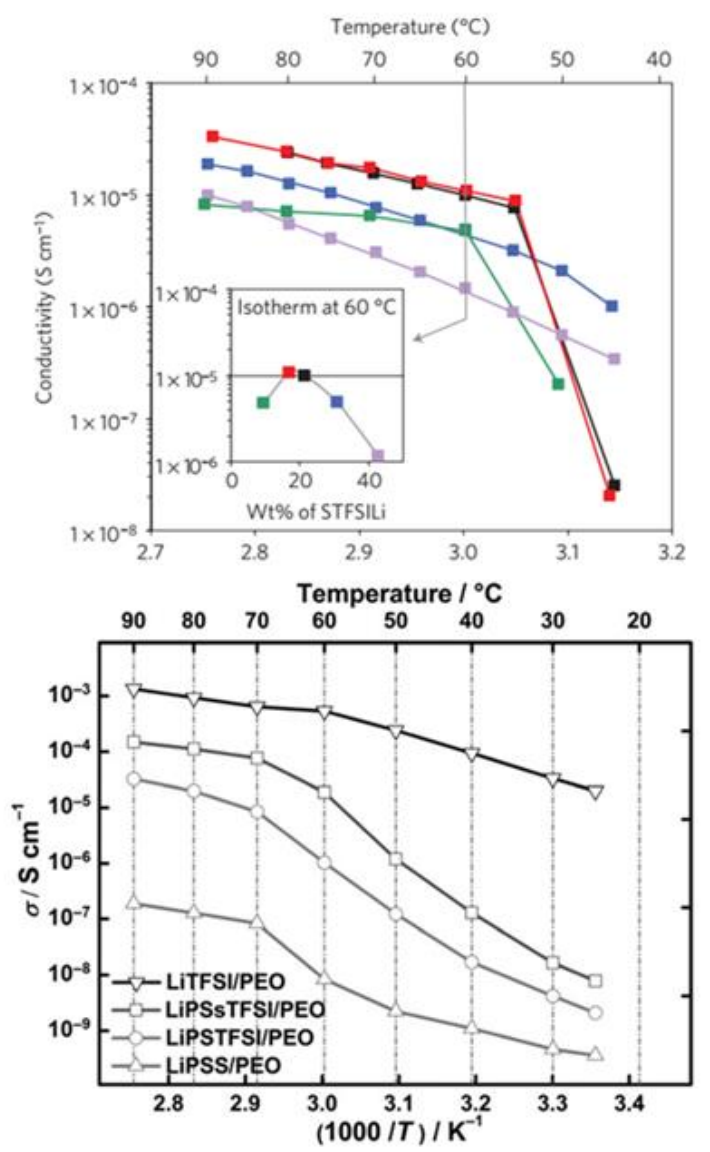
Figure 21. a) (Left) Chemical structure of the single-ion conductor, triblock copolymer P(STFSILi)- $b$-PEO- $b$-P(STFSILi). (Right) Ionic conductivity for several P(STFSILi)-PEO-P(STFSILi) A-BCEs at different temperatures. Reproduced with permission $^{[250]}$. Copyright 2013, Macmillan Publishers Limited. b) (Left) Chemical structure of the single-ion conductor, LiPSsTFSI. (Right) Ionic conductivities for the LiX/PEO (X=PSS, PSTFSI, PSsTFSI, TFSI) blended polymer electrolytes $\left(\mathrm{EO} / \mathrm{Li}^{+}=20\right)$ at different temperatures. Reproduced with permission. ${ }^{[251]}$ Copyright 2016, Wiley-VCH Verlag GmbH \& Co. KGaA, Weinheim.

In traditional electrolyte system, anions and cations migrate together, and the transference of anions results in concentration polarization within the system, which reduces the cycle performance of a battery. Single-lithium-ion conducting polymer electrolyte can achieve single-ion conduction. Anions cannot migrate in the electrolyte system and the Li ion transference number is close to 1 . Bouchet et al. ${ }^{[250]}$ synthesized a triblock polyanion (LiPSTFSI- $b$-PEO- $b$-LiPSTFSI) electrolyte by copolymerization (Figure 21a). The EO chains enhanced the flexibility of LiPSTFSI main chains and provided pathways for migration of $\mathrm{Li}^{+}$. The electrolyte delivered the highest ionic conductivity of $1.3 \times 10^{-5} \mathrm{~S} \mathrm{~cm}^{-1}$ at $60{ }^{\circ} \mathrm{C}$ with 20 wt $\%$ LiPSTFSI $(\mathrm{EO} / \mathrm{Li} \approx 30)$. The $\mathrm{Li} / \mathrm{LiFePO}_{4}$ cells displayed good discharge specific capacity and rate capacity between $60{ }^{\circ} \mathrm{C}$ to $80{ }^{\circ} \mathrm{C}$. Ma et al. ${ }^{[251]}$ synthesized a novel single-lithium-ion conductor composed of a polyanion, PSsTFSI', and then blended it with PEO to fabricate a composite polymer electrolyte (Figure 21b). LiPSsTFSI ionomer displayed a low glass transition temperature $\left(44.3{ }^{\circ} \mathrm{C}\right)$, due to the shortcomings of PEO. The LiPSsTFSI/PEO composite membrane exhibited a high lithium ion transference number (0.91) and an ionic conductivity as high as $1.35 \times 10^{-4} \mathrm{~S} \mathrm{~cm}^{-1}$ at $90{ }^{\circ} \mathrm{C}$. Villaluenga et al. ${ }^{[252]}$ prepared a glass-polymer hybrid single ion-conducting electrolyte in which inorganic sulfide glass particles were covalently bonded to perfluoropolyether polymer chains. The electrolyte 
showed an ionic conductivity of $10^{-4} \mathrm{~S} \mathrm{~cm}^{-1}$ at room temperature, a lithium ion transference number close to 1 , and an electrochemical stability window up to $5 \mathrm{~V}$ vs. $\mathrm{Li} / \mathrm{Li}^{+}$.

\subsection{Gel polymer electrolytes and quasi solid electrolytes}

\subsubsection{Gel polymer electrolytes}

Polymer gels are the special form, between solid and liquid phases, which possesses both the strong mechanical properties of solid polymers and super diffusion ability of ions in liquids. Gel polymer electrolytes can be formed by adding one or more plasticizers into a solid polymer electrolyte.

In general, gel polymer electrolytes create three main domains: polymer crystalline phases, swollen amorphous phases and interconnected electrolyte phases in pores. The transport of Li ions is mainly contributed by solvation of plasticizers. Polymers mainly play a supporting structural role in gel polymer electrolytes. Polymer matrices, such as polyethylene (PEO), polyacrylonitrile (PAN), polyvinyl chloride (PVC), poly(methyl methacrylate) (PMMA), polyvinylidene fluoride (PVDF), poly(vinylidene fluoride-hexafluoropropylene) (PVDF-HFP), polyvinyl acetate (PVAC), polystyrene (PS), polyvinylpyrrolidone (PVP), etc. , are widely used as frameworks in gel polymer electrolytes. 

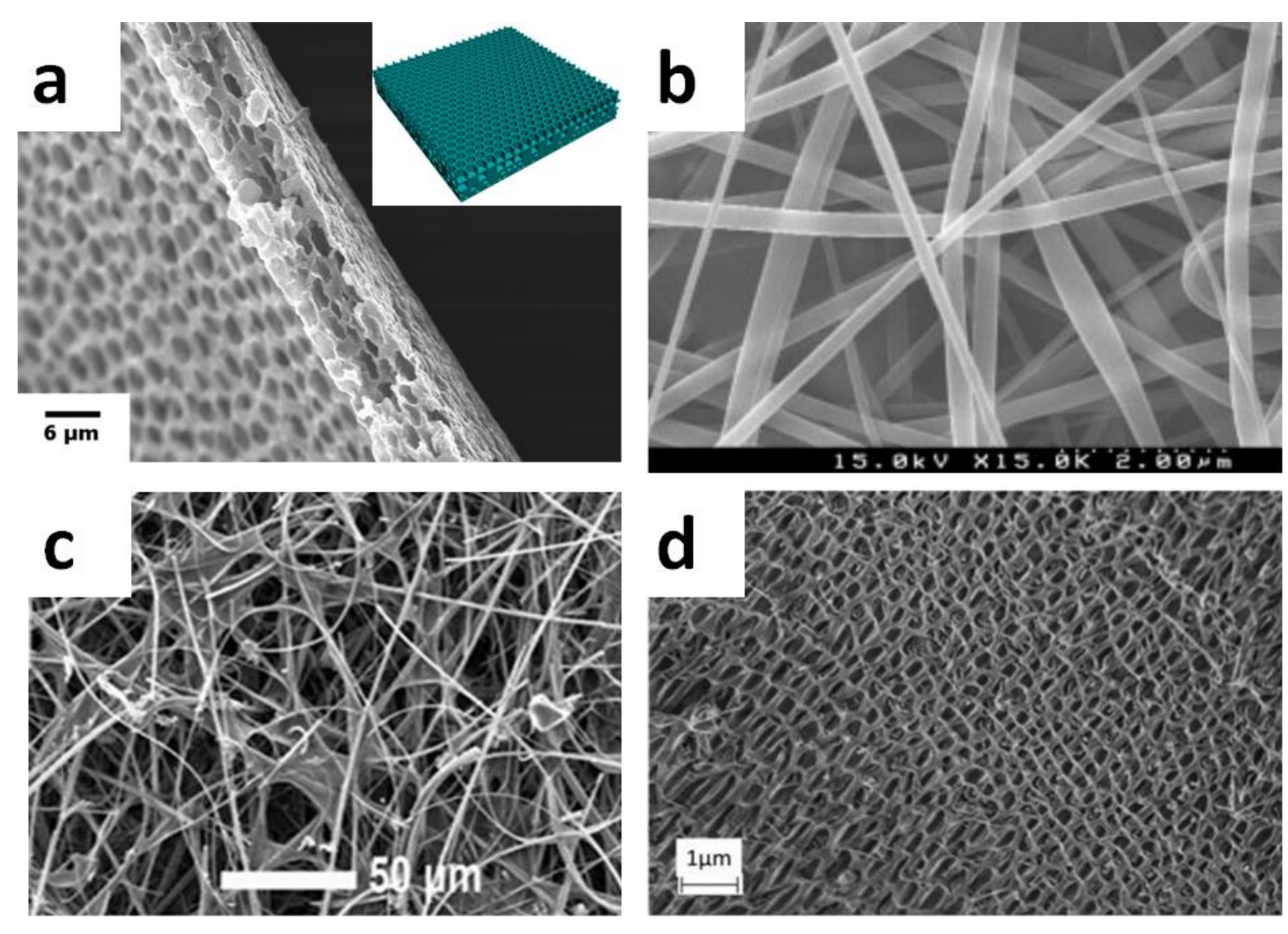

Figure 22. SEM of a PVDF membrane obtained by different methods: a) Breath-Figureure method. Reproduced with permission. ${ }^{[253]}$ Copyright 2014, Nature Publishing Group. ; b) Electrospinning. Reproduced with permission. ${ }^{[254]}$ Copyright 2003, WILEY-VCF Verlag GmbH \& KGaA, Weinheim.; c) Casting PVDF on glass fiber mats. Reproduced with permission. ${ }^{[255]}$ Copyright 2013, Nature Publishing Group.; d) Casting PVDF-HFP on nanoporous alumina layer. Reproduced with permission. ${ }^{[256]}$ Copyright 2013, WILEY-VCH Verlag GmbH \& Co. KGaA, Weinheim.

Among these polymer matrices, PVDF-based gel polymer electrolytes have been applied to the practical production of lithium batteries because of their large dielectric constant $8.4^{[10]}$, high glass transition temperature $\left(-40^{\circ} \mathrm{C}\right)^{[9]}$, good chemical and electrochemical stability and the easiness in the fabrication of spacious films. Plasticizers can increase the content of an amorphous phase and promote segment motion. Li et al. ${ }^{[257]}$ prepared a highly porous polymer membrane based on PVDF-HFP by means of a simple process using urea as the foaming agent. The obtained membrane was soaked in $1 \mathrm{M} \mathrm{LiPF}_{6} / \mathrm{EC}+\mathrm{DMC}+\mathrm{DEC}(1: 1: 1$, wt \%). The 
ionic conductivity of the resultant porous gelled polymer electrolyte arrived at $1.43 \times 10^{-3} \mathrm{~S}$ $\mathrm{cm}^{-1}$ at room temperature, showing a promising application in rechargeable Li batteries. Zhang et al. ${ }^{[253]}$ fabricated a honeycomb-like porous gel polymer electrolyte membrane with $78 \%$ porosity, which resulted in the high electrolyte uptake of $86.2 \mathrm{wt} \%$ for $1 \mathrm{M}$ $\mathrm{LiPF}_{6} / \mathrm{EC}+\mathrm{DMC}(1: 1$, wt \%)(Figure 22a). The electrolyte membranes exhibited a high ionic conductivity of $1.03 \times 10^{-3} \mathrm{~S} \mathrm{~cm}^{-1}$ at room temperature, much higher than the commercial separator. Moreover, the gel polymer electrolyte was also thermally stable up to $350{ }^{\circ} \mathrm{C}$; and the electrochemical stability was up to $5 \mathrm{~V}$. Such good performance is related to porous structure of PVDF or PVDF-HFP matrix. This enhances the ability of electrolyte uptake for a lithium battery. On the other hand, a large amount of electrolytes absorption may lead to poor mechanical strength. Choi et al. ${ }^{[254]}$ produced a PVDF membrane by electrospinning. The latter exhibited high porosity, large surface area, fully interconnected pore structure, and sufficient mechanical strength (Figure 22b). After soaking it in the electrolyte solution, $1 \mathrm{M}$ $\mathrm{LiPF}_{6} / \mathrm{EC}+\mathrm{DMC}(1: 1$, wt \%) mixture, they got a PVDF-based gel electrolyte membrane. The electrolyte showed a high ionic conductivity of $1 \times 10^{-3} \mathrm{~S} \mathrm{~cm}^{-1}$ at room temperature and a broad electrochemical stability window of $4.5 \mathrm{~V}$. The mechanical strength was further enhanced by electrospinning technology. To the same purpose, Zhu et al. ${ }^{[255]}$ developed an economic gel composite membrane based on glass fiber mats; these displayed high safety and good mechanical strength (Figure 22c). The maximum stress and strain came to $14.3 \mathrm{MPa}$ and $1.8 \%$, respectively The gelled membrane exhibited high ionic conductivity $\left(1.13 \times 10^{-3} \mathrm{~S}\right.$ $\mathrm{cm}^{-1}$ ), high Li ion transference number (0.56) and a wide electrochemical window. Similarly, researchers added inorganic fillers, such as $\mathrm{SiO}_{2}, \mathrm{Al}_{2} \mathrm{O}_{3}, \mathrm{TiO}_{2}$ or $\mathrm{MgO}$, etc. to improve mechanical strength and electrochemical properties. Tu et al. ${ }^{[256]}$ prepared a dendrite-free polymer/ceramic composite electrolyte using porous $\mathrm{Al}_{2} \mathrm{O}_{3}$ films and PVDF (Figure 22d). The electrolyte demonstrated excellent mechanical strength and good ionic conductivity. Electrolyte membranes with strong shear modulus can suppress Li dendrite growth. ${ }^{[12]}$ In 
addition to the mechanical strength, another problem of PVDF or PVDF-HFP electrolytes is the interfacial instability against $\mathrm{Li}$ metal anode. Walkowiak et al. ${ }^{[258]}$ studied on the application of different surface modified $\mathrm{SiO}_{2}$ as inorganic fillers for PVDF-HFP based gel electrolytes.

PMMA, PVC and PAN can also be used to prepare gel polymer electrolytes. Each polymer matrix has its advantage, but cannot fulfill all the requirements for the best cell performance. Blending, copolymerization and crosslinking are the strategies to fabricate an electrolyte with all needed advantages.

\subsubsection{Quasi solid electrolytes}

Besides inorganic-based, polymer-based and gel polymer-based electrolytes, some composite systems with liquid electrolytes have also been used as solid electrolytes in batteries. These systems can be called as quasi-solid electrolytes.

Gong et al. ${ }^{[259]}$ developed an electrolyte membrane fabricated by biopolymer of lignin, then activated it by immersion in liquid electrolytes. Before $100{ }^{\circ} \mathrm{C}$, the electrolyte did not not loss weight and was thermally stable. It showed a high ionic conductivity of $3.73 \times 10^{-3} \mathrm{~S} \mathrm{~cm}^{-1}$ at room temperature and a high $\mathrm{Li}$ ion transference number of 0.85 . The electrolyte was compatible with lithium metal anode and had a wide electrochemical window of up to $7.5 \mathrm{~V}$. $\mathrm{Li}$ et al. ${ }^{[11]}$ reported a solid electrolyte based on nanoporous graphene-analogues $\mathrm{g}-\mathrm{BN}$ nanosheets confining ionic liquids. The amount of ILs was as much as 10 times of the host's weight. These nanosheets demonstrated high ionic conductivity of $3.85 \times 10^{-3} \mathrm{~S} \mathrm{~cm}^{-1}$ at $25^{\circ} \mathrm{C}$, even $2.32 \times 10^{-4} \mathrm{~S} \mathrm{~cm}^{-1}$ at $-20{ }^{\circ} \mathrm{C}$. Similarly, ILs electrolytes were filled in mesoporous silica, and the materials could also exhibit good Li ion transference number of $>0.8$ and an electrochemical window of $>5 \mathrm{~V} \cdot{ }^{[260]} \mathrm{Wu}$ et al. ${ }^{[261]}$ presented a $\mathrm{Ti}(\mathrm{OH})_{4}$ sol electrolyte prepared via a nonaqueous self-assembly sol-gel process, in which ionic liquid electrolyte was immobilized within an inorganic gel (Figure 23a,b). Batteries using $\mathrm{LiFePO}_{4}$ cathodes and 
ionogel electrolytes offered a capacity of $150 \mathrm{mAh} \mathrm{g}^{-1}$ for over 300 cycles, and even at a $2 \mathrm{C}$ rate, the capacity still stayed above $98 \mathrm{mAh} \mathrm{g}^{-1}$. The electrolyte exhibited a liquid-like ionic conductivity above $1 \times 10^{-3} \mathrm{~S} \mathrm{~cm}^{-1}$ at room temperature. Later, Wu's group ${ }^{[262]}$ developed a silica sol electrolyte and a solid-state Li-ion full cell technology. Solid-state full cells $\left(\mathrm{LiFePO}_{4}, \mathrm{LiCoO}_{2}, \mathrm{LiCo}_{1 / 3} \mathrm{Ni}_{1 / 3} \mathrm{Mn}_{1 / 3} \mathrm{O}_{2}\right.$ as cathodes, and MCMB as anode) all delivered high specific capacities, long cycling stability, and excellent high-temperature performances (Figure 23c,d). The silica sol electrolyte could also be synthesized by organically modified silica. $^{[263]}$

a

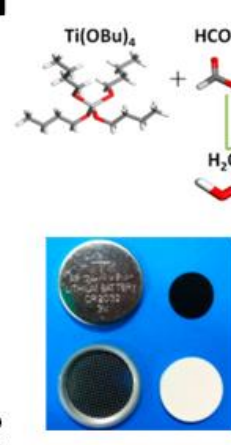

C

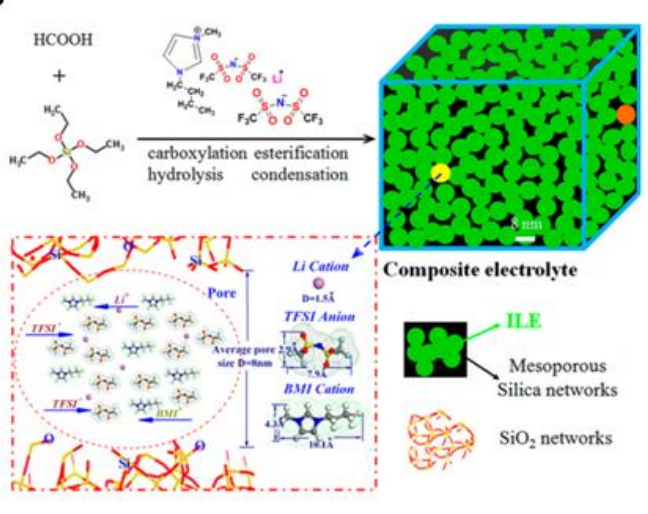

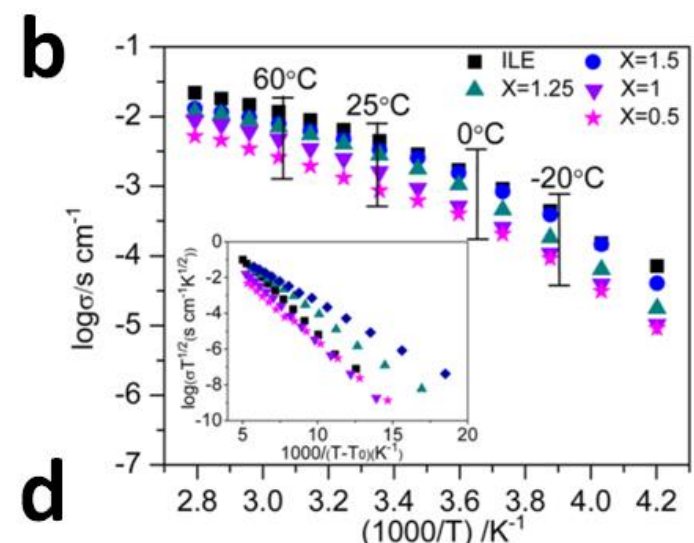

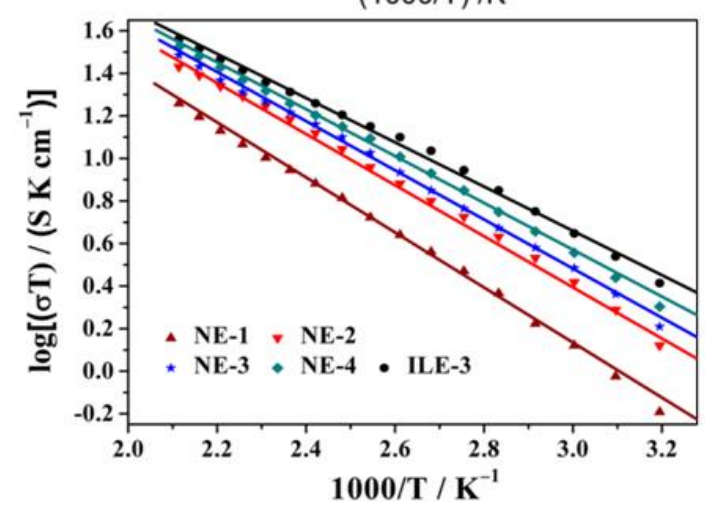

Figure 23. a) Sol-gel reaction of tetrabutyl titanate (TBOT) with formic acid in the solution of $1 \mathrm{M}$ LiTFSI-EMITFSI, b) Arrhenius plots of the ionic conductivity of ILE (1 M LiTFSI-[EMI][TFSI]) and IGE containing different molar ratios of EMITFSI/TBOT $(\mathrm{X}=0.5$, $\mathrm{X}=1, \mathrm{X}=1.25$, and $\mathrm{X}=1.5$ ) as a function of temperature. Inset: VTF fitting curves. Reproduced with permission. ${ }^{[261]}$ Copyright 2016, American Chemical Society. c) The synthetic route and structural composition of the $\mathrm{SiO}_{2} / \mathrm{BMITFSI} / \mathrm{LiTFSI}$ nanocomposite 
electrolytes. d) Arrhenius plots of ionic conductivity of the ILE-3 and NEs containing different molar ratios of BMITFSI/TEOS $(X=0.5, X=1, X=1.5$, and $X=2)$ as a function of temperature. Reproduced with permission. ${ }^{[262]}$ Copyright 2016, American Chemical Society.

\subsection{Ionic Liquids in solid electrolytes}

\subsubsection{Ionic liquids in solid electrolytes}

Polymer electrolytes usually possess low ionic conductivity at room temperature. The addition of plasticizer and solvent can enhance their room temperature ionic conductivity. Ionic liquids can be used as a kind of plasticizer or solvent in solid/gel electrolyte systems, with no volatile and no flammable properties. Interactions between PEO and different ionic liquids can be characterized by hard and soft acid and base theory. ${ }^{[264]}$ EO segments in PEO matrix are hard base. ILs with hard cations show good miscibility with PEO, such as imidazolium groups; conversely, pyrrolidinium groups show poor miscibility. Shin et al. ${ }^{[265]}$ added PYR 13 TFSI into PEO$_{20}$-LiTFSI to form an IL-based solid polymer electrolyte. The composite electrolyte had an ionic conductivity of $\sim 10^{-4} \mathrm{~S} \mathrm{~cm}^{-1}$ at $20{ }^{\circ} \mathrm{C}$. Fisher et al. ${ }^{[266]}$ prepared a solid polymer electrolyte by adding triethyl sulfonium bis(trifluorosulfonyl)imide ( $\mathrm{S}_{2}$ TFSI) into $\mathrm{PEO}_{20}$-LiTFSI. The hybrid electrolyte possessed a sufficient ionic conductivity, $1.17 \times 10^{-4} \mathrm{~S} \mathrm{~cm}^{-1}$ at $0{ }^{\circ} \mathrm{C}$, and $1.20 \times 10^{-3} \mathrm{~S} \mathrm{~cm}^{-1}$ at $25^{\circ} \mathrm{C}$. At the temperature of the human body $\left(\sim 37{ }^{\circ} \mathrm{C}\right)$, ionic conductivity of the hybrid electrolyte system approached to $1 \times 10^{-2} \mathrm{~S} \mathrm{~cm}^{-1}$. The system demonstrated reversible cathodic stability, up to $4.5 \mathrm{~V}$, and long term cycling stability against metallic lithium. Susan et al. ${ }^{[267]}$ exploited a high ionic conductivity of ionic liquid-based gel polymer electrolyte. In situ free radical polymerization of compatible vinyl monomers at room temperature ionic liquid, 1-ethyl-3-methyl imidazolium bis(trifluoromethane sulfonyl)imide (EMITFSI), afforded a novel series of polymer electrolytes. Polymer gels obtained by the polymerization of methyl methacrylate (MMA) in EMITFSI with a small amount of a cross-linker could give a self-standing, flexible, and 
optically-clear film. And the ionic conductivity reached a value of approximately $10^{-2} \mathrm{~S} \mathrm{~cm}^{-1}$ at ambient temperature.

\subsubsection{Poly ionic liquid based solid electrolytes}

Polymerized or poly(ionic liquids) are polymers derived from ionic liquids. In the structure of poly(ionic liquids), either the cations or anions are participated within the backbone of the matrix. ${ }^{[264]}$ Poly(diallydimethylammonium)TFSI (PPYR ${ }_{11}$ TFSI) cooperated with PYR 14 TFSI and LiTFSI was exploited by Pont et al. ${ }^{[268,269]}$ The research showed that higher ionic liquid content had led to higher ionic conductivity. The highest ionic conductivity of $5 \times 10^{-4} \mathrm{~S} \mathrm{~cm}^{-1}$ was found at the ionic liquid content of $60 \mathrm{wt} \%$ and temperature of $40{ }^{\circ} \mathrm{C}$. A series of guanidinium polymeric ionic liquid (PIL) electrolyte membranes combining different anions, such as $\mathrm{BF}_{4}^{-}, \mathrm{PF}_{6}{ }^{-}, \mathrm{ClO}_{4}{ }^{-}$and TFSI, were synthesized through copolymerization or anion exchange processes. ${ }^{[270]}$ Specifically, the $\mathrm{BF}_{4}^{-}$anode possessed the best thermal stability; the TFSI anode showed the lowest $T_{\mathrm{g}}$ and enhanced ionic conductivity. Pyrrolidinium based poly(ionic liquid) (PIL) electrolytes with poly (ethylene glycol) (PEG) side chains was reported by Döbbelin et al. ${ }^{[271]}$ The obtained electrolyte displayed very good ionic conductivities, in the optimal case of up to $2.4 \times 10^{-3} \mathrm{~S} \mathrm{~cm}^{-1}$ at $25{ }^{\circ} \mathrm{C}$ and $1.02 \times 10^{-2} \mathrm{~S}$ $\mathrm{cm}^{-1}$ at $100{ }^{\circ} \mathrm{C}$. A PIL-LiTFSI-PYR ${ }_{13}$ TFSI-SiO $_{2}$ electrolyte membrane was found to be chemically stable even at $80{ }^{\circ} \mathrm{C}$ in contact with lithium metal anode and thermally stable up to $320{ }^{\circ} \mathrm{C} .{ }^{[272]}$ Particularly, LMBs using the quaternary polymer electrolytes exhibited high lithium ion conductivity at high temperature, wide electrochemical stability window, low time-storage interfacial resistance values and good lithium stripping/plating performance. Even at $80{ }^{\circ} \mathrm{C}$, LMBs were capable to deliver $140 \mathrm{mAh} \mathrm{g}^{-1}$ at $0.1 \mathrm{C}$ with good capacity retention. Kuo et al. ${ }^{[273]}$ used an oligomeric ionic liquid to synthesize a PVDF-HFP based gel polymer electrolyte (Figure 24). The gel polymer electrolyte showed a low interfacial resistance. The electrolyte possessed high ionic conductivities of $2.0 \times 10^{-3} \mathrm{~S} \mathrm{~cm}^{-1}$ at $30{ }^{\circ} \mathrm{C}$ and 
$6.6 \times 10^{-3} \mathrm{~S} \mathrm{~cm}^{-1}$ at $80{ }^{\circ} \mathrm{C}$, respectively, though the liquid electrolyte uptake was low $(<50 \%)$.

These two factors resulted in high cell capacity under different charge/discharge rates.

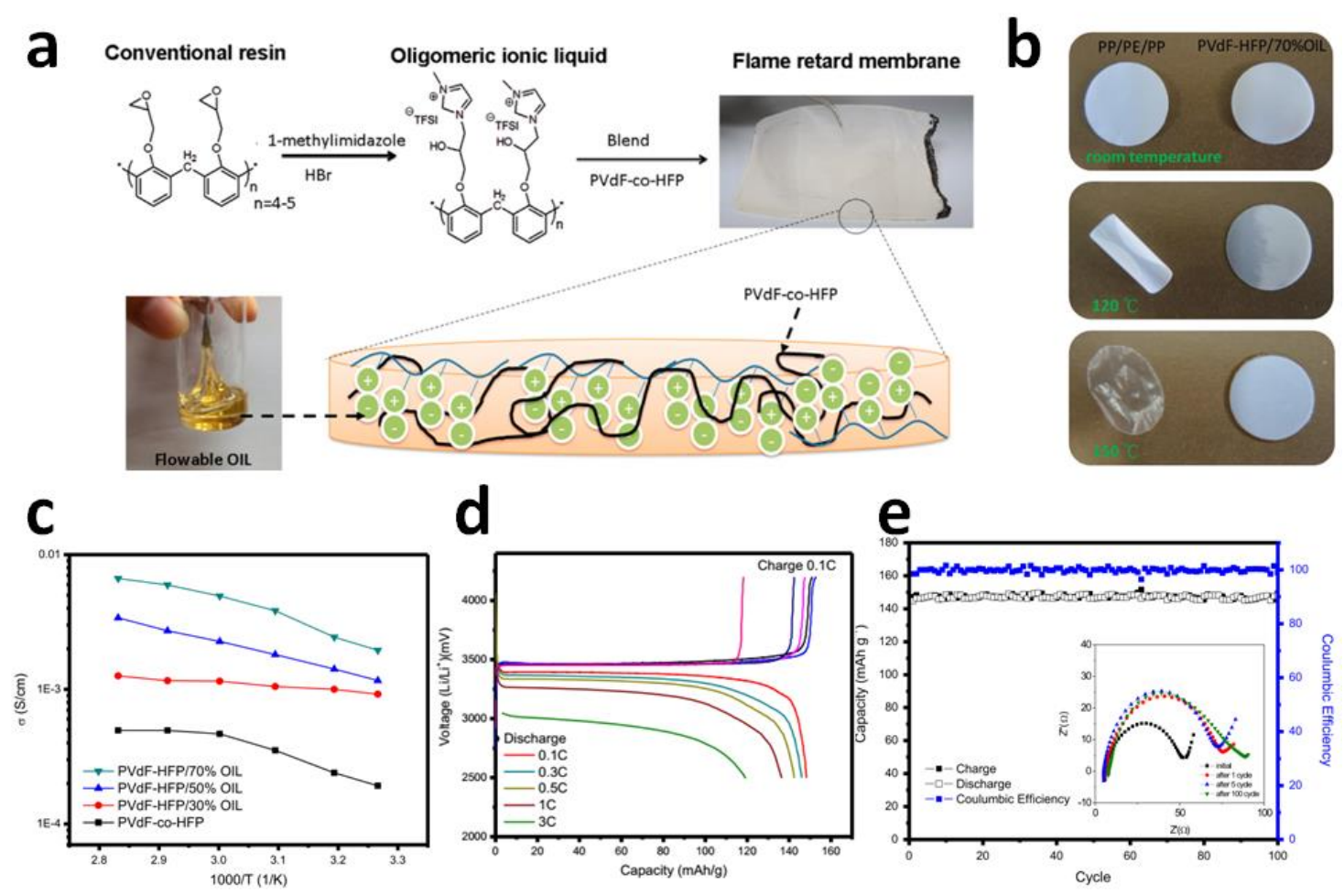

Figure 24. a) Preparation of a PVDF-HFP/X\%OIL membrane and its scheme; b) Thermal and dimensional stability of the PVDF-HFP/70\%OIL tested at various temperatures. c) Ionic conductivity of the electrolyte membrane at different OIL contents tested at various temperatures. d) Charge-discharge profiles of Li/PVDF-HFP/70\%OIL/LiFePO 4 battery tests at various $\mathrm{C}$ rates. e) Cyclic performance of $\mathrm{Li} / \mathrm{PVDF}-\mathrm{HFP} / 70 \% \mathrm{OIL} / \mathrm{LiFePO}_{4}$ at a constant current density of 0.5 C. The inset is EIS before and after charge-discharge. Reproduced with permission. ${ }^{[273]}$ Copyright 2016, Elsevier B.V.

Thus, we have provided an extensive overview of solid state electrolytes for lithium batteries. The characteristics of these electrolytes are summarized in Table 1.

Table 1. Characteristics of solid state electrolytes used for lithium batteries 


\begin{tabular}{|c|c|c|c|c|}
\hline Electrolyte & $\begin{array}{l}\text { Typical } \\
\text { example }\end{array}$ & $\begin{array}{l}\text { Ionic } \\
\text { conductivity } \\
\left.\mathrm{cm}^{-1}\right)\end{array}$ & Advantages & Limitations \\
\hline Crystalline & $\begin{array}{l}\text { Perovskite, } \\
\text { NASICON, } \\
\text { LISICON, } \\
\text { garnet }\end{array}$ & $10^{-5} \sim 10^{-3}$ & $\begin{array}{l}\text { High chemical and } \\
\text { electrochemical } \\
\text { stability, high oxidation } \\
\text { voltage, high } \\
\text { mechanical strength }\end{array}$ & $\begin{array}{l}\text { inelastic, expensive } \\
\text { for large-scale } \\
\text { production }\end{array}$ \\
\hline $\begin{array}{l}\text { Amorphous } \\
\text { Thio-LISIC }\end{array}$ & $\begin{array}{l}\mathrm{Li}_{2} \mathrm{~S}-\mathrm{P}_{2} \mathrm{~S}_{5} \\
\mathrm{Li}_{10} \mathrm{GeP}_{2} \mathrm{~S}_{12}\end{array}$ & $\begin{array}{l}10^{-8} \sim 10^{-3} \\
10^{-3}\end{array}$ & $\begin{array}{l}\text { High ionic conductivity } \\
\text { High } \mathrm{Li}^{+} \text {transference }\end{array}$ & $\begin{array}{l}\text { Sensitive to moisture } \\
\text { High operation }\end{array}$ \\
\hline $\mathrm{ON}$ & & & $\begin{array}{l}\text { numbers, stable against } \\
\text { lithium metal anode and } \\
\text { thermal stability }\end{array}$ & $\begin{array}{l}\text { temperature, low } \\
\text { conductivity, poor } \\
\text { rate capability, }\end{array}$ \\
\hline LIPON & $\begin{array}{l}\mathrm{Li}_{0.99} \mathrm{PO}_{2.55} \mathrm{~N}_{0.3} \\
0\end{array}$ & $10^{-7}$ & $\begin{array}{l}\text { Stable with lithium } \\
\text { metal anode and } \\
\text { cathode materials }\end{array}$ & $\begin{array}{l}\text { Expensive for } \\
\text { large-scale } \\
\text { production }\end{array}$ \\
\hline $\begin{array}{l}\text { Glass-cera } \\
\text { mic }\end{array}$ & LATP, LAGP & $10^{-4} \sim 10^{-3}$ & $\begin{array}{l}\text { Lower grain-boundary } \\
\text { resistance, }\end{array}$ & $\begin{array}{l}\text { low oxidation } \\
\text { stability }\end{array}$ \\
\hline $\begin{array}{l}\text { Solid } \\
\text { polymer }\end{array}$ & PEO & $\begin{array}{l}10^{-4} \sim 10^{-3} \\
\text { (elevated } \\
\text { temperature } \\
\text { ) }\end{array}$ & $\begin{array}{l}\text { Flexible, stable with } \\
\text { lithium anode, easy to } \\
\text { be fabricated }\end{array}$ & $\begin{array}{l}\text { unstable at elevated } \\
\text { temperature, low } \\
\text { oxidation voltage }\end{array}$ \\
\hline $\begin{array}{l}\text { Gel } \\
\text { polymer }\end{array}$ & $\begin{array}{l}\text { PVDF, } \\
\text { PVDF-HFP }\end{array}$ & $10^{-3}$ & $\begin{array}{l}\text { Higher conductivity } \\
\text { than solid polymer }\end{array}$ & $\begin{array}{l}\text { Evaporation, still } \\
\text { leakage, poorer }\end{array}$ \\
\hline
\end{tabular}




$$
\begin{aligned}
& \text { mechanically stable than organic liquid } \\
& \text { electrolytes }
\end{aligned}
$$

Ionic liquid EMimTFSI, $10^{-6} \sim 10^{-3}$ High conductivity, expensive for \& $\quad$ PYR 13 TFSI, large capacity, no vapor large-scale



d ionic non-flammability of

liquid electrolytes

\section{Summary and Perspectives}

The principal issues facing the development of lithium-based batteries for the vehicle industry are safety, rate capacity and energy density. To improve the safety of an electrolyte, the inflammable solvents, like ionic liquids and sulfone-based solvents, have been developed. To improve the energy density, high voltage electrolytes have been designed through the inclusion of new high voltage solvents and additives. In this review, four aspects of electrolytes based on current investigations, including (i) high voltage solvents, (ii) additives, (iii) ionic liquids, (iv) and superconcentrated salt strategy have been discussed. These new components always have one or more desirable functions toward the improvement of battery performance. However, they may simultaneously introduce some negative impacts. For example, the completely new electrolyte solvents, like sulfone-based solvents and the ionic liquids with high anodic stability and inflammability, still confront severe capacity fading and inferior rate performance because of their high viscosity, poor wettability with a separator and poor SEI forming ability on the graphite anode. Blending the traditional carbonate solvents with the new high voltage solvents can mitigate these restrictions. A working mechanism of the high voltage additives is their sacrificial decomposition to form a protective film on the electrode surface which can inhibit the dissolution of the cathode materials and the oxidative decomposition of the solvents. A small amount of additive can significantly improve the 
battery performance, so the development of additives is essential for the next generation high voltage LIBs.

The superconcentrated salt strategy is a new route combining various useful functionalities, such as improved reductive and oxidative stability owing to the peculiar structure at a high salt concentration. For example, the superconcentrated salt strategy can improve the reductive and oxidative stability of acetonitrile and the ethers, respectively, and to expand the stable range of solvents in lithium-based batteries. In addition, the superconcentrated salt strategy can also improve the Al-anti corrosion ability and the electrode reaction kinetics to allow the electrolite not to rely on $\mathrm{LiPF}_{6}$ salt for the passivation of aluminum current collector and attaining the fast charging process. As a result, a lot of lithium salts and aprotic solvents can be used in LIBs to diversity the electrolyte design. Noticeably high rate capability and high voltage tolerant ability have been demonstrated in the laboratories worldwide. However, there are still several problems to be overcome before the practical application of the superconcentrated salts. These are high viscosity, poor wettability with the separator and high cost (mostly because of large requirements for lithium salts). Thus these studies still have a long way to go before their final practical accomplishment. Nonetheless, such fundamental studies are still significantl and meaningful. They can give a guide to rebuild the composition of the electrolyte through optimization, such as smart selection of solvents, lithium salts and concentration.

The solid state electrolyte is the key component in advanced solid state lithium batteries. High ionic conductivity, good charging/discharging performances, decent mechanical strength to suppress lithium dendrite growth, high chemical and thermal stability are important properties that should be highligted.

Inorganic solid electrolytes include NASICON-type, LISICON-type, perovskite-type, garnet-type and sulfide-based glass-ceramics. Among these electrolytes, sulfides have the highest ionic conductivities, but they are sensitive to humidity and chemically unstable. 
Garnet-type and perovskite-type inorganic solid electrolytes are particularly becoming attractive in recent years due to their high ionic conductivities and chemical stabilities, but these electrolytes show poor interfacial compatibility with electrodes. To overcome these challenges, three possible directions are proposed: (1) increasing the conductivity of the solid electrolytes; (2) optimizing their structure; (3) using interfacial engineering to decrease the interfacial resistance and to stabilize the lithium metal anode.

Solid polymer electrolytes comprise polymer organic frameworks, lithium salts and fillers. PEO-based polymer electrolytes possess low ionic conductivity at room temperature, which is attributed to the crystallization of a PEO phase. Strategies of blending, crosslinking, copolymerization and adding fillers can suppress crystallization and increase ionic conductivity at different levels. Even so, the ionic conductivities of solid polymer electrolytes are still two orders of magnitude lower than those of solid inorganic electrolytes. Meanwhile, PEO-based polymer electrolytes show instabilities at elevated temperature and low oxidation voltage. Further research should be focused on the modification of PEO chains and the development of new structures.

Gel polymer electrolytes are formed by adding plasticizers or solvents in solid polymer electrolytes. The plasticizers or solvents can be ether solvents, liquid oligomers or ionic liquids. PVDF and PVDF-HFP are elite candidates as polymer matrixes for gel polymer electrolytes. These electrolytes exhibit good performance in electrochemical measurements and cell operations, which is due to the predominant liquid phase. On the one hand, organic liquids are inflammable and they increase the safety risk of lithium batteries in operation. On the other hand, too much organic liquids can decrease mechanical strength of gel polymer matrices and cause short circuiting under lithium dendrite penetration through the gel polymer electrolytes. The addition of fillers can enhance the mechanical strength of the electrolytes and nonflammable solvents, like ionic liquids, and to ensure the safe use of lithium batteries. 
Polymer electrolytes, based on ionic liquids and polymerized ionic liquids, exhibit high ionic conductivity and high interfacial stability against lithium metal anode. The good properties make these electrolytes promising polymer electrolytes in future LIBs. Overall, researchers have achieved a great progress in the design of solid electrolytes and development of solid state lithium batteries. In the future, the inorganic solid electrolytes may be applied in power batteries for vehicles and large scale power grids. In addition, the polymer electrolytes may be assembled in flexible batteries for flexible screens, wearable devices and other $3 \mathrm{C}$ products.

\section{Acknowledgements}

This work was supported by National Natural Science Foundation of China (Nos. 91534109 and 21276257), the "Strategic Priority Research Program" of the Chinese Academy of Sciences (No. XDA09010103) and National Key Projects for Fundamental Research and Development of China (No. 2016YFB0100104). S. Chen, K. Wen and J. Fan contributed equally to this work.

D. Golberg is grateful to the Australian Research Council for granting a Laureate Fellowship.

Received: ((will be filled in by the editorial staff))

Revised: ((will be filled in by the editorial staff)) Published online: ((will be filled in by the editorial staff))

\section{References}

[1] B. L. Ellis, P. Knauth, T. Djenizian, Adv. Mater. 2014, 26, 3368.

[2] J. B. Goodenough, K. S. Park, J. Am. Chem. Soc. 2013, 135, 1167.

[3] J.-W. Jung, W.-H. Ryu, J. Shin, K. Park, I.-D. Kim, ACS Nano 2015, 9, 6717.

[4] N. Liu, Z. D. Lu, J. Zhao, M. T. McDowell, H. W. Lee, W. T. Zhao, Y. Cui, Nat. Nanotechnol. 2014, 9, 187.

[5] X. Su, Q. Wu, J. Li, X. Xiao, A. Lott, W. Lu, B. W. Sheldon, J. Wu, Adv. Energy Mater. 2014, 4, 1300882.

[6] K. Xu, Chem. Rev. 2014, 114, 11503.

[7] A. Manthiram, X. Yu, S. Wang, Nature Reviews Materials 2017, 2, 16103.

[8] C. Sun, J. Liu, Y. Gong, D. P. Wilkinson, J. Zhang, Nano Energy 2017, 33, 363.

[9] L. Long, S. Wang, M. Xiao, Y. Meng, J. Mater. Chem. A 2016, 4, 10038.

[10] Q. Li, J. Chen, L. Fan, X. Kong, Y. Lu, Green Energy Environ. 2016, 1, 18.

[11] X. Fu, D. Yu, J. Zhou, S. Li, X. Gao, Y. Han, P. Qi, X. Feng, B. Wang, CrystEngComm 2016, 18, 4236.

[12] M. D. Tikekar, S. Choudhury, Z. Tu, L. A. Archer, Nature Energy 2016, 1, 16114.

[13] V. Etacheri, R. Marom, R. Elazari, G. Salitra, D. Aurbach, Energ. Environ. Sci. 2011, 4, 3243 . 
[14] B. Scrosati, J. Hassoun, Y. K. Sun, Energ. Environ. Sci. 2011, 4, 3287.

[15] Y. Yamada, A. Yamada, J. Electrochem. Soc. 2015, 162, A2406.

[16] Y. Liu, S. Fang, P. Shi, D. Luo, L. Yang, S.-i. Hirano, J. Power Sources 2016, 331, 445.

[17] Y. Liu, S. Fang, D. Luo, L. Yang, S.-i. Hirano, J. Electrochem. Soc. 2016, 163, A1951.

[18] Z. Zeng, B. Wu, L. Xiao, X. Jiang, Y. Chen, X. Ai, H. Yang, Y. Cao, J. Power Sources 2015, 279, 6 .

[19] Y. Wang, W.-H. Zhong, Chemelectrochem 2015, 2, 22.

[20] X. Sun, X. Zhu, X. Yang, J. Sun, Y. Xia, D. Yang, Green Energy Environ. 2017, DOI: 10.1016/j.gee.2017.01.008.

[21] X. Zhang, X.-G. Wang, Z. Xie, Z. Zhou, Green Energy Environ. 2016, 1, 4.

[22] Y. Lu, Green Energy Environ. 2016, 1, 3.

[23] W. Li, S. Chen, J. Yu, D. Fang, B. Ren, S. Zhang, Green Energy Environ. 2016, 1, 91.

[24] Y. Luo, T. L. Lu, Y. X. Zhang, L. Q. Yan, J. Y. Xie, S. S. Mao, J. Power Sources 2016, $323,134$.

[25] A. Manthiram, J. Phys. Chem. Lett. 2011, 2, 176.

[26] K. Xu, Chem. Rev. 2004, 104, 4303.

[27] G. M. Zhou, F. Li, H. M. Cheng, Energ. Environ. Sci. 2014, 7, 1307.

[28] M. D. Bhatt, C. O'Dwyer, Chem. Phys. Lett. 2015, 618, 208.

[29] H. Zhao, S.-J. Park, F. Shi, Y. Fu, V. Battaglia, P. N. Ross, Jr., G. Liu, J. Electrochem. Soc. 2014, 161, A194.

[30] M. D. Bhatt, M. Cho, K. Cho, J. Solid State Electrochem. 2012, 16, 435.

[31] C. X. Wang, H. Nakamura, H. Komatsu, H. Noguchi, M. Yoshio, H. Yoshitake, Denki Kagaku 1998, 66, 286.

[32] M. D. Bhatt, M. Cho, K. Cho, Appl. Surf. Sci. 2010, 257, 1463.

[33] B. Jiang, V. Ponnuchamy, Y. N. Shen, X. M. Yang, K. J. Yuan, V. Vetere, S. Mossa, I. Skarmoutsos, Y. F. Zhang, J. R. Zheng, J. Phys. Chem. Lett. 2016, 7, 3554.

[34] D. Ortiz, I. J. Gordon, S. Legand, V. Dauvois, J. P. Baltaze, J. L. Marignier, J. F. Martin, J. Belloni, M. Mostafavi, S. Le Caer, J. Power Sources 2016, 326, 285.

[35] S. Das, A. Ghosh, J. Phys. D Appl. Phys. 2016, 49.

[36] J. Inamoto, T. Fukutsuka, K. Miyazaki, T. Abe, Chemistryselect 2017, 2, 2895.

[37] E. G. Leggesse, R. T. Lin, T.-F. Teng, C.-L. Chen, J.-C. Jiang, J. Phys. Chem. A 2013, $117,7959$.

[38] M. J. Boyer, L. Vilciauskas, G. S. Hwang, Phys. Chem. Chem. Phys. 2016, 18, 27868.

[39] S. S. Zhang, K. Xu, T. R. Jow, J. Electrochem. Soc. 2002, 149, A586.

[40] T. Doi, Y. Shimizu, M. Hashinokuchi, M. Inaba, J. Electrochem. Soc. 2017, 164, A6412.

[41] H. Zhou, K. Xiao, J. Li, J. Power Sources 2016, 302, 274.

[42] M. Dahbi, F. Ghamouss, F. Tran-Van, D. Lemordant, M. Anouti, J. Power Sources 2011, 196, 9743.

[43] D. Ensling, M. Stjerndahl, A. Nyten, T. Gustafsson, J. O. Thomas, J. Mater. Chem. 2009, 19, 82.

[44] Y. Xie, H. Xiang, P. Shi, J. Guo, H. Wang, J. Membrane Sci. 2017, 524, 315.

[45] M. Iliksu, A. Khetan, S. Yang, U. Simon, H. Pitsch, D. U. Sauer, ACS Appl. Mater. Inter. 2017, DOI: 10.1021/acsami.7b03592.

[46] J. Hassoun, B. Scrosati, J. Electrochem. Soc. 2015, 162, A2582.

[47] X. R. Lin, M. Salari, L. M. R. Arava, P. M. Ajayan, M. W. Grinstaff, Chem. Soc. Rev. 2016, 45, 5848.

[48] B. Flamme, G. R. Garcia, M. Weil, M. Haddad, P. Phansavath, V. Ratovelomanana-Vidal, A. Chagnes, Green Chemistry 2017, 19, 1828.

[49] L. Xue, S.-Y. Lee, Z. Zhao, C. A. Angell, Journal of Power Sources 2015, 295, 190. 
[50] M. Hu, X. L. Pang, Z. Zhou, J. Power Sources 2013, 237, 229.

[51] A. Abouimrane, I. Belharouak, K. Amine, Electrochem. Commun. 2009, 11, 1073.

[52] K. Xu, C. A. Angell, J. Electrochem. Soc. 2002, 149, A920.

[53] N. Shao, X. G. Sun, S. Dai, D. E. Jiang, J. Phys. Chem. B 2011, 115, 12120.

[54] J. Xia, J. R. Dahn, J. Power Sources 2016, 324, 704.

[55] C. C. Su, M. N. He, P. Redfern, L. A. Curtiss, C. Liao, L. Zhang, A. K. Burrell, Z. C. Zhang, Chemelectrochem 2016, 3, 790.

[56] L. G. Xue, S. Y. Lee, Z. F. Zhao, C. A. Angell, J. Power Sources 2015, 295, 190.

[57] X.-G. Sun, C. A. Angell, Electrochem. Commun. 2005, 7, 261.

[58] F. Wu, J. Xiang, L. Li, J. Z. Chen, G. Q. Tan, R. J. Chen, J. Power Sources 2012, 202, 322.

[59] L. G. Xue, K. Ueno, S. Y. Lee, C. A. Angell, J. Power Sources 2014, 262, 123.

[60] T. Achiha, T. Nakajima, Y. Ohzawa, M. Koh, A. Yamauchi, M. Kagawa, H. Aoyama, J. Electrochem. Soc. 2009, 156, A483.

[61] G. Q. Ma, L. Wang, J. J. Zhang, H. C. Chen, X. M. He, Y. S. Ding, Prog. Chem. 2016, $28,1299$.

[62] Z. C. Zhang, L. B. Hu, H. M. Wu, W. Weng, M. Koh, P. C. Redfern, L. A. Curtiss, K. Amine, Energ. Environ. Sci. 2013, 6, 1806.

[63] C. Y. Wang, S. H. Tang, X. X. Zuo, X. Xiao, J. S. Liu, J. M. Nan, J. Electrochem. Soc. 2015, 162, A1997.

[64] X. S. Wang, X. W. Zheng, Y. H. Liao, Q. M. Huang, L. D. Xing, M. Q. Xu, W. S. Li, J. Power Sources 2017, 338, 108.

[65] C. Y. Wang, L. Yu, W. Z. Fan, J. W. Liu, L. Z. Ouyang, L. C. Yang, M. Zhu, ACS Appl. Mater. Inter. 2017, 9, 9630.

[66] M. Nagahama, N. Hasegawa, S. Okada, J. Electrochem. Soc. 2010, 157, A748.

[67] E. Nanini-Maury, J. Swiatowska, A. Chagnes, S. Zanna, T. V. Pierre, P. Marcus, M. Cassir, Electrochim. Acta 2014, 115, 223.

[68] Y. Xu, L. Y. Wan, J. L. Liu, L. C. Zeng, Z. G. Yang, J. Alloys Compd. 2017, 698, 207.

[69] C. C. Su, M. He, P. C. Redfern, L. A. Curtiss, I. A. Shkrob, Z. C. Zhang, Energ. Environ. Sci. 2017, 10, 900.

[70] S. S. Zhang, J. Power Sources 2006, 162, 1379.

[71] X. Z. Zheng, W. G. Wang, T. Huang, G. H. Fang, Y. Pan, M. X. Wu, J. Power Sources 2016, 329, 450.

[72] D. Aurbach, Y. Eineli, O. Chusid, Y. Carmeli, M. Babai, H. Yamin, J. Electrochem. Soc. 1994, 141, 603.

[73] W. N. Huang, L. D. Xing, Y. T. Wang, M. Q. Xu, W. S. Li, F. C. Xie, S. G. Xia, J. Power Sources 2014, 267, 560.

[74] S. J. Lee, J. G. Han, Y. Lee, M. H. Jeong, W. C. Shin, M. Ue, N. S. Choi, Electrochim. Acta 2014, 137, 1.

[75] R. Zheng, W. Wang, Y. Dai, Q. Ma, Y. Liu, D. Mu, R. Li, J. Ren, C. Dai, Green Energy Environ. 2016, DOI: 10.1016/j.gee.2016.11.010.

[76] X. Zhang, F. Cheng, J. Yang, J. Chen, Nano Lett. 2013, 13, 2822.

[77] D. Aurbach, B. Markovsky, Y. Talyossef, G. Salitra, H.-J. Kim, S. Choi, J. Power Sources 2006, 162, 780.

[78] J. Liu, A. Manthiram, J. Electrochem. Soc. 2009, 156, A833.

[79] X. L. Xu, S. X. Deng, H. Wang, J. B. Liu, H. Yan, Nano-Micro Lett. 2017, 9, 19.

[80] Y. Zhang, Y. Pan, J. Liu, G. Wang, D. Cao, Chem. Res. Chinese U. 2015, 31, 117.

[81] M. K. Devaraju, T. Quang Duc, H. Hyodo, Y. Sasaki, I. Honma, Sci. Rep. 2015, 5.

[82] J. Ni, H. Wang, L. Gao, L. Lu, Electrochim. Acta 2012, 70, 349.

[83] V. Aravindan, Y. L. Cheah, W. C. Ling, S. Madhavi, J. Electrochem. Soc. 2012, 159, A1435. 
[84] J. L. Allen, T. R. Jow, J. Wolfenstine, J. Power Sources 2011, 196, 8656.

[85] P. Dong, D. Wang, Y. Yao, X. Li, Y. J. Zhang, J. J. Ru, T. Ren, J. Power Sources 2017, $344,111$.

[86] T. Yim, K. S. Kang, J. Mun, S. H. Lim, S. G. Woo, K. J. Kim, M. S. Park, W. Cho, J. H. Song, Y. K. Han, J. S. Yu, Y. J. Kim, J. Power Sources 2016, 302, 431.

[87] S. Kim, M. Kim, I. Choi, J. J. Kim, J. Power Sources 2016, 336, 316.

[88] W. Lu, J. Zhang, J. Xu, X. Wu, L. Chen, ACS Appl. Mater. Inter. 2017, DOI: 10.1021/acsami.7b03024.

[89] M. D. Bhatt, C. O'Dwyer, Curr. Appl. Phys. 2014, 14, 349.

[90] A. M. Haregewoin, E. G. Leggesse, J.-C. Jiang, F.-M. Wang, B.-J. Hwang, S. D. Lin, J. Power Sources 2013, 244, 318.

[91] L. J. Miara, W. D. Richards, Y. E. Wang, G. Ceder, Chem. Mater. 2015, 27, 4040.

[92] P. Jankowski, W. Wieczorek, P. Johansson, J. Mol. Model. 2017, 23, 9.

[93] X. R. Yang, J. H. Li, L. D. Xing, Y. H. Liao, M. Q. Xu, Q. M. Huang, W. S. Li, Electrochim. Acta 2017, 227, 24.

[94] J. H. Li, L. D. Xing, R. Q. Zhang, M. Chen, Z. S. Wang, M. Q. Xu, W. S. Li, J. Power Sources 2015, 285, 360 .

[95] B. Wang, Q. T. Qu, Q. Xia, Y. P. Wu, X. Li, C. L. Gan, T. van Ree, Electrochim. Acta 2008, 54, 816 .

[96] L. Imholt, S. Roser, M. Borner, B. Streipert, B. R. Rad, M. Winter, I. Cekic-Laskovic, Electrochim. Acta 2017, 235, 332.

[97] S. Dalavi, M. Q. Xu, B. Knight, B. L. Lucht, Electrochem. Solid State Lett. 2012, 15, A28.

[98] P. K. Nayak, J. Grinblat, M. Levi, D. Aurbach, J. Electrochem. Soc. 2015, 162, A596.

[99] M. Q. Xu, L. Zhou, Y. N. Dong, Y. J. Chen, J. Demeaux, A. D. MacIntosh, A. Garsuch, B. L. Lucht, Energ. Environ. Sci. 2016, 9, 1308.

[100] J. H. Li, L. P. Zhang, L. Yu, W. Z. Fan, Z. S. Wang, X. R. Yang, Y. L. Lin, L. D. Xing, M. Q. Xu, W. S. Li, J. Phys. Chem. C 2016, 120, 26899.

[101] K. Abe, Y. Ushigoe, H. Yoshitake, M. Yoshio, J. Power Sources 2006, 153, 328.

[102] H. Lee, T. Han, K. Y. Cho, M. H. Ryou, Y. M. Lee, ACS Appl. Mater. Inter. 2016, 8, 21366.

[103] A. Abouimrane, S. A. Odom, H. Tavassol, M. V. Schulmerich, H. M. Wu, R. Bhargava, A. A. Gewirth, J. S. Moore, K. Amine, J. Electrochem. Soc. 2013, 160, A268.

[104] L. Liu, M. Qing, Y. Wang, S. Chen, J. Ind. Eng. Chem. 2015, 31, 599.

[105] J.-N. Lee, G.-B. Han, M.-H. Ryou, D. J. Lee, S. Jongchan, J. W. Choi, J.-K. Park, Electrochim. Acta 2011, 56, 5195.

[106] J. Zhang, J. L. Wang, J. Yang, Y. N. Nuli, Electrochim. Acta 2014, 117, 99.

[107] X. Zheng, T. Huang, Y. Pan, W. Wang, G. Fang, M. Wu, J. Power Sources 2015, 293, 196.

[108] E. Markevich, V. Baranchugov, D. Aurbach, Electrochem. Commun. 2006, 8, 1331.

[109] X. Cao, X. He, J. Wang, H. D. Liu, S. Roser, B. R. Rad, M. Evertz, B. Streipert, J. Li, R. Wagner, M. Winter, I. Cekic-Laskovic, ACS Appl. Mater. Inter. 2016, 8, 25971.

[110] T. Yim, M. S. Kwon, J. Mun, K. T. Lee, Isr. J. Chem. 2015, 55, 586.

[111] G. A. Elia, U. Ulissi, S. Jeong, S. Passerini, J. Hassoun, Energ. Environ. Sci. 2016, 9, 3210 .

[112] F. Wu, Q. Zhu, R. Chen, N. Chen, Y. Chen, L. Li, Electrochim. Acta 2015, 184, 356.

[113] H. Nakagawa, Electrochemistry 2015, 83, 707.

[114] S. N. Chavan, A. Tiwari, T. C. Nagaiah, D. Mandal, Phys. Chem. Chem. Phys. 2016, $18,16116$.

[115] A. Fernicola, F. Croce, B. Scrosati, T. Watanabe, H. Ohno, J. Power Sources 2007, 174, 342. 
[116] Y. Wang, M. C. Turk, M. Sankarasubramanian, A. Srivatsa, D. Roy, S. Krishnan, J. Mater. Sci. 2017, 52, 3719.

[117] X. He, Z. Wang, W. Zhou, X. Jiang, Z. Han, D. Chen, J. Appl. Polym. Sci. 2017, 134.

[118] S. Kazemiabnavi, Z. C. Zhang, K. Thornton, S. Banerjee, J. Phys. Chem. B 2016, 120, 5691.

[119] P. Bonhote, A. P. Dias, N. Papageorgiou, K. Kalyanasundaram, M. Gratzel, Inorg. Chem. 1996, 35, 1168.

[120] P. A. Z. Suarez, C. S. Consorti, R. F. de Souza, J. Dupont, R. S. Goncalves, J. Brazil. Chem. Soc. 2002, 13, 106.

[121] M. IshikawaT. Sugimoto, M. Kikuta, E. Ishiko, Journal name, volume, pages ?????2006.

[122] M. Ishikawa, T. Sugimoto, M. Kikuta, E. Ishiko, M. Kono, J. Power Sources 2006, 162,658 .

[123] M. H. Kowsari, M. Fakhraee, S. Alavi, B. Najafi, J. Chem. Eng. Data 2014, 59, 2834.

[124] S. Seki, Y. Ohno, Y. Kobayashi, H. Miyashiro, A. Usami, Y. Mita, H. Tokuda, M. Watanabe, K. Hayamizu, S. Tsuzuki, M. Hattori, N. Terada, J. Electrochem. Soc. 2007, 154, A173.

[125] Y. Shimizu, K. Fujii, M. Imanari, K. Nishikawa, J. Phys. Chem. B 2015, 119, 12552.

[126] J. H. Lee, J. B. Ryu, A. S. Lee, W. Na, H. S. Yoon, W. J. Kim, C. M. Koo, Electrochim. Acta 2016, 222, 1847.

[127] M. Montanino, M. Moreno, M. Carewska, G. Maresca, E. Simonetti, R. Lo Presti, F. Alessandrini, G. B. Appetecchi, J. Power Sources 2014, 269, 608.

[128] S. Yamaguchi, M. Yoshizawa-Fujita, Y. Takeoka, M. Rikukawa, J. Power Sources 2016, 331, 308.

[129] M. Agostini, S. Brutti, M. A. Navarra, S. Panero, P. Reale, A. Matic, B. Scrosati, Sci. Rep. 2017, 7, 1104.

[130] A. I. Bhatt, P. Kao, A. S. Best, A. F. Hollenkamp, J. Electrochem. Soc. 2013, 160, A1171.

[131] A. I. Bhatt, A. S. Best, J. H. Huang, A. F. Hollenkamp, J. Electrochem. Soc. 2010, 157, A66.

[132] B. B. Yang, C. H. Li, J. H. Zhou, J. H. Liu, Q. L. Zhang, Electrochim. Acta 2014, 148, 39.

[133] K. Ababtain, G. Babu, X. R. Lin, M. T. F. Rodrigues, H. Gullapalli, P. M. Ajayan, M. W. Grinstaff, L. M. R. Arava, ACS Appl. Mater. Inter. 2016, 8, 15242.

[134] A. Lewandowski, A. Swiderska-Mocek, J. Power Sources 2009, 194, 601.

[135] V. Baranchugov, E. Markevich, E. Pollak, G. Salitra, D. Aurbach, Electrochem. Commun. 2007, 9, 796.

[136] K. Kim, Y.-H. Cho, H.-C. Shin, J. Power Sources 2013, 225, 113.

[137] K. Gao, S. D. Li, J. Power Sources 2014, 270, 304.

[138] T. Belhocine, S. A. Forsyth, H. Q. N. Gunaratne, M. Nieuwenhuyzen, P. Nockemann, A. V. Puga, K. R. Seddon, G. Srinivasan, K. Whiston, Phys. Chem. Chem. Phys. 2015, 17, 10398.

[139] L. Fang, Y. F. Hu, J. G. Qi, Y. F. Chen, H. R. Zhang, H. Z. Huang, Electrochim. Acta 2014, 133, 440.

[140] M. Shukla, H. Noothalapati, S. Shigeto, S. Saha, Vib. Spectrosc 2014, 75, 107.

[141] T. Dong, L. Zhang, S. M. Chen, X. M. Lu, S. J. Zhang, Ionics 2015, 21, 2109.

[142] A. Lewandowski, A. Swiderska-Mocek, I. Acznik, Electrochim. Acta 2010, 55, 1990.

[143] N. Bucher, S. Hartung, M. Arkhipova, D. Yu, P. Kratzer, G. Maas, M. Srinivasan, H. E. Hoster, RSC Adv. 2014, 4, 1996.

[144] M. A. Navarra, K. Fujimura, M. Sgambetterra, A. Tsurumaki, S. Panero, N. Nakamura, H. Ohno, B. Scrosati, ChemSusChem 2017, DOI: 10.1002/cssc.201700346. 
[145] G. B. Appetecchi, M. Montanino, M. Carewska, M. Moreno, F. Alessandrini, S. Passerini, Electrochim. Acta 2011, 56, 1300.

[146] F. Trequattrini, O. Palumbo, S. Gatto, G. B. Appetecchi, A. Paolone, Adv. Chem. 2016, 2016, 1 .

[147] J. H. Wang, Y. Yamada, K. Sodeyama, C. H. Chiang, Y. Tateyama, A. Yamada, Nat. Commun. 2016, 7.

[148] Y. Yamada, C. H. Chiang, K. Sodeyama, J. H. Wang, Y. Tateyama, A. Yamada, Chemelectrochem 2015, 2, 1687.

[149] Y. Yamada, K. Usui, C. H. Chiang, K. Kikuchi, K. Furukawa, A. Yamada, ACS Appl. Mater. Inter. 2014, 6, 10892.

[150] Y. Yamada, K. Furukawa, K. Sodeyama, K. Kikuchi, M. Yaegashi, Y. Tateyama, A. Yamada, J. Am. Chem. Soc. 2014, 136, 5039.

[151] Y. Yamada, M. Yaegashi, T. Abe, A. Yamada, Chem. Commun. 2013, 49, 11194.

[152] K. Yoshida, M. Nakamura, Y. Kazue, N. Tachikawa, S. Tsuzuki, S. Seki, K. Dokko, M. Watanabe, J. Am. Chem. Soc. 2011, 133, 13121.

[153] K. Sodeyama, Y. Yamada, K. Aikawa, A. Yamada, Y. Tateyama, J. Phys. Chem. C 2014, 118, 14091.

[154] J. Qian, B. D. Adams, J. Zheng, W. Xu, W. A. Henderson, J. Wang, M. E. Bowden, S. $\mathrm{Xu}$, J. Hu, J.-G. Zhang, Adv. Funct. Mater. 2016, 26, 7094.

[155] K. Arbi, J. M. Rojo, J. Sanz, J. Eur. Ceram. Soc. 2007, 27, 4215.

[156] X. Xu, Z. Wen, X. Wu, X. Yang, Z. Gu, J. Am. Ceram. Soc. 2007, 90, 2802.

[157] K. Arbi, W. Bucheli, R. Jiménez, J. Sanz, J. Eur. Ceram. Soc. 2015, 35, 1477.

[158] W. Zhou, S. Wang, Y. Li, S. Xin, A. Manthiram, J. B. Goodenough, J. Am. Chem. Soc. 2016, 138, 9385.

[159] P. R. Chinnam, S. L. Wunder, ACS Energy Lett. 2017, 2, 134.

[160] O. Bohnke, Solid State Ionics 2008, 179, 9.

[161] W. J. Kwon, H. Kim, K.-N. Jung, W. Cho, S. H. Kim, J.-W. Lee, M.-S. Park, J. Mater. Chem. A 2017, 5, 6257.

[162] Z. D. Hood, H. Wang, A. Samuthira Pandian, J. K. Keum, C. Liang, J. Am. Chem. Soc. 2016, 138, 1768.

[163] Y. Li, W. Zhou, S. Xin, S. Li, J. Zhu, X. Lu, Z. Cui, Q. Jia, J. Zhou, Y. Zhao, J. B. Goodenough, Angew. Chem. Int. Ed. 2016, 55, 9965.

[164] R. Kanno, T. Hata, Y. Kawamoto, M. Irie, Solid State Ionics 2000, $130,97$.

[165] R. Kanno, M. Murayama, J. Electrochem. Soc. 2001, 148, A742.

[166] C. Cao, Z.-B. Li, X.-L. Wang, X.-B. Zhao, W.-Q. Han, Frontiers in Energy Research 2014, 2 .

[167] I. Kokal, K. V. Ramanujachary, P. H. L. Notten, H. T. Hintzen, Mater. Res. Bull. 2012, 47, 1932.

[168] Y. Li, J.-T. Han, C.-A. Wang, H. Xie, J. B. Goodenough, J. Mater. Chem. 2012, 22, 15357.

[169] R. Murugan, V. Thangadurai, W. Weppner, Angew. Chem. Int. Ed. 2007, 46, 7778.

[170] I. Kokal, M. Somer, P. H. L. Notten, H. T. Hintzen, Solid State Ionics 2011, 185, 42.

[171] Y. Li, B. Xu, H. Xu, H. Duan, X. Lu, S. Xin, W. Zhou, L. Xue, G. Fu, A. Manthiram, J. B. Goodenough, Angew. Chem. Int. Ed. 2017, 56, 753.

[172] J. Chai, Z. Liu, J. Ma, J. Wang, X. Liu, H. Liu, J. Zhang, G. Cui, L. Chen, Adv. Sci. 2017, 4, 1600377.

[173] C. H. Lee, K. H. Joo, J. H. Kim, S. G. Woo, H. J. Sohn, T. Kang, Y. Park, J. Y. Oh, Solid State Ionics 2002, 149, 59.

[174] T. Ohtomo, A. Hayashi, M. Tatsumisago, K. Kawamoto, J. Solid State Electrochem. 2013, 17, 2551.

[175] T. Inada, Solid State Ionics 2003, 158, 275. 
[176] M. Tatsumisago, S. Hama, A. Hayashi, H. Morimoto, T. Minami, Solid State Ionics 2002, 154-155, 636.

[177] A. Hayashi, Solid State Ionics 2004, 175, 637.

[178] K. Joo, Solid State Ionics 2003, 160, 51.

[179] N. S. Saetova, A. A. Raskovalov, B. D. Antonov, T. V. Yaroslavtseva, O. G. Reznitskikh, N. I. Kadyrova, J. Non-Cryst. Solids 2016, 443, 75.

[180] A. V. Deshpande, V. K. Deshpande, Solid State Ionics 2002, 154-155, 433.

[181] M. Tatsumisago, H. Yamashita, A. Hayashi, H. Morimoto, T. Minami, J. Non-Cryst. Solids. 2000, 274, 30.

[182] Y. Seino, T. Ota, K. Takada, A. Hayashi, M. Tatsumisago, Energ. Environ. Sci. 2014, 7, 627.

[183] Z. Liu, Y. Tang, X. Lü, G. Ren, F. Huang, Ceram. Int. 2014, 40, 15497.

[184] Y. Seino, K. Takada, B. Kim, L. Zhang, N. Ohta, H. Wada, M. Osada, T. Sasaki, Solid State Ionics 2006, 177, 2601.

[185] K. Ohara, A. Mitsui, M. Mori, Y. Onodera, S. Shiotani, Y. Koyama, Y. Orikasa, M. Murakami, K. Shimoda, K. Mori, T. Fukunaga, H. Arai, Y. Uchimoto, Z. Ogumi, Sci. Rep. 2016, 6, 21302.

[186] K. Takada, Solid State Ionics 2003, 158, 269.

[187] E. Rangasamy, Z. Liu, M. Gobet, K. Pilar, G. Sahu, W. Zhou, H. Wu, S. Greenbaum, C. Liang, J. Am. Chem. Soc. 2015, 137, 1384.

[188] J. Wei, H. Kim, D.-C. Lee, R. Hu, F. Wu, H. Zhao, F. M. Alamgir, G. Yushin, J. Power Sources 2015, 294, 494.

[189] A. Hayashi, R. Komiya, M. Tatsumisago, T. Minami, Solid State Ionics 2002, 152-153, 285.

[190] N. Kamaya, K. Homma, Y. Yamakawa, M. Hirayama, R. Kanno, M. Yonemura, T. Kamiyama, Y. Kato, S. Hama, K. Kawamoto, A. Mitsui, Nat. Mater. 2011, 10, 682.

[191] P. Bron, S. Johansson, K. Zick, J. Schmedt auf der Gunne, S. Dehnen, B. Roling, J. Am. Chem. Soc. 2013, 135, 15694.

[192] A. C. Kozen, A. J. Pearse, C.-F. Lin, M. Noked, G. W. Rubloff, Chem. Mater. 2015, 27, 5324.

[193] A. J. Pearse, T. E. Schmitt, E. J. Fuller, F. El-Gabaly, C.-F. Lin, K. Gerasopoulos, A. C. Kozen, A. A. Talin, G. Rubloff, K. E. Gregorczyk, Chem. Mater. 2017, 29, 3740.

[194] J. Glenneberg, F. Andre, I. Bardenhagen, F. Langer, J. Schwenzel, R. Kun, J. Power Sources 2016, 324, 722.

[195] J. C. Li, C. Ma, M. F. Chi, C. D. Liang, N. J. Dudney, Adv. Energy Mater. 2015, 5.

[196] M. Tatsumisago, M. Nagao, A. Hayashi, Journal of Asian Ceramic Societies 2013, 1, 17.

[197] M. Kotobuki, M. Koishi, Ceram. Int. 2013, 39, 4645.

[198] V. Patil, A. Patil, S. J. Yoon, J. W. Choi, J. Nanosci. Nanotechno. 2013, 13, 3665.

[199] J. D. Nikolić, S. V. Smiljanjić, S. D. Matijašević, V. D. Živanović, M. B. Tošič, S. R. Grujić, J. N. Stojanović, Process. Appl. Ceram. 2013, 7, 147.

[200] K. He, C. Zu, Y. Wang, B. Han, X. Yin, H. Zhao, Y. Liu, J. Chen, Solid State Ionics 2014, 254, 78 .

[201] R.-c. Xu, X.-h. Xia, X.-1. Wang, Y. Xia, J.-p. Tu, J. Mater. Chem. A 2017, 5, 2829.

[202] M. Eom, S. Choi, S. Son, L. Choi, C. Park, D. Shin, J. Power Sources 2016, 331, 26.

[203] B. Huang, X. Yao, Z. Huang, Y. Guan, Y. Jin, X. Xu, J. Power Sources 2015, 284, 206.

[204] R. B. Nuernberg, A. C. M. Rodrigues, Solid State Ionics 2017, 301, 1.

[205] Z. Stoeva, I. Martin-Litas, E. Staunton, Y. G. Andreev, P. G. Bruce, J. Am. Chem. Soc. 2003, 125, 4619.

[206] W. A. Henderson, N. R. Brooks, V. G. Young, J. Am. Chem. Soc. 2003, 125, 12098.

[207] L. Y. Yang, D. X. Wei, M. Xu, Y. F. Yao, Q. Chen, Angew. Chem. Int. Ed. 2014, 53, 
3631 .

[208] J. Zhang, L. Yue, P. Hu, Z. Liu, B. Qin, B. Zhang, Q. Wang, G. Ding, C. Zhang, X. Zhou, J. Yao, G. Cui, L. Chen, Sci. Rep. 2014, 4, 6272.

[209] L. Porcarelli, C. Gerbaldi, F. Bella, J. R. Nair, Sci. Rep. 2016, 6.

[210] Q. Pan, D. M. Smith, H. Qi, S. Wang, C. Y. Li, Adv. Mater. 2015, 27, 5995.

[211] X. X. Zeng, Y. X. Yin, N. W. Li, W. C. Du, Y. G. Guo, L. J. Wan, J. Am. Chem. Soc. 2016, $138,15825$.

[212] S. Klongkan, J. Pumchusak, Electrochim. Acta 2015, 161, 171.

[213] F. Croce, L. Persi, B. Scrosati, F. Serraino-Fiory, E. Plichta, M. A. Hendrickson, Electrochim. Acta 2001, 46, 2457.

[214] M. Dissanayake, P. Jayathilaka, R. S. P. Bokalawala, I. Albinsson, B. E. Mellander, J. Power Sources 2003, 119, 409.

[215] E. M. Masoud, A. A. El-Bellihi, W. A. Bayoumy, M. A. Mousa, J. Alloys Compd. 2013, $575,223$.

[216] W. Wang, E. Yi, A. J. Fici, R. M. Laine, J. Kieffer, J. Phys. Chem. C 2017, 121, 2563.

[217] A. R. Polu, H.-W. Rhee, J. Ind. Eng. Chem. 2016, 37, 347.

[218] D. Lin, W. Liu, Y. Liu, H. R. Lee, P. C. Hsu, K. Liu, Y. Cui, Nano Lett. 2016, 16, 459.

[219] T. Jurkin, I. Pucić, Polym. Eng. Sci. 2013, 53, 2318.

[220] C. W. Lin, C. L. Hung, M. Venkateswarlu, B. J. Hwang, J. Power Sources 2005, 146, 397.

[221] S. Choudhury, R. Mangal, A. Agrawal, L. A. Archer, Nat. Commun. 2015, 6, 10101.

[222] T. Itoh, Y. Ichikawa, T. Uno, M. Kubo, O. Yamamoto, Solid State Ionics 2003, 156, 393.

[223] K. Kesavan, S. Rajendran, C. M. Mathew, Polym. Compos. 2015, 36, 302.

[224] H. Y. Sun, Y. Takeda, N. Imanishi, O. Yamamoto, H. J. Sohn, J. Electrochem. Soc. 2000, 147, 2462.

[225] Z. Y. Wen, T. Itoh, T. Uno, M. Kubo, O. Yamamoto, Solid State Ionics 2003, 160, 141.

[226] C. Yuan, J. Li, P. Han, Y. Lai, Z. Zhang, J. Liu, J. Power Sources 2013, 240, 653.

[227] K. Zhu, Y. Liu, J. Liu, RSC Adv. 2014, 4, 42278.

[228] R. Senthil Kumar, M. Raja, M. Anbu Kulandainathan, A. Manuel Stephan, RSC Adv. 2014, 4, 26171.

[229] F. Croce, L. Settimi, B. Scrosati, Electrochem. Commun. 2006, 8, 364.

[230] P. P. Chu, M. J. Reddy, H. M. Kao, Solid State Ionics 2003, 156, 141.

[231] J. Xi, X. Qiu, X. Ma, M. Cui, J. Yang, X. Tang, W. Zhu, L. Chen, Solid State Ionics 2005, 176, 1249.

[232] C. Shen, J. Wang, Z. Tang, H. Wang, H. Lian, J. Zhang, C.-n. Cao, Electrochim. Acta 2009, 54, 3490.

[233] Y.-X. Jiang, J.-M. Xu, Q.-C. Zhuang, L.-Y. Jin, S.-G. Sun, J. Solid State Electrochem. 2008, 12, 353 .

[234] J. Xi, X. Qiu, J. Wang, Y. Bai, W. Zhu, L. Chen, J. Power Sources 2006, 158, 627.

[235] J. Xi, X. Qiu, L. Chen, Solid State Ionics 2006, 177, 709.

[236] A. Manuel Stephan, K. S. Nahm, Polymer 2006, 47, 5952.

[237] E. M. Masoud, A. A. El-Bellihi, W. A. Bayoumy, M. A. Mousa, Mater. Res. Bull. 2013, 48,1148 .

[238] Y.-J. Wang, Y. Pan, D. Kim, J. Power Sources 2006, 159, 690.

[239] C. Wang, Y. Yang, X. Liu, H. Zhong, H. Xu, Z. Xu, H. Shao, F. Ding, ACS Appl. Mater. Inter. 2017, 9, 13694.

[240] J. Zheng, M. Tang, Y. Y. Hu, Angew. Chem. Int. Ed. 2016, 55, 12538.

[241] J.-H. Choi, C.-H. Lee, J.-H. Yu, C.-H. Doh, S.-M. Lee, J. Power Sources 2015, 274, 458.

[242] K. Fu, Y. Gong, J. Dai, A. Gong, X. Han, Y. Yao, C. Wang, Y. Wang, Y. Chen, C. Yan, 
Y. Li, E. D. Wachsman, L. Hu, Proc. Natl. Acad. Sci. U. S. A. 2016, 113, 7094.

[243] W. Liu, S. W. Lee, D. Lin, F. Shi, S. Wang, A. D. Sendek, Y. Cui, Nature Energy 2017, 2,17035 .

[244] W. H. Hou, C. Y. Chen, C. C. Wang, Polymer 2003, 44, 2983.

[245] J. Zhang, J. Zhao, L. Yue, Q. Wang, J. Chai, Z. Liu, X. Zhou, H. Li, Y. Guo, G. Cui, L. Chen, Adv. Energy Mater. 2015, 5 .

[246] Y. J. Lim, H. W. Kim, S. S. Lee, H. J. Kim, J.-K. Kim, Y.-G. Jung, Y. Kim, ChemPlusChem 2015, 80, 1100.

[247] J. Li, Y. Lin, H. H. Yao, C. F. Yuan, J. Liu, Chemsuschem 2014, 7, 1901.

[248] A. I. Horowitz, M. J. Panzer, Angew. Chem. Int. Ed. 2014, 53, 9780.

[249] D. Zhou, R. Liu, Y.-B. He, F. Li, M. Liu, B. Li, Q.-H. Yang, Q. Cai, F. Kang, Adv. Energy Mater. 2016, 6, 1502214.

[250] R. Bouchet, S. Maria, R. Meziane, A. Aboulaich, L. Lienafa, J.-P. Bonnet, T. N. T. Phan, D. Bertin, D. Gigmes, D. Devaux, R. Denoyel, M. Armand, Nat. Mater. 2013, $12,452$.

[251] Q. Ma, H. Zhang, C. Zhou, L. Zheng, P. Cheng, J. Nie, W. Feng, Y. S. Hu, H. Li, X. Huang, L. Chen, M. Armand, Z. Zhou, Angew. Chem. Int. Ed. 2016, 55, 2521.

[252] I. Villaluenga, K. H. Wujcik, W. Tong, D. Devaux, D. H. Wong, J. M. DeSimone, N. P. Balsara, Proc. Natl. Acad. Sci. U. S. A. 2016, 113, 52.

[253] J. Zhang, B. Sun, X. Huang, S. Chen, G. Wang, Sci. Rep. 2014, 4, 6007.

[254] S. W. Choi, S. M. Jo, W. S. Lee, Y. R. Kim, Adv. Mater. 2003, 15, 2027.

[255] Y. Zhu, F. Wang, L. Liu, S. Xiao, Y. Yang, Y. Wu, Sci. Rep. 2013, 3, 3187.

[256] Z. Y. Tu, Y. Kambe, Y. Y. Lu, L. A. Archer, Adv. Energy Mater. 2014, 4.

[257] Z. H. Li, C. Cheng, X. Y. Zhan, Y. P. Wu, X. D. Zhou, Electrochim. Acta 2009, 54, 4403.

[258] M. Walkowiak, A. Zalewska, T. Jesionowski, D. Waszak, B. Czajka, J. Power Sources 2006, 159, 449.

[259] S.-D. Gong, Y. Huang, H.-J. Cao, Y.-H. Lin, Y. Li, S.-H. Tang, M.-S. Wang, X. Li, J. Power Sources 2016, 307, 624.

[260] Y. Li, K. W. Wong, K. M. Ng, Chem. Commun. 2016, 52, 4369.

[261] F. Wu, N. Chen, R. Chen, Q. Zhu, J. Qian, L. Li, Chem. Mater. 2016, $28,848$.

[262] G. Tan, F. Wu, C. Zhan, J. Wang, D. Mu, J. Lu, K. Amine, Nano Lett. 2016, 16, 1960.

[263] F. Wu, N. Chen, R. Chen, L. Wang, L. Li, Nano Energy 2017, 31, 9.

[264] I. Osada, H. de Vries, B. Scrosati, S. Passerini, Angew. Chem. Int. Ed. 2016, 55, 500.

[265] J. H. Shin, W. A. Henderson, S. Passerini, Electrochem. Commun. 2003, 5, 1016.

[266] A. S. Fisher, M. B. Khalid, M. Widstrom, P. Kofinas, J. Power Sources 2011, 196, 9767.

[267] M. A. B. H. Susan, T. Kaneko, A. Noda, M. Watanabe, J. Am. Chem. Soc. 2005, 127, 4976.

[268] A.-L. Pont, R. Marcilla, I. De Meatza, H. Grande, D. Mecerreyes, J. Power Sources 2009, $188,558$.

[269] G. B. Appetecchi, G. T. Kim, M. Montanino, M. Carewska, R. Marcilla, D. Mecerreyes, I. De Meatza, J. Power Sources 2010, 195, 3668.

[270] M. Li, L. Yang, S. Fang, S. Dong, J. Membrane Sci. 2011, 366, 245.

[271] M. Doebbelin, I. Azcune, M. Bedu, A. Ruiz de Luzuriaga, A. Genua, V. Jovanovski, G. Cabanero, I. Odriozola, Chem. Mater. 2012, 24, 1583.

[272] M. Li, L. Yang, S. Fang, S. Dong, S.-i. Hirano, K. Tachibana, J. Power Sources 2011, 196, 8662.

[273] P.-L. Kuo, C.-H. Tsao, C.-H. Hsu, S.-T. Chen, H.-M. Hsu, J. Membrane Sci. 2016, 499, 462. 


\section{Table of Contents:}

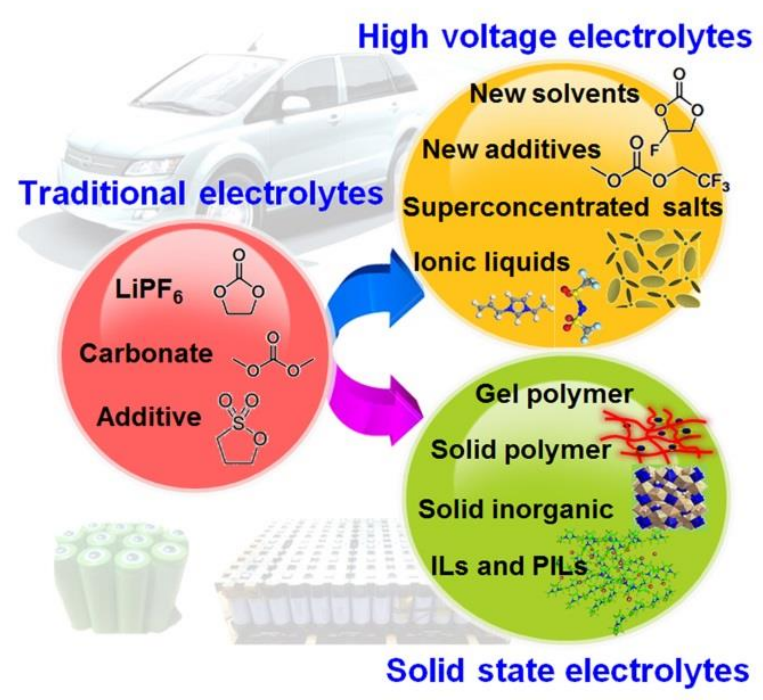

\section{Author biographical sketch:}

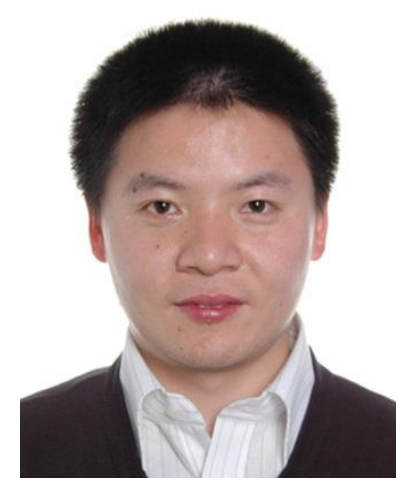

Shimou Chen received his BS degree from Zhengzhou University in 2002, and his $\mathrm{PhD}$ degree from Shanghai Institute of Applied Physics, Chinese Academy of Sciences in 2007. In Apr. 2008, he moved to Nagoya University as a JSPS postdoctoral fellow. From 2011 to 2012 he was a Research Associate at National Institute for Materials Science (NIMS), Japan. In 
April, 2012, he joined Institute of Processing and Engineering as a Professor funded by "Hundred Talent Project" of Chinese Academy of Sciences. His research interests include structure and properties, application of ionic liquid in lithium-ion battery, development of advanced energy storage systems, etc.

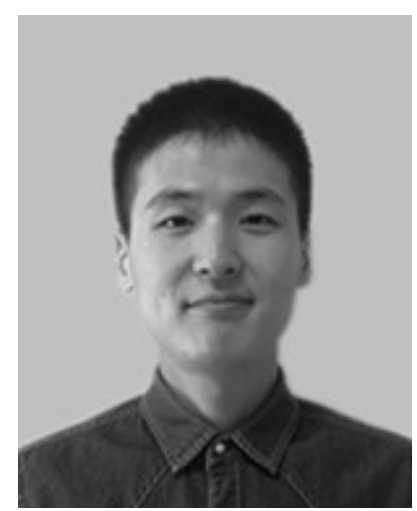

Kaihua Wen obtained his B.S. degree from the School of Chemical Engineering and Environment, Beijing Institute of Technology in 2011. He is currently pursuing his M.S. degree under the supervision of Professor Shimou Chen at Institute of Process Engineering, Chinese Academy of Sciences. His research interests mainly focus on the design, synthesis and applications of ionic liquids based novel solid-state electrolytes for lithium batteries.

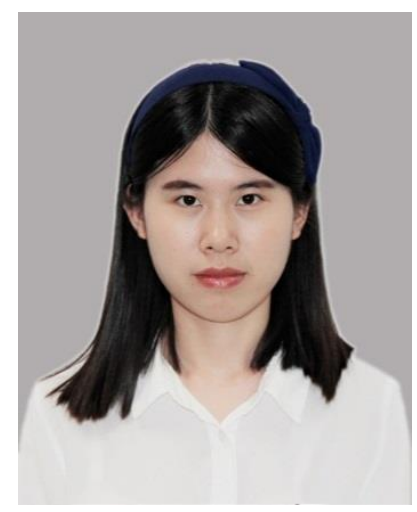

Juntian Fan is currently working as a graduate student (towards a Master's degree) at the Key Laboratory of Green Process and Engineering in the Institute of Process Engineering, Chinese Academy of Sciences. Her current research focuses on the high voltage electrolytes and their applications in the energy storage. 


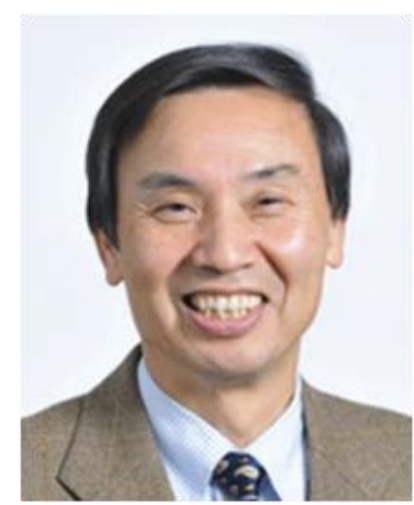

Prof. Yoshio Bando received his $\mathrm{PhD}$ degree from Osaka University in 1975 and joined the National Institute for Research in Inorganic Materials (at present NIMS) in the same year. From 1979 to 1981 he also worked as a visiting researcher at Arizona State University. Currently, he is a consulting researcher of the International Center for Materials Nanoarchitectonics (MANA) of NIMS. His research concentrates on the synthesis and properties of various inorganic nanostructures and their TEM characterizations.

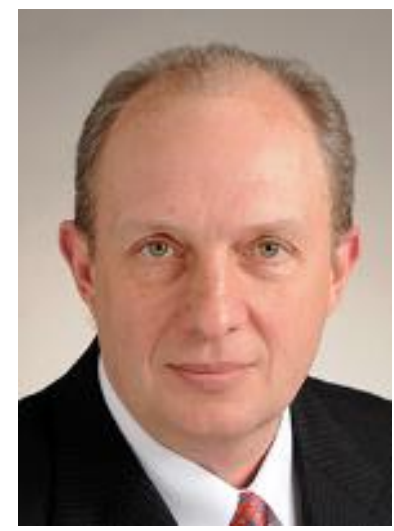

Prof. Dmitri Golberg obtained his B.S., MS and PhD degrees in Moscow, Russia, and in 1995 joined the National Institute for Materials Science (NIMS), Tsukuba, Japan. From 2017 he became a Professor of the Queensland University of Technology (QUT), Australia. Dmitri's numerous awards include "Tsukuba Prize", “Thomson Reuters Research Front Award" and "Seto Award" from the Microscopy Society of Japan. Over the last consecutive years he was nominated as a Highly-Cited Researcher by "Thomson Reuters" being currently listed among top-200 most-cited world materials scientists on the Web of Science. His research is focused on inorganic nanotubes, nanowires and nanosheets and their in situ TEM studies. 